\title{
Antibiotic resistance in the non-hospital environment
}

Citation for published version (APA):

London, N. H. H. J. (1995). Antibiotic resistance in the non-hospital environment. [Doctoral Thesis, Maastricht University]. Rijksuniversiteit Limburg. https://doi.org/10.26481/dis.19950331nl

Document status and date:

Published: 01/01/1995

DOI:

10.26481/dis.19950331nl

Document Version:

Publisher's PDF, also known as Version of record

\section{Please check the document version of this publication:}

- A submitted manuscript is the version of the article upon submission and before peer-review. There can be important differences between the submitted version and the official published version of record.

People interested in the research are advised to contact the author for the final version of the publication, or visit the DOI to the publisher's website.

- The final author version and the galley proof are versions of the publication after peer review.

- The final published version features the final layout of the paper including the volume, issue and page numbers.

Link to publication

\footnotetext{
General rights rights.

- You may freely distribute the URL identifying the publication in the public portal. please follow below link for the End User Agreement:

www.umlib.nl/taverne-license

Take down policy

If you believe that this document breaches copyright please contact us at:

repository@maastrichtuniversity.nl

providing details and we will investigate your claim.
}

Copyright and moral rights for the publications made accessible in the public portal are retained by the authors and/or other copyright owners and it is a condition of accessing publications that users recognise and abide by the legal requirements associated with these

- Users may download and print one copy of any publication from the public portal for the purpose of private study or research.

- You may not further distribute the material or use it for any profit-making activity or commercial gain

If the publication is distributed under the terms of Article $25 \mathrm{fa}$ of the Dutch Copyright Act, indicated by the "Taverne" license above, 
ANTIBIOTIC RESISTANCE

IN THE

NON-HOSPITAL ENVIRONMENT 



\section{ANTIBIOTIC RESISTANCE \\ IN THE \\ NON-HOSPITAL ENVIRONMENT}

\section{PROEFSCHIRIFT}

Ter verkrijging van de graad van doctor

aan de Rijksuniversiteit Limburg te Maastricht, op gezag van de Rector Magnificus, Prof. Mr. M. J. Cohen, volgens het besluit van het College van Dekanen, in het openbaar te verdedigen op vrijdag 31 maart 1995 om 16.00 uur

door NANCY HUBERTINA HENDRIKUS JOYCE LONDON geboren te Maastricht 
Promotor:

Co-promotores:

Beoordelingscommissie:
Prof. Dr. J. A. Knottnerus

Dr. E. E. Stobberingh

Drs. A. E. J. M. van den Bogaard

Prof. Dr. J. W. van Ree (voorzitter)

Prof. Dr. C. P. A. van Boven (Rijksuniversiteit Leiden)

Prof. Dr. P. G. Knipschild

Prof. Dr. Ir. M. J. M. Tielen (Universiteit Utrecht)

Dr. H. Thijssen

ISBN: 90-9008068-6

Druk: Unigraphic

De studies gepresenteerd in dit proefschrift werden gefinancierd met behulp van grant 28.0275 van het Praeventiefonds. 
Aan mijn ouders 


\section{CONTENTS}

Introduction

chapter I: Review of the literature

Aims of the study

chapter II: $\quad$ Resistance in faecal Escherichia coli isolated from pig farmers and abattoir workers.

Epidemiol. Infect. 1994; 113: 45-52.

chapter III: Antibiotic resistance of faecal Enterobacteriaceae isolated from healthy volunteers, a 15-week follow-up study.

J. Antimicrob. Chemother. 1993; 32: 83-91.

chapter IV: Carriage of antibiotic-resistant Escherichia coli by healthy volunteers during a 15 -week period.

Infection 1994; 22: 187-192.

chapter V: Effect of antibiotic therapy on the antibiotic resistance of faecal Escherichia coli in patients attending general practitioners.

J. Antimicrob. Chemother. 1994; 34: 239-246.

chapter VI: Comparison of virulence factors of urinary and faecal Escherichia coli isolated from the same patient (submitted).

chapter VII: A piperacillin-tazobactam resistant Escherichia coli strain isolated from a faecal sample of a healthy volunteer (submitted).

chapter VIII: General discussion

Summary

Samenvatting

Dankwoord

Curriculum vitae 


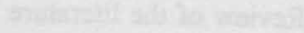

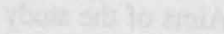

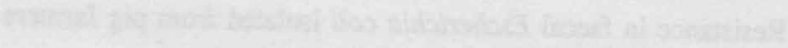

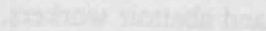

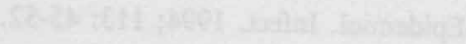

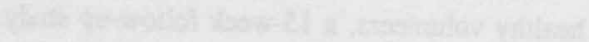
Then

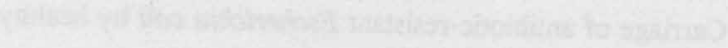

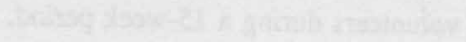

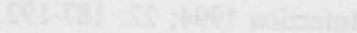




\section{INTRODUCTION}





\section{NTRODUCTION}

\section{General background}

Since the introduction of antimicrobial agents an increase in the prevalence of antibiotic-resistant microorganisms has been observed. In the pre-antibiotic era pathogenic bacteria of medical importance generally showed a lower prevalence of antibiotic resistance than after the introduction and (extensive) use of antibiotics. In 1940, for example, nearly all Staphylococcus aureus isolates were susceptible to penicillin, at present more than $80 \%$ of hospital as well as extramural isolates are penicillin-resistant.

To describe the extent of the problem of antibiotic resistance it is convenient to consider the hospital and the community as two separate ecosystems, different among aspects in populations, selective pressures and reservoirs and each with a characteristic pattern of emergence, prevalence and transmission of antibiotic-resistant microorganisms. However, the ecosystems are not completely isolated from each other as an exchange of antibiotic resistance genes and antibiotic-resistant microorganisms does take place. Both ecosystems have in common an increasing problem of antibiotic resistance among microorganisms, which may have serious consequences for public health.

The impact of the emerging antimicrobial resistance on health care can be summarized as follows: First, treatment failure in infections caused by resistant microorganisms treated with what is considered an appropriate empirical therapy. This leads to an increased morbidity and mortality and an increase in health care costs. Second, antibiotic resistance is sometimes encoded on plasmids that also encode for virulence factors. This phenomenon of "indirect selection" will therefore result in more severe infections with a higher morbidity and mortality as compared to those infections caused by susceptible microorganisms. Third, treatment of an infected person with an antibiotic to which the causative microorganism is resistant will provide a selective advantage for this resistant microorganism since in many cases the susceptible bacteria of the patient's own microflora will be eradicated. This results in a longer period of persistence of the resistant microorganisms in the host.

Finally, an essential part of the infection-prevention strategy for communicable diseases is effective eradication of the source. Persons who have infections and who are 
inadequately treated because of antibiotic resistance will therefore remain a potential source for a longer period of time.

It is generally accepted that antimicrobial usage relates to the emergence, persistence and dissemination of antibiotic-resistant microorganisms. However, a direct causal relationship between antibiotic usage and emergence of resistance is sometimes difficult to prove. Some authors have described this phenomenon in a single hospital with a single specific antibiotic. Other cofactors that contribute to or exert an influence on the selection of the bacteria are the presence of an environmental or human reservoir, the socioeconomic circumstances and the characteristics of the microorganisms.

The presence in nature of dense bacterial populations, e.g. the human gut flora, can be considered as ecological niches in which a large reservoir of genetic material, including resistance genes, is maintained, continuously introduced, and exchanged. Among the socio-economic circumstances that contribute to the resistance problem are the increase in numbers of elderly and immunocompromised patients in the population, resulting in an increased risk of infection and the usage of antimicrobial agents. This, in turn, increases the chance for the spread of resistant microorganisms. Also crowding and malnutrition are well known factors that contribute to the persistance and transmission of infectious diseases. The characteristics of the microorganisms concerned include their intrinsic resistance, their ability to survive adverse environmental conditions, their capacity to colonize and infect susceptible hosts and their capacity to exchange genetic material.

Several strategies have been developed in order to reduce the risk of emergence, persistence and spread of antibiotic-resistant microorganisms. Among these, the effort to reduce the inappropriate use of antibiotics in humans and in animals is by far the most important one. Relevant and up to date information on antibiotic resistance patterns of medically important bacterial species is an important tool for guiding the empirical choice of antibiotics and for improving appropriate therapy. Active population-based surveillance on a national and an international level is necessary to provide these data.

In this context, the present study was performed to look into several aspects of antibiotic resistance in the non-hospital environment and the results are described in this thesis. 
II. Outline of the thesis

In chapter I relevant literature is reviewed concerning the prevalence of antibiotic resistance in several human populations that differ in their exposure to risk factors for the emergence of resistance and selection of resistant strains. Especially, the available data in several groups of healthy humans, i.e. pig farmers, abattoir workers, (sub)urban residents, and general practice patients, the mechanisms of bacterial resistance and the effect of antimicrobial therapy on antibiotic resistance are emphazised.

Chapter II, entitled 'Resistance in faecal Escherichia coli isolated from pigfarmers and abattoir workers' describes the prevalence and degree of antibiotic resistance of faecal Escherichia coli isolated from pig farmers and abattoir workers as compared to a control group of (sub)urban residents.

The variation in prevalence and degree of antibiotic resistance and the reproducibility of sampling over time in a certain group of healthy people was the subject of the study presented in chapter III, entitled 'Antibiotic resistance of faecal Enterobacteriaceae isolated from healthy volunteers, a 15-week follow-up study'.

Chapter IV, entitled 'Carriage of antibiotic-resistant Escherichia coli by healthy volunteers during a 15-week period' presents the results of the study of the antibiotic susceptibilities of Escherichia coli strains isolated from healthy volunteers with special emphasis on the variation in antibiotic resistance patterns over a 15-week period. In addition, the mechanism of high level trimethoprim resistance (i.e. MIC $\geq 1024 \mathrm{mg} / \mathrm{l}$ ) is characterized with probes specifying type I and type $\mathrm{V}$ mediated resistance.

The effect of amoxycillin or doxycycline therapy on the antibiotic resistance of faecal Escherichia coli isolated from general practice patients treated for a respiratory tract infection is presented in chapter $V$, entitled 'Effect of antibiotic therapy on the antibiotic resistance of faecal Escherichia coli in patients attending general practitioners'.

Chapter VI, entitled 'Comparison of virulence factors of urinary and faecal Escherichia coli isolated from the same patient' presents the results of the study in which faecal and urinary Escherichia coli isolated from patients with an uncomplicated urinary tract infection from general practice were compared with respect to virulence factors, serotype and antibiotic susceptibility in order to determine the role of the faecal flora as a reservoir for uropathogens. 
Chapter VII, entitled 'A piperacillin-tazobactam resistant Escherichia coli strain isolated from a faecal sample of a healthy volunteer', describes the mechanism of a TEM1 "like" producing Escherichia coli strain resistant to the combination of piperacillin and the B-lactamase inhibitor tazobactam.

In chapter VIII the results of the studies presented are reviewed, discussed and conclusions and recommendations are formulated. 


\section{CHAPTER I}

REVIEW OF THE LITERATURE

$\&$

AIMS OF THE STUDY 



\section{Antibiotic resistance}

Nowadays bacterial resistance to antimicrobial agents is an important obstacle for the successful treatment of bacterial infections, leading not only to treatment failures but consequently to prolonged morbidity and even mortality $[40,58,59,60]$. Since the introduction of antimicrobial agents into clinical practice, microorganisms have been labelled sensitive or resistant. In clinical practice "resistance" means that an infection caused by an antibiotic-resistant microorganism of a normally sensitive species cannot be treated successfully with that particular agent using standard dosages. For microbiologists, resistance means that an antimicrobial agent, even used in higher doses, has little or no effect on a particular microorganism or that an isolate has become less susceptible to an antimicrobial agent while other bacteria of the same species still remain susceptible $[5,26]$.

In considering the problems caused by antibiotic-resistant bacteria it is usually the emergence of resistance in previously susceptible bacteria that is of concern and not the intrinsically resistant microorganisms. Lack of susceptibility (also called natural or intrinsic resistance) is species-restricted; this means that an antimicrobial agent cannot reach its target or binding site or because these sites are absent in the species involved. For example Enterobacteriaceae are intrinsically resistant to benzylpenicillin, because penicillin cannot penetrate the outer membrane of these Gram-negative bacteria. Therefore this compound cannot be used for the treatment of Escherichia coli infections $[26,70,73]$.

There are three ways for a microorganism to become resistant to an antimicrobial agent. First, selection. Even before the introduction of an agent a few strains are already found to be resistant. The classic example of this type of resistance is Staphylococcus aureus and penicillin [17]. Second, resistance due to chromosomal mutations. The frequency of these spontaneous mutations is not influenced by exposure to antimicrobial agents unless these agents are mutagens. Such mutations usually involve the genes encoding the target site of the agent, or cell structures affecting access of the agent to the target site. This kind of resistance is not transferable to other species, but only vertically transferred to the next generation of the microorganism involved. If this spontaneous mutation frequency is high enough, use of the antimicrobial agent will select for resistant 
strains which will then replace the sensitive bacterial population. However, in the absence of that agent these resistant strains have no particular survival advantage and mostly disappear sooner or later $[22,40,58,69,70,73]$. The third kind of antibiotic resistance is transferable resistance. The genes responsible for this kind of resistance, the so-called resistance factors ( $R$-factors) are mainly located on extrachromosomal circular elements of DNA: plasmids. R-plasmids can transfer themselves from one bacterial cell to another by conjugation, i.e. conjugative plasmids. Transfer of this type of resistance occurs not only between bacteria belonging to the same species but also between bacteria of different species. In addition to conjugative plasmids, bacteria may possess transposons, the socalled "jumping genes", which are usually small pieces of DNA. Unlike plasmids, transposons do not rely on a particular host cell or any particular host DNA in order to exist or multiply. Transposons can "jump ship" on to the host chromosome or on to a resident plasmid already stably present in the bacterial cell and while the new host may lose the plasmid and even its copy, the transposon will remain with the new cell since it has found a stable place in the new host. Other possible mechanisms for transferring resistance genes include transformation and transduction. Transformation involves the pickup by a recipient bacterial cell of pieces of naked DNA released after death by the donor bacteria. Once taken up, the DNA can become part of the DNA of the recipient cell if donor and recipient belong to the same species. Transduction is the process by which genes, both from plasmid(s) or from their chromosome, are transferred to a new host via bacterial viruses called bacteriophages. Phages infect only those bacterial hosts that have a particular membrane site to which they can attach. Once there, the phage injects its DNA into the bacterial cell and gene exchange can take place as soon as the phage and its DNA piece integrate into a second host's chromosome of a bacterial cell of the same species.

The most common way of transferring resistance in vivo in Gram-positive as well as in Gram-negative bacteria, however, is by plasmid-mediated conjugation [32]. In contrast to chromosomally-mediated antibiotic resistance, plasmid-mediated resistance to one or several antibiotics, once acquired, may remain in the environment for prolonged periods, even in the absence of selection by exposure to that antibiotic. This is because the resistance factors are often linked to plasmids encoding for other virulence factors and/or to resistance to other antibiotics, so-called multiple antibiotic resistance $[41,70]$. Multiple resistance occurs when genes conferring resistance to several unrelated antimi- 
crobial agents are linked together into one plasmid and are transferred from one bacterial cell to another. Use of one agent will not only select for an increase of resistance to that agent but to the other agents as well. In 1959, Japanese workers showed that multiple resistance, in this case resistance to chloramphenicol, tetracycline, streptomycin and sulphonamides, was transmissible from shigellae to Escherichia coli [56]. In a nosocomial outbreak among children in Mexico City, the Shigella dysenteriae involved was not only resistant to chloramphenicol, tetracycline, streptomycin and sulphonamides but the microorganism had also acquired resistance to ampicillin [56]. Since that time many additional outbreaks due to multiply resistant pathogens have been recognized and documented all over the world.

\section{Mechanisms of antibiotic resistance}

Microorganisms can become resistant to antibiotics in a number of ways. The most common mechanism is inactivation of the antimicrobial agent. An example of this is the hydrolysis of B-lactam antibiotics by B-lactamases [74]. By far the most common of the plasmid-mediated B-lactamases is TEM-1 [75]. To overcome the action of these enzymes, B-lactamase inhibitors such as clavulanic acid and tazobactam have been developed [76]. Other mechanisms of resistance include alteration of the antibiotic target or binding site [2], reduction in bacterial accumulation of the agent involving active efflux of the agent out of the bacterial cell or reduced penetration of the agent into the cell due to alterations in outer membrane proteins (OMPs) $[10,12]$, development of a separate metabolic pathway that allows bypassing of the target metabolic process of the antibiotic [8], alteration of a molecule so that it does not effectively bind to its receptor site [18], elimination or reduction of the requirement for a metabolite [37], or elimination of enzymes whose action stimulated by the substance resulted in destruction of the bacteria [30].

\section{Antibiotic use and antibiotic resistance}

It is generally accepted that antibiotic resistance is related to the frequency and amount of usage of that particular agent in a certain population $[50,65]$. Several studies in 
humans dealing with the relation between antibiotic consumption and antibiotic resistance have been performed in hospitals and describe a positive correlation between usage and resistance $[11,33,55]$. In contrast, other studies have either failed to observe any relationship between usage and resistance [31,34] or have shown a decrease in resistance despite an increase in usage of a particular agent [55].

Apart from antibiotic use in humans, both in general practice and in hospitals, veterinary and agricultural usage of antibiotics may also be partly responsible for the increase in resistant bacteria, but it is still not clear whether antibiotic use in humans or in animals has contributed most to the environmental pool of resistant microorganisms [44]. Just as is the case with humans, animals receive antibiotics prescribed by veterinary surgeons therapeutically and prophylactically. However, quantitatively much more antibiotic is used in agriculture for crop protection and given to animals in small subtherapeutic levels as growth promotors $[5,41]$.

Concern for the public health implications of indiscriminate antibiotic use in animals resulted in the Swann Report (1969) in Great Britain and an Interim Report of a Food and Drug Administration Task Force (1972) in the USA. Both reports recommended that antimicrobials agents be excluded from animal feed as growth promoter if these antibiotics were also used as therapeutic agents in human or animal medicine (i.e., penicillins or tetracyclines) or if they were associated with the development of crossresistance to drugs that were registered for use in humans [23]. However, although the recommendations of these reports have been implemented in the member states of the European Union, they have not yet been implemented in the USA.

In human medicine, resistance to antimicrobial agents is mainly a problem in hospitals, in which large quantities of antibiotics are frequently used for treating infections. As in the hospital environment new microorganisms are constantly being introduced from new patients and personnel, this setting most probably represents the greatest reservoir of significant resistant bacteria [32]. The heavy use of antibiotics exerts a selective pressure on these resistant microorganisms which may consequently accumulate in the hospital and may be spread to the open population as soon as the patients are discharged back to the community $[14,70]$.

The prevalence of antibiotic-resistant microorganisms in general practice patients and the spread of these resistant strains in that population are less well documented 
$[25,72,77,78]$. General practitioners prescribe most antimicrobial agents for the treatment of urinary tract infections or respiratory tract infections [24]. The choice of antibiotic is usually made and treatment started on an educated guess before laboratory data on the susceptibility of the causative organism are available. For an educated guess and an optimal antibiotic therapy knowledge of the probable infecting organism and its likely susceptibility is essential [71].

The prevalence of antibiotic resistance in clinical isolates might be considered as the top of the iceberg as the usage of antibiotics also selects for antibiotic-resistant strains in the human gut flora. Several studies have analysed the effect of antimicrobial therapy on selection of antibiotic-resistant microorganisms in the faecal flora $[1,64]$. Therapeutic oral courses of ampicillin or a sulphonamide had only slight effect in selection of faecal Escherichia coli resistant to that particular agent [15]. Similar observations were made after use of trimethoprim or co-trimoxazole [36], but tetracycline, a broad spectrum antibiotic, exerted strong selection, not only for tetracycline resistance but also for resistance to ampicillin, streptomycin, chloramphenicol and sulphonamides [15].

Another aspect of the problem of antibiotic resistance is the contamination and possible colonization of the human gut with resistant microorganisms from an exogenous source. Colonization or even transit of the human gut with exogenous resistant microorganisms seems to be an important factor for the introduction of new resistant genes into commensal microorganisms and into (potentially) pathogenic microorganisms $[5,70]$. Some studies described the colonization of the human gut with antibiotic-resistant animal isolates $[29,41]$. However, other studies suggest that under certain circumstances Escherichia coli strains carrying R-factors may not be such good colonizers as those that are drug-sensitive [4] and that it is very difficult to prove that the Escherichia coli strains colonizing the human gut are indeed the same as those found in animals [48].

If $\mathbf{R}$-factors of colonizing resistant Escherichia coli are transferred to pathogens such as Salmonella spp. or Yersinia spp. the chance of infection after eating a product contaminated with these pathogens is higher in people taking antibiotics to which the microorganism is resistant. In the USA Salmonella newport caused serious disease in 18 persons, of whom 12 had taken antibiotics recently for other reasons. All of them had 
prepared and eaten minced beef (hamburger) in the week before illness. It was found that the meat used for the hamburgers was obtained from beef cattle which had been fed subtherapeutic doses of chlortetracycline. It seemed very likely that the resistant strain had a selective survival advantage in the antibiotic-treated people [29]. The importance of person-to-person spread [9] and food-bome illness resulting from contamination of foods with Salmonella spp. transmitted by human carriers must be considered along with animal sources [23].

\section{Reservoirs of antibiotic-resistant Escherichia coli}

The intestinal flora is considered the main reservoir of antibiotic-resistant Escherichia coli and antibiotic resistance genes in the population as well as in hospitals $[20,28,35,38,43,51,66]$.

The bacterial flora of hospitalized patients consists of bacterial strains which they brought with them to the hospital, i.e. the flora of the community, plus the microorganisms acquired in the hospital, i.e. the nosocomial flora [62]. In the early years of the antibiotic era, Gram-positive cocci (Streptococcus pyogenes, Streptococcus pneumoniae, and Staphylococcus aureus) were the most common causes of hospital infections. More recently they have been replaced by facultatively anaerobic Gram-negative bacilli and multi-resistant Pseudomonas aeruginosa strains as the most important cause of nosocomial infections [52]. Nowadays, however, the importance of Gram-positive cocci is again increasing. When patients leave the hospital, the resistant microorganisms can be transferred to people in the population either directly, e.g. by close contact, or indirectly, e.g. by food handling $[13,16]$.

To reduce the chance of emergence of resistance often combinations of antimicrobial agents are used, such as a cephalosporin or broad-spectrum penicillin plus an aminoglycoside [53]. The improved hygienic practices in the hospital to avoid the spread of multi-resistant strains from patient to patient seem to be effective. Also an understanding of resistance mechanisms will assist the clinician in the rational and appropriate use of antibiotics [73]. 
Antibiotic resistance in animals: an additional reservoir

As the environments of animals and humans are not separate, exchange of bacteria and bacterial genes occurs between both groups. The indirect effects caused by the use of antibiotics in animals on the acquisition of antibiotic-resistant bacteria affecting humans include the possible transfer of resistant bacterial strains and R-factors from animal to man. The transfer of bacterial strains can take place after direct contact with the animal, after contact with animal faeces or contaminated animal carcasses as is the case by farmers, abattoir workers or butchers or following the preparation and ingestion of contaminated meat. Levy et al. demonstrated cross infection of Escherichia coli from chickens to the humans in contact with the birds. The Escherichia coli strain involved was marked by a temperature-sensitive chloramphenicol-resistance [39]. Transfer of R-factors between man and domestic pets can also occur and is likely to take place since the contact between owner and pet is often very close [19]. It is to be expected that people having close contacts with pigs or pig carcasses have a greater risk of becoming contaminated with animal intestinal bacteria which might harbour R-plasmids than people without or with less contact. Abattoir workers are in close contact with pig carcasses contaminated with gut contents following slaughter [46] and pig farmers also have close and regular contact with their animals and waste $[63,79]$. Direct contact with antibiotics used for treatment of pigs and with their antibiotic-enriched feed is another possible risk factor for selection of resistant strains in the intestinal flora of pig farmers $[61,63]$. As the number of people having direct contact with food animals (cattle, pigs, poultry) is relatively small, it is very likely that the effect on the population is of minor importance. Consequently this route of crossinfection is only important for individuals [48]. The main route by which resistant Escherichia coli and resistant genes pass to the human population from outside is via the food chain: slaughter, packaging, distribution, handling raw meat, cooking, and eating $[47,48,49,68]$.

Prevalence of antibiotic-resistant Escherichia coli in developing countries

The prevalence of antimicrobial resistance in the healthy human population is often higher in developing countries than in developed ones. In developing countries antibiotics 
are available over the counter, without prescription. Even the antimicrobial agents which are easy and inexpensive to obtain, but which are no longer effective because of common resistance, are still continuously used. Since the bacteria involved are often multiresistant, use of one antibiotic will select for the same multi-resistant strain and perhaps coupled with poor hygiene and daily ingestion of high numbers of faecal bacteria in contaminated water supplies, the high prevalence percentages of resistance will be maintained in those countries $[3,38,44,51,66,67]$. The extensive reservoirs of resistance genes in commensal bacteria from developing countries may also serve to introduce resistance genes into the bacterial populations of developed countries [3]. In a study of travellers to Mexico from the USA, 57\% of those who had no trimethoprim-resistant Escherichia coli in their commensal faecal flora on entering the country had nevertheless acquired them on return [57]. The major problem of antibiotic resistance in developed countries is caused by indiscriminate and excessive consumption of antibiotics.

\section{Prevalence of antibiotic-resistant Escherichia coli in developed countries}

Relatively little is known about the prevalence of antibiotic-resistant bacteria in the healthy human population not subjected to antimicrobial chemotherapy or prophylaxis. In Dublin, faecal Escherichia coli strains from healthy infants were examined for antibiotic resistance [54]. In 81 out of a total of 100 faecal samples antibiotic-resistant strains were isolated; resistance to ampicillin was found in $62 \%$, and to streptomycin and tetracycline resistance in $63 \%$ and $67 \%$, respectively. Eighty-four percent of these 81 strains were shown to possess R-factors. Only a low correlation between previous antibacterial therapy and antibiotic-resistant enterobacteria was found, i.e. 7 (39\%) of 18 infants who had received either penicillin or ampicillin recently had a predominantly ampicillin-resistant bacterial flora [54].

Similarly, Datta (1969) examined faecal samples collected from patients before admission to hospital for elective surgery and found that $52 \%$ contained antibioticresistant Escherichia coli. Resistance to sulphamethoxazole and tetracycline occurred most frequently, i.e. $38 \%$ and $34 \%$, respectively. Resistance to streptomycin and ampicillin was found in $27 \%$ and $17 \%$ of the patients, respectively [14].

A significant difference in the prevalence of antibiotic-resistant strains was found 
between children and adults, in both rural and urban groups in the study of Linton et al. (1972). For the children in the urban group the prevalence of resistance was $64 \%$, for the rural group even higher $(73 \%)$ although not significantly. For the adults the figures were $42 \%$ and $49 \%$, respectively. In addition, in the rural group $63 \%$ of faeces from adults of farming families contained resistant coliform bacilli compared with a significantly lower proportion $(29 \%)$ of adults in non-farming rural families. Overall $61 \%$ of the antibiotic resistance was transferable; ampicillin, tetracycline, streptomycin and sulphamethoxazole resistance alone or in various combinations was transferred most frequently [45].

Levy et al. (1988) found a significantly higher prevalence of resistance to ampicillin for hospitalized patients than for healthy individuals; all of the latter were known not to be taking antibiotics. This group consisted of laboratory workers, as well as urban and rural dwellers. No significant differences in prevalence of resistance to any of the antibiotics tested were found among the subpopulations of the ambulatory group, although the general trend was towards lower numbers of resistant bacteria in the rural samples. Eight to nine years later, in 1987, the urban group was again studied and yielded similar results for the prevalences of resistance; also the high degrees of resistance ( $\geq 50 \%$ of the faecal flora resistant) were of the same order of magnitude as in the previous study: $11.3 \%$ for ampicillin, $17.5 \%$ for streptomycin, $21.3 \%$ for tetracycline, and $7.5 \%$ for kanamycin [43].

\section{Prevalence of antibiotic-resistant Escherichia coli in the Netherlands}

In the Netherlands only limited data are available on the prevalence of antibiotic resistance in healthy people $[6,7,20,21,27]$.

In the study of Guinee et al. (1970) the prevalence of Escherichia coli carrying Rfactors was examined in meat-consuming individuals (military kitchen personnel and office employees) and in those not consuming meat (vegetarians and babies below the age of 6 months). Of the office employees, 38\% yielded tetracycline-resistant Escherichia coli; $22 \%$ yielded one or more Escherichia coli strains with transferable resistance. For the adult vegetarians the respective figures were $52 \%$ and $27 \%$, and for the babies $49 \%$ and $31 \%$. It was assumed that these babies had acquired the resistant organisms from 
their mothers. The percentages found for the vegetarians were higher than those found for the non vegetarians; so the most important mechanism with regard to the incidence of resistant Escherichia coli in man in this study was not likely to have been due to the human consumption of meat containing antibiotic-resistant Escherichia coli [27]. Raw vegetables and salads often carry large numbers of resistant bacteria due to the use of antibiotics in agriculture [42].

Degener ef al. (1978-1980 and 1987) determined the faecal carriage rates for antibiotic-resistant Escherichia coli in an urban population in Zoetermeer, a new town in the West of the Netherlands. In the period 1978-1980 the prevalence of resistance to ampicillin was $25 \%$, for tetracycline $42 \%$ and sulphamethoxazole $45 \%$. In 1987 these percentages were $27 \%, 20 \%$ and $46 \%$, respectively. The high degree of resistance, i.e. $\geq 50 \%$ of the faecal Escherichia coli flora in one individual being resistant, increased from $5 \%$ to $11 \%$ for ampicillin, decreased from $12 \%$ to $6 \%$ for tetracycline and remained almost the same for sulphamethoxazole,i.e. $19 \%$ and $21 \%$ [20,21].

In a more recently performed study of Bonten et al. (1990) the antibiotic resistance level of Escherichia coli isolated from faecal samples from 172 students in Maastricht, a city in the South of the Netherlands, was determined. In 165 out of 172 samples resistance to either ampicillin, tetracycline, sulphamethoxazole, trimethoprim or nitrofurantoin was observed. The highest percentages were found for sulphamethoxazole $(86 \%)$, ampicillin $(76 \%)$ and tetracycline $(47 \%)$. For ampicillin the high degree of resistance was $8 \%$, for tetracycline and sulphamethoxazole $11 \%$ and $37 \%$ were found [6].

Comparison of the data of these studies on the healthy population not using any antibiotics is difficult because of differences in methods and in selective antibiotic concentrations used as well as in the populations studied. Furthermore, except for the study of Levy et al. (1988), who analysed two faecal samples from the same individual and found that $90 \%$ of all individuals showed a gain $(47.6 \%)$ and/or loss $(65.7 \%)$ of one or more detectable resistances [43], data from other studies were based upon only one faecal sample per individual. There are thus no data on the reproducibility of sampling, or on the intra-(or within) individual variation regarding the presence of antibiotic resistance in faecal isolates and possible changes in resistance over time. 


\section{AIMS OF THE STUDY}

With respect to the literature as discussed in this chapter several questions concerning the prevalence of antibiotic resistance in non-hospitalized patients still remain unanswered. The present study has been designed to answer the following questions;

I The prevalence of resistance to antimicrobial agents and the antibiotic resistance patterns of faecal Escherichia coli isolated from healthy volunteers, i.e. pig farmers, abattoir workers and (sub)urban residents. In the last group special attention has been paid to the reproducibility of sampling and the intra-individual variation over time.

II The effect of antibiotic therapy on antibiotic resistance of faecal Escherichia coli in general practice patients with respiratory tract infections.

III To provide evidence for the reservoir function of the faecal Escherichia coli flora as uropathogens.

IV To determine the mechanism of resistance to the combination of a B-lactam antibiotic and a new B-lactamase inhibitor in an isolate from a healthy individual who had not undergone any antibiotic therapy in the previous three months. 


\section{REFERENCES}

1. Ahart JG, Burton GC, Blenden DC. The influence of antimicrobial agents on the percentage of tetracyclineresistant bacteria in faeces of humans and animals. J Appl Bacteriol 1978; 44: 183-190.

2. Amyes SGB, Smith JT. R-factor mediated dihydrofolate reductases which confer trimethoprim resistance. J Gen Microbiol 1978; 107; 263-271.

3. Amyes SGB, Tait S, Thomson CJ, Payne DJ, Nandivada LS, Jesudason MV, Mukundan UD, Young HK. The incidence of antibiotic resistance in aerobic faecal flora in South India. J Antimicrob Chemother 1992; 29: $415-425$.

4. Anderson JD. Factors that may prevent transfer of antibiotic resistance between gram-negative bacteria in the gut. J Med Microbiol 1975; 8: 83-88.

5. Bogaard van den AEJM, Breeuwsma AJ, Julicher CHM, Mostert A, Nieuwenhuijs JHM, Vaarkamp H, Verhoeff J, Vulto A. Veterinair antibioticumbeleid: Aanbevelingen van een werkgroep. Tijdschr Diergeneeskd 1994; 119: 160-183.

6. Bonten M, Stobberingh E, Philips J, Houben A. High prevalence of antibiotic resistant Escherichia coli in faecal samples of students in the south-east of the Netherlands. J Antimicrob Chemother 1990; 26: 585-592.

7. Bonten M, Stobberingh E, Philips J, Houben A. Antibiotic resistance of Escherichia coli in fecal samples of healthy people in two different areas in an industrialized country. Infection 1992; 20: 258-262.

8. Bryan LE, Van Den Elzen BM. Effects of membrane-energy mutations and cations on streptomycin and gentamicin accumulation by bacteria: a model for entry of streptomycin and gentamicin in susceptible and resistant bacteria. Antimicrob Agents Chemother 1977; 12: 163-177.

9. Cherubin CE, Fodor T, Denmark L, Master C, Fuerst HT, Winter J. The epidemiology of salmonellosis in New York City. Am J Epidemiol 1969; 90: 112-125.

10. Chopra I, Howe TGB. Bacterial resistance to the tetracyclines. Microbiol Rev 1978; 42: 707-724.

11. Courcol RJ, Pinkas M, Martin GR. A seven year survey of antibiotic susceptibility and its relationship with usage. J Antimicrob Chemother 1989; 23: 441-451.

12. Curtis NAC, Richmond MH, Stanisich V. R-factor mediated resistance to penicillins which does not involve a B-lactamase. J Gen Microbiol 1973; 79: 163-166.

13. Damato JJ, Eitzmann DV, Baer H. Persistence and dissemination in the community of R-factors of nosocomial origin. J Infect Dis 1974; 129: 205-209.

14. Datta N. Drug resistance and $R$-factors in the bowel bacteria of London patients before and after admission to hospital. Brit Med J 1969; 2: 407-411.

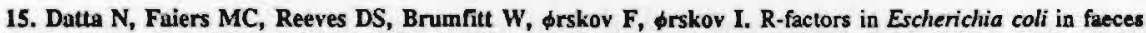
after oral chemotherapy in general practice. Lancet 1971 ; i: 312-315.

16. Datta N, Dacey S, Hughes V, Knight S, Richards H, Williams G, Casewell M, Shannon K. Distribution of genes for trimethoprim and gentamicin resistance in bacteria and their plasmids in a general hospital. J Gen Microbiol 1980; 118: 495-508.

17. Datta N. Plasmids of enteric bacteria. In: Bryan LE (ed): Antimicrobial drug resistance. Academic Press, Inc, 1984, pp. 487-496. 
18. Davies J, Smith DI. Plasmid-determined resistance to antimicrobial agents. Annu Rev Microbiol 1978; 32: 469-518.

19. Davies M, Stewart PR. Transferable drug resistance in man and animals: genetic relationship between Rplasmids in enteric bacteria from man and domestic pets. Austr Vet J 1978; 54: 507-512.

20. Degener JE, Michel MF, Valkenburg HA, Smit AC, Muller L, Thonus IP. Bacterial drug resistance in the community and in hospitals. Neth J Med 1985; 28: 182-191.

21. Degener JE, Hooft van IMS, Stiphout WAHJ, Luchmun R. Veranderende gevoeligheid van Escherichia coli voor antibiotica in de bevolking. Ned Tijdschr Geneeskd 1990; 134: 2296-2299.

22. Doss SA. Chromosomally-mediated antibiotic resistance and virulence. J Med Microbiol 1994; 40: 305-306.

23. DuPont HI, Steele JH. Use of antimicrobial agents in animal feeds: implications for human bealth. Rev Infect Dis 1987; 9: 447-460.

24. Fraser A. The use of antibiotics in general practice. Austr Fam Phys 1987; 16: 1264-1271.

25. Gillespie WA, Lee PA, Linton KB. Antibiotic resistance of coliform bacilli in urinary infection acquired by women outside hospital. Lancet 1971; ii: 675-677.

26. Greenwood D (ed). Antimicrobial chemotherapy, Oxford University Press 1989, 2nd edition, New York.

27. Guinée P, Ugueto N, Leeuwen van WJ. Escherichia coli with resistance factors in vegetarians, babies, and nonvegetarians. Appl Microbiol 1970; 20: 531-535.

28. Hawkey PM. Resistant bacteria in the normal human flora. J Antimicrob Chemother 1986; 18, Suppl.C : 133-139.

29. Holmberg SD, Osterholm MT, Senger KA, Cohen ML. Drug-resistant Salmonella from animals fed antimicrobials. N Engl J Med 1984; 311: 617-622.

30. Horne D, Tomasz A. Tolerant response of Streptococcus sanguis to B-lactams and other cell wall inhibitors. Antimicrob Agents Chemother 1977; 11: 888-896.

31. Huovinen P, Renkonen O-V, Pulkkinen L, Sunila R, Grobroos P, Klossner M-L, Virtanen S, Toivanen

P. Trimethoprim resistance of Escherichia coli in outpatients in Finland after ten years'use of plain trimethoprim. J Antimicrob Chemother 1985; 16: 435-441.

32. Kayser FH. Evolution of resistance in microorganisms of human origin. Vet Microbiol 1993; 35: 257-267.

33. King JW, White MC, Todd JR, Conrad SA. Alterations in the microbial flora and in the incidence of bacteremia at a university hospital after adoption of amikacin as the sole formulary aminoglycoside. Clin Infect Dis 1992; 14: 908-915.

34. Kling P-A, Östensson R, Granstrơm S, Burman LG. A 7-year survey of drug resistance in aerobic and anaerobic fecal bacteria of surgical inpatients: clinical relevance and relation to local antibiotic consumption. Scand J Infect Dis 1989; 21: 589-596.

35. Kunin CM, Lipton HL, Tupasi $\mathrm{T}$ at al. Social, behavioral, and practical factors affecting antibiotic use worldwide: report of Task Force 4. Rev Infect Dis 1987; 9,Suppl.3: S270-S285.

36. Lacey RW, Lord VL, Gunasekera HKW, Leiberman PJ, Luxton DEA. Comparison of trimethoprim alone with trimethoprim sulphamethoxazole in the treatment of respiratory and urinary infections with particular 
reference to selection of trimethoprim resistance. Lancet 1980, i: 1270-1273.

37. Landy M, Gerstung RB. p-Aminobenzoic acid synthesis by Neisseria gonorrhoeae in relation to clinical and cultural sulfonamide resistance [abstract]. J Bacteriol 1944; 47: 488.

38. Lester SC, Pilar Pla del M, Wang F, Perez Schael I, Jiang H, O'Brien TF. The carriage of Escherichia coli resistant to antimicrobial agents by healthy children in Boston, in Caracas, Venezuela, and in Qin Pu, China. N Engl J Med 1990; 323: 285-289.

39. Levy SB, Fitzgerald GB, Macone AB. Spread of antibiotic-resistant plasmids from chicken to chicken and from chicken to man. Nature 1976; $260: 40-42$.

40. Levy SB. Microbial resistance to antibiotics. An evolving and persistent problem. Lancet 1982; ii: 83-88.

41. Levy SB. Playing antibiotic pool: time to tally the score. N Engl I Med 1984; 311: 663-665.

42. Levy SB. Drug resistant bacteria in food for humans and animals. In : Woodbine $\mathbf{M}$ (ed). Antimicrobials and agriculture: London: Butterworth, 1984: 525-531.

43. Levy SB, Marshall B, Schluederberg S, Rowse D, Davis J. High frequency of antimicrobial resistance in human fecal flora. Antimicrob Agents Chemother 1988; 32: 1801-1806.

44. Levy SB. Antibiotic availability and use: cosequences to man and his environment. J Clin Epidemiol 1991; 44, Suppl.II: 83S-87S.

45. Linton KB, Lee PA, Richmond MH, Gillespie WA. Antibiotic resistance and transmissible R-factors in the intestinal coliform flora of healthy adults and children in an urban and a rural community. J Hygiene 1972; 70: 99-104.

46. Linton AH, Handley B, Osborne AD, Shaw BG, Roberts TA, Hudson WR. Contamination of pig carcasses at two abattoirs by Escherichia coli with special reference to O-serotypes and antibiotic resistance. J Appl Bacteriol 1976; 41: 89-110.

47. Linton AH. Antibiotic resistance: The present situation reviewed. Vet Rec 1977; 100: 354-360.

48. Linton AH. Animal to man transmission of Enterobacteriaceac. R Soc Health $J$ 1977; 97; 115-118.

49. Linton Af. Flow of resistance genes in the environment and from animals to man. J Antimicrob Chemother 1986; 18, Suppl. C: $189-197$.

50. Ma MY, Goldstein EJC, Friedman MH, Anderson MS, Mulligan ME. Resistance of gram-negative bacilli as related to hospital use of antimicrobial agents. Antimicrob Agents Chemother 1983; 24: 347-352.

51. Mamun KZ, Shears P, Hart CA. The prevalence and genetics of resistance to commonly used antimicrobial agents in faecal Enterobacteriaceae from children in Bangladesh. Epidemiol Infect 1993; 110; 447-458.

52. Mayer K. The epidemiology of antibiotic resistance in hospitals. J Antimicrob Chemother 1986; 18, Suppl.C: 223-233.

53. Michéa-Hamzehpour M, Pechère J-C, Marchou B, Auckenthaler R. Combination therapy: a way to limit emergence of resistance? Am J Med 1986; 80, Suppl.6B.: 138-142.

54. Moorhouse EC. Transferable drug resistance in Enterobacteria isolated from urban infants. Brit Med J 1969; 2: $405-407$.

55. Mouton RP, Hermans J, Simoons-Smit AM, Hoogkamp-Korstanje JAA, Degener JE, Klingeren van B. Correlations between consumption of antibiotics and methicillin resistance in coagulase negative rtaphylococci. J 
Antimicrob Chemother 1990; 26: 573-583.

56. Murray BE. Emergence of diseases caused by bacteria resistant to antimicrobial agents. In: Steele J (ed): Handbook Series in Zoonoses:Antibiotics, Sulfonamides, and Public Health, Sect. D, CRC Press, Inc, Boca Raton, Florida 1984, pp.201-216.

57. Murray BE. Emergence of resistant fecal Escherichia coli in travellers not taking prophylactic antimicrobial agents. Antimicrob Agents Chemother 1990; 34: 515-518.

58. Murray BE. New aspects of antimicrobial resistance and the resulting therapeutic dilemmas. I Infect Dis 1991; 163: 1185-1194.

59. Neu HC. The emergence of bacterial resistance and its influence on empiric therapy. Rev Lnfect Dis 1983; 5, Suppl.: $\$ 9.520$.

60. Neu HC. The crisis in antibiotic resistance. Science 1992; 257: 1064-1073.

61. Nijsten R, London N, Bogaard van den A, Stobberingh E. Resistance in fecal Escherichia coli isolated from pigfarmers and abattoir workers. Epidemiol Infect 1994; 113: 45-52.

62. O'Brien TF, Norton RA, Kent RL, Medeiros AA. International surveillance of prevalence of antibiotic resistance. J Antimicrob Chemother 1977; 3, Suppl.C: 59-66.

63. Ozanne G, Bedard P, Ducic S, Panisset J-C. Antibiotic multiresistance among coliforms isolated from the gut of swine and abattoir workers: evidence of transfer from animal to man. Can J Public Health 1987; 78: 340344.

64. Richmond MH, Linton KB. The use of tetracycline in the community and its possible relation to the excretion of tetracycline-resistant bacteria. J Antimicrob Chemother 1980; 6:33-41.

65. Rosendal K, Jessen O, Bentzon MW, Bülow P. Antibiotic policy and spread of Staphylococcus aureus strains in Danish hospitals, 1969-1974. Acta Path Microbiol Scand 1977; 85, Sect. B: 143-152.

66. Shanahan PMA, Wylie BA, Adrian PV, Koornhof HJ, Thomson CJ, Amyes SGB. The prevalence of antimicrobial resistance in buman faecal flora in South Africa. Epidemiol Infect 1993; 111: 221-228.

67. Shears P, Suliman G, Hart CA. Occurrence of multiple antibiotic resistance and R plasmids in Enterobacteriaceae isolated from children in the Sudan. Epidemiol Infect 1988; 100: 73-81.

68. Shooter RA, Faiers MC, Cooke EM, Breaden AL, O'Farrell SM. Isolation of Escherichia coli, Pseudomonas aeruginosa, and KTebsiella from food in hospitals, canteens, and schools. Lancet 1971; ii: 390392.

69. Silver LL, Bostian KA. Discovery and development of new antibiotics: the problem of antibiotic resistance. Antimicrob Agents Chemother 1993; 37: 377-383.

70. Smith JT, Lewin CS. Mechanisms of antimicrobial resistance and implication for epidemiology. Vet Microbiol 1993; 35: 233-242.

71. Spencer RC, Whent PF, Magee JT, Brown EH. A three year aurvey of clinical isolates in the United Kingdom and their antimicrobial susceptibility. J Antimicrob Chemother 1990; 26: 435-446.

72. Stobberingh EE, Houben AW. Antibioticagebruik en antibiotica resistentie in de huisartspraktijk. Ned Tijdschr Geneeskd 1990; 132: 1793-1797. 
73. Stratton CW. new insights on the genetic basis for resistance. Infect Control Hosp Epidemiol 1989; 10: 371-375.

74. Sykes RB, Mntthew M. The B-lactamases of gramnegative bacteria and their role in resistance to B-lactam antibiatics. J Antimicrob Chemother 1976; 2: 115-157.

75. Thomson CJ, Amyes SGB. Selection of variants of the TEM-1 B-lactamase, encoded by a plasmid of clinical origin, with increased resistance to B-lactamase inhibitors. J Antimicrob Chemother 1993; 31: 655-664.

76. Thomson CJ, Amyes SGB. TRC-1: Emergence of a clavulanic acid-resistant TEM B-lactamase in a clinical strain. FEMS Microbiol Lett 1992; 91: 113-118.

77. Towner KJ, Wise PJ. Transferable resistance plasmids as a contributory cause of increasing trimethoprim resistance in general practice. J Antimicrob Chemother 1983; 11: 33-39.

78. Vorland LH, Carlson K, Aalen 0 . Antibiotic resistance and small R plasmids among Escherichia coli isolates from outpatient urinary tract infections in Northern Norway. Antimicrob Agents Chemother 1985; 27: 107-113.

79. Wells DM, James OB. Transmission of infectious drug resistance from animals to man. J Hyg Camb 1973; 71: 209-215. 


\section{CHAPTER II}

\section{RESISTANCE IN FAECAL ESCHERICHIA COLI ISOLATED}

FROM PIG FARMERS AND ABATTOIR WORKERS.

R. Nijsten, N. London, A. van den Bogaard, E. Stobberingh Epidemiology and Infection 1994; 113: 45-52. 


\section{SUMMARY}

Faecal samples collected from three populations of healthy adult volunteers (290 pig farmers, 316 abattoir workers, 160 (sub)urban residents) living in the south of The Netherlands were analysed for the prevalence and degree of antibiotic resistance of Escherichia coli. Significant differences in prevalence of resistance to amoxycillin, neomycin, oxytetracycline, sulphamethoxazole and trimethoprim were observed. The pig farmers showed the highest percentages of resistance and the (sub)urban residents the lowest. In contrast no significant differences in high degrees of resistance were observed, except for neomycin. Although both pig farmers and abattoir workers have regular contact with pigs differences in prevalences of resistance were observed. However, because abattoir workers with intensive and less intensive pig(carcass) contact did not show significant differences, this is probably not the only important source of resistant Escherichia coli in pig farmers.

The high antibiotic use by pig farmers (5\%) and abattoir workers $(8 \%)$ than by (sub)urban residents $(0 \%)$ did not result in significantly different resistance percentages.

\section{INTRODUCTION}

Since their introduction antimicrobial agents have been successfully used for treatment and prophylaxis of bacterial diseases in man and other species. The availability of antibiotics means that many previously severe infections can now be treated. In addition, antibiotics are used for growth promotion in animal husbandry and in agriculture for crop protection. As antibiotics are not only very effective, but also remarkably safe drugs this safety may have provoked liberal, even lavish, use in man and other animals. The use of antibiotics, however, leads inevitably to emergence of resistance in the endogenous bacterial flora of treated persons and animals alike, against the antibiotics used or to other drugs $[4,18]$. These enteric microorganisms may colonize other persons and animals and may spread resistance further by transfer of resistance plasmids to their faecal flora. Consequently the environmental bacterial population may be contaminated after faeces excretion. Lester et al.[9] showed that persons with a few resistant bacteria in their intestinal flora will have more chance of developing an infection with resistant bacteria 
after antibiotic therapy than persons with no resistant strains at all.

Many studies have examined the resistance of enteric bacteria in humans after antibiotic therapy $[1,6,8,17$, but there is much less information available on the prevalence of antibiotic resistance in the faecal flora of healthy adults who have not used antibiotics recently $[2,3,5,13,14]$. However, such subjects are potential recipients of antimicrobial agents.

Farmworkers can directly become colonized by resistant bacteria due to close contact with animals and their faeces $[10,11,21]$, but are also directly exposed to antibiotics used for treatment or prevention of diseases in animals [12]. Abattoir workers have daily contact with contaminated carcasses and gut contents $[7,15,16,26]$. A common risk factor for colonization with resistant microorganisms in all three groups is personal use of antibiotics.

To elucidate the importance of spread of resistance from food-animals to man we studied in the same region the antibiotic resistance in three populations with different risks of exposure to faecal bacteria from pigs i.e. pig farmers, abattoir workers and as a control group, (sub)urban residents.

As the faecal flora is considered the most important reservoir of resistant microorganisms and the antibiotic resistance of this flora is an indicator for the resistance of potentially pathogenic bacteria in a population $[8,9,13,28]$, faecal samples of these three populations were analyzed for the prevalence and degree of antibiotic resistance of Escherichia coli.

\section{MATERIALS AND METHODS}

\section{Collection of the faecal samples.}

Faecal samples, one from each person, were received from adult pig farmers (290), pig-abattoir workers (316, of which 73 were meat inspectors) and (sub)urban residents (160) all living in the same area. After receipt, the samples were diluted $\left(10^{-1}\right)$ in physiological saline, containing $20 \%(\mathrm{v} / \mathrm{v})$ glycerol and stored at $-20^{\circ} \mathrm{C}$ until examined. All participants were asked to answer a questionnaire concerning antibiotic use in the previous three months. Additional information about recent hospital stay and previous antibiotic use by family members was obtained from the pig farmers and abattoir 
workers. The abattoir workers were also asked to give some information about keeping domestic animals or pigs and their daily duties at the slaughterhouse.

Bacteriological analysis of the faecal samples.

The methods used to determine the prevalence and degree of resistance were as described before [20]. In brief, after thawing the samples $\left(10^{-1}\right)$, tenfold dilutions $\left(10^{-2}-10^{-}\right.$ 5) in physiological saline were made. Thirty-seven $\mu \mathrm{l}$ of these dilutions were inoculated with a spiral plater on Levine-agar plates (BBL 11221, [27]), a selective medium for Escherichia coli, with and without antibiotics. The antibiotic concentrations (Table 1) were based on NCCLS guidelines and modified where appropiate so that the data were comparable with those of previous studies [2,3]. Only colonies with the appearance of Escherichia coli (i.e. purple with a black center and a metallic green shine) were counted. The total number and the number of resistant Escherichia coli were determined. The minimum detection level of bacterial growth was $10^{3}$ colony forming units (CFU) /g faeces. From each agar plate without antibiotics one colony with the appearance of Escherichia coli was picked and tested for growth at $42^{\circ} \mathrm{C}$ overnight in tryptone water (Oxoid L42) and for the indole reaction. If these tests were positive the microorganism was considered to be Escherichia coli. For the first 50 isolates this identification was confirmed with Api-20E test (BioMerieux, Den Bosch, The Netherlands).

Prevalence of antibiotic resistance:

The prevalence of antibiotic resistance was defined as the percentage of faecal samples showing any growth of Escherichia coli on antibiotic-containing plates.

\section{Degree of antibiotic resistance:}

The degree of resistance of each sample was calculated as the percentage of the total number of colonies that was resistant.

Two degrees of antibiotic resistance to a particular antimicrobial agent were distinguished $[3,13]$, namely the proportion of faecal samples with a ratio $<50 \%$ was defined as low degree of resistance, and the proportion of faecal samples with a ratio $\geq 50 \%$ was defined as high degree of resistance (thus the majority of the strains showed resistance to 
that agent).

The antimicrobial agents used in this study were selected because these or closely related compounds are regularly used for the treatment of humans and pigs in The Netherlands, except apramycin which is only registered for use in animals but is not extensively used in The Netherlands.

\section{Statistical analysis.}

In the analysis of the differences in prevalence and degree of antibiotic resistance of the faecal samples of the three populations a Chi Square test with continuity correction was performed. A Fisher Exact test was used if the expected frequency in at least one cell was five or less. A two-sided significance level of $\leq 0.05$ was used.

Multiple logistic regression was used to analyse the contribution of the origin of the three study populations (independent variable) to the prevalence of resistance (dependent variable) to a particular antibiotic. The antibiotics other than the dependent variable were considered to be independent variables simultaneously, a two-sided significance level of $\leq 0.05$ was used.

The error of the method by using the spiral plater and by making tenfold dilutions, calculated from the standard error of the mean, was $0.5 \log _{10}$.

\section{RESULTS}

Ninety-five percent of the pigfarmer colonies, $94 \%$ of the abattoir workers colonies and $92 \%$ of the (sub)urban residents colonies that grew on Levine-agar showing the morphology typical of Escherichia coli were identified as Escherichia coli. The other colonies tested were also Enterobacteriaceae: Klebsiella spp., Citrobacter spp., Enterobacter spp. and Proteus spp. Finally, 278 samples of pig farmers, 289 of abattoir workers and 150 of (sub)urban residents were included in the analysis. The other samples failed to grow on the agar plates without antibiotics.

Antibiotic use was recorded by 15 pig farmers and 17 of their family members. Two farmers had been hospitalized recently. Twenty-five abattoir workers and 25 family members recorded antibiotic use, 5 abattoir workers had been hospitalized recently. By the (sub)urban residents no antibiotic use in the three previous months was recorded. 
Intensive contact with pigs or pig carcasses was recorded by 182 abattoir workers, whereas 104 workers had other duties as well or no direct contact. No information about contact with pigs/carcasses was obtained from the remaining abattoir workers $(n=30)$. Fifty-two percent of the abattoir workers kept at least one domestic animal, whereas only three persons kept pigs.

\section{Prevalence of antibiotic resistance:}

The prevalence and high degree of resistance are shown in Table 1 and Figure 1. The most significant differences were noticed between pig farmers and (sub)urban residents. The highest prevalence percentages were found for the pig farmers and the lowest for the (sub)urban residents. The highest percentages (i.e. $47 \%$ ) in the abattoir workers and in the (sub)urban residents group were found for oxytetracycline and amoxycillin, respectively, and in the pigfarmer group for sulphamethoxazole (84\%).

Further analysis as to the patterns of prevalence of resistance to amoxycillin, neomycin, oxytetracycline and trimethoprim of Escherichia coli isolated from the three populations studied showed that the highest percentage of fully susceptible strains (34\%) as well as the lowest percentage of completely resistant isolates $(4 \%)$ were found in the (sub)urban residents. The converse was observed for the pig farmers.

Logistic regression analysis was performed to estimate the relative risk of prognostic and risk factors (i.e. antibiotics used and population groups) with regard to the (sub)urban residents. The odds ratio (OR), with the $95 \%$ confidence interval $(\mathrm{Cl})$, for resistance to a particular antibiotic under consistent circumstances was calculated. Both pig farmers (OR 0.4, CI 0.2-0.6) and abattoir workers (OR 0.5, CI 0.3-0.9) showed a low odds ratio for amoxycillin resistance. The pig farmers showed a high odds ratio for neomycin (OR 3.6, CI 2.5-5.4), sulphamethoxazole (OR 6.5, CI 4.0-10.6) and trimethoprim (OR 2.1, CI 1.4-2.9). Resistance to oxytetracycline appeared to be independent of the population tested. For the other antibiotics tested no significant prognostic and risk factors were found. 
Table 1: Prevalence and high degree of antibiotic-resistant Escherichia coli (\%).

\begin{tabular}{lllllll}
\hline $\begin{array}{llll}\text { Antibiotic } \\
(\mathrm{mg} / \mathrm{L})\end{array}$ & $\begin{array}{l}\text { Prevalence } \\
\mathrm{PF}\end{array}$ & $\mathrm{AW}$ & $\mathrm{UR}$ & $\mathrm{PF}$ & $\mathrm{AW}$ & $\mathrm{UR}$ \\
& $\mathrm{n}=278$ & $\mathrm{n}=289$ & $\mathrm{n}=150$ & $\mathrm{n}=278$ & $\mathrm{n}=289$ & $\mathrm{n}=150$ \\
\hline AMX (25) & 62 & $42^{\circ}$ & $47^{\prime} \cdot$ & 7 & 9 & 13 \\
AP (32) & 3 & 1 & $\mathrm{nt}^{\circ}$ & 0 & 0 & $\mathrm{nt}$ \\
CIP (4) & 1 & 0 & 0 & 0 & 0 & 0 \\
NA (32) & 5 & 3 & 1 & 1 & 0 & 0 \\
NE (8) & 66 & $36^{\circ}$ & $25^{\prime} \cdot$ & 7 & $2^{\circ}$ & $2^{\prime} \cdot$ \\
FT (50) & 8 & 4 & 3 & 0 & 0 & 0 \\
OT (25) & 79 & $47^{\circ}$ & $36^{\prime} \cdot \cdot$ & 10 & 15 & 8 \\
SMX (100) & 84 & $45^{\circ}$ & $40^{\prime} \cdot$ & 17 & 13 & 10 \\
TMP (8) & 53 & $23^{\circ}$ & $15^{\prime} \cdot$ & 4 & 4 & 3 \\
\hline
\end{tabular}

"AMX = amoxycillin, $\mathrm{AP}=$ apramycin, $\mathrm{CIP}=$ ciprofloxacin, $\mathrm{NA}=$ nalidixic acid,

$\mathrm{NE}=$ neomycin, $\mathrm{FT}=$ nitrofurantoin, $\mathrm{OT}=$ oxytetracycline, $\mathrm{SMX}=$ sulphamethoxazole,

TMP $=$ trimethoprim

'PF = pig farmers, $\mathrm{AW}=$ abattoir workers, $\mathrm{UR}=$ (sub)urban residents

'Apramycin was only tested for the abattoir workers and the last 116 pig farmers faecal samples.

${ }^{\mathrm{n}} \mathrm{t}=\mathrm{not}$ tested

Significantly different $(\mathrm{P} \leq 0.05)$ : $\mathrm{PF}$ and $\mathrm{AW}:{ }^{\circ}, \mathrm{PF}$ and UR: ${ }^{\prime}, \mathrm{AW}$ and UR: '; PF and AW and UR *-

\section{Degree of antibiotic resistance:}

As presented in Figure 1 all three populations showed, except for neomycin, similar percentages for high degree of resistance, but distinct variations in low degree of resistance. The prevalence and degree of resistance of the meat inspector samples were not significantly different from those of the abattoir workers. In addition, no differences in prevalence and degree of resistance were observed between abattoir workers with and without domestic animals. Because only three abattoir workers kept pigs no conclusions about the influence of regular contact with pigs could be drawn. 
No significant differences could be observed between abattoir workers with intensive and those without or with less intensive contact with pig faecal contents or pig carcasses.

No significantly different prevalence or degree of resistance rates were observed for those people who had recently used antibiotics compared with those who had not used antibiotics recently (pig farmers $5 \%$, abattoir workers $8 \%$ ). Nor were differences observed for those recording recent hospital stay (pig farmers $1 \%$, abattoir workers $2 \%$ ) or antibiotic use by family members (pig farmers $6 \%$, abattoir workers $8 \%$ ) when compared with those who did not record these factors.

Figure 1. Prevalence of antibiotic resistance (\%) of Escherichia coli from pig farmers (PF, first bar per antibiotic), abattoir workers (AW, second bar) and (sub)urban residents (UR, third bar). Also shown are the proportions (\%) of low degree $(<50 \%)$ and high degree $(\geq 50 \%)$ of resistance. $\mathrm{AMX}=$ amoxycillin; $\mathrm{AP}=$ apramycin; $\mathrm{CIP}=$ ciprofloxacin; $\mathrm{NA}=$ nalidixic acid; $\mathrm{NE}=$ neomycin; $\mathrm{FT}=$ nitrofurantoin; $\mathrm{OT}=$ oxytetracycline; $\mathrm{SMX}=$ sulphamethoxazole; $\mathrm{TMP}=$ trimethoprim.

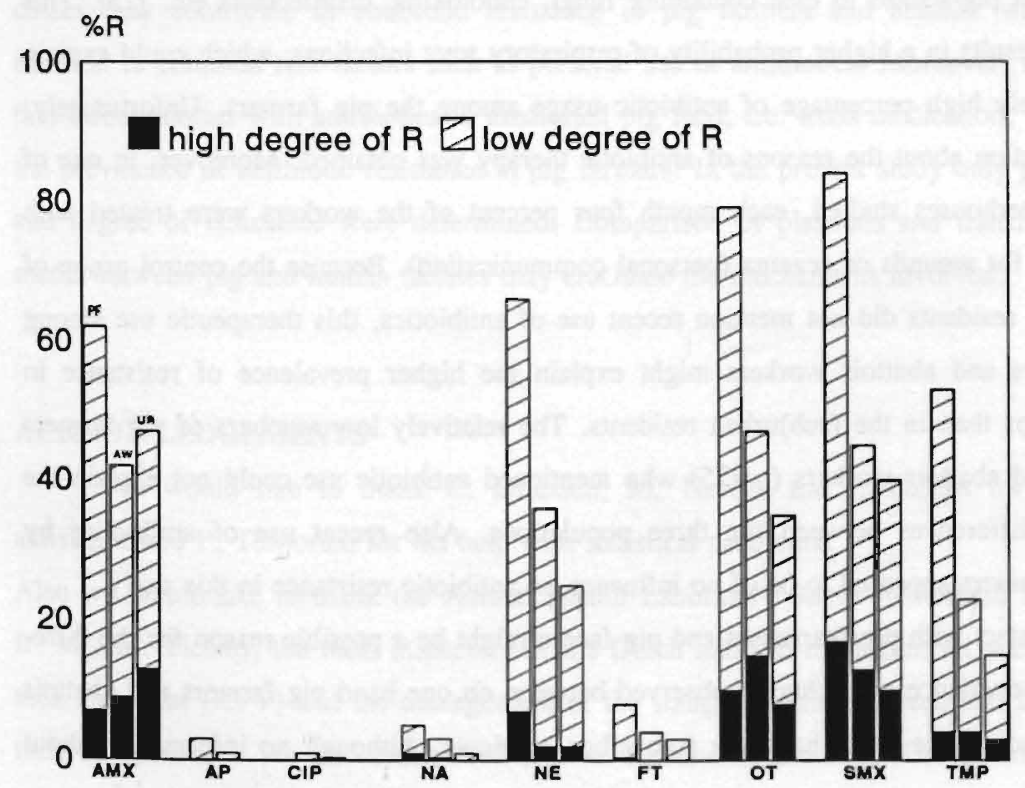




\section{DISCUSSION}

The present study showed significant differences in prevalence of resistance between pig farmers and (sub)urban residents for antibiotics extensively used in human and veterinary medicine in The Netherlands [19]. In contrast the prevalence of a high degree of resistance was, except for neomycin, not significantly different.

Several investigators have also observed differences in resistance of the faecal flora of pig farmers/abattoir workers and urban residents [14,22,24] suggesting that contact with live- stock was one route by which antibiotic resistance entered the human gut flora. In contrast, Levy et al. [13] found no significant difference between rural and urban residents. The general trend in their study was for lower numbers of resistant bacteria to be found in rural samples.

Remarkably, in the present study 15 (5\%) pig farmers and 25 (8\%) abattoir workers used antibiotics during the three months previous to faecal sampling, whereas none of the (sub)urban residents mentioned recent antibiotic use. This might be an indication that people in contact with pigs or pig carcasses have a greater risk of bacterial infections. A recent study about occupational risk factors for pig farmers showed that pig farmers often suffer from chronic non-specific respiratory tract afflictions, due to regular exposure in pig-stables to dust containing fungi, endotoxins, disinfectants etc. [23]. This exposure results in a higher probability of respiratory tract infections, which could explain the relatively high percentage of antibiotic usage among the pig farmers. Unfortunately, no information about the reasons of antibiotic therapy was obtained. Moreover, in one of the slaughterhouses studied, each month four percent of the workers were treated with antibiotics for wounds or eczema (personal communication). Because the control group of (sub)urban residents did not mention recent use of antibiotics, this therapeutic use among pig farmers and abattoir workers might explain the higher prevalence of resistance in these groups than in the (sub)urban residents. The relatively low numbers of pig farmers $(n=15)$ and abattoir workers $(n=25)$ who mentioned antibiotic use could not explain the observed differences between the three populations. Also recent use of antibiotics by family members appeared to be of no influence on antibiotic resistance in this study.

Contact with pigs/carcasses and pig faeces might be a possible reason for the differences in prevalence of resistance observed between on one hand pig farmers and abattoir workers and on the other hand the (sub)urban residents. Although no information about 
the professions of the last group was obtained, it is to be expected that they do not have regular direct contact with pigs. However, no significant differences were observed between the abattoir workers with intensive and those with less intensive pig contact. Therefore, other factors such as more intensive faecal contact, less personal hygiene and protection taken by farmers as compared to abattoir workers might have contributed to these differences. Moreover, it is very likely that direct contact with antibiotics used for treatment of pigs is an additional risk factor for emergence of resistance and selection of resistant strains in the intestinal flora of pig farmers. The results of the logistic regression analysis underscore these suggestions.

Remarkably, significantly different prevalences and high degrees of resistance to neomycin were observed for the pig farmers. Because neomycin is seldom used orally and never parenterally in human medicine but frequently in pigs, the suggestion seems likely that it is not human but mainly veterinary use of neomycin that is responsible for a higher prevalence and high degree of resistance in pig farmers.

This study showed significant differences in the prevalence of antibiotic resistance in the faecal flora of the three populations tested. Direct contact with pigs and pig carcasses may contribute to antibiotic resistance in pig farmers and abattoir workers, in addition to common risk factors such as personal use of antibiotics. Moreover, it is likely that direct contact with antibiotics in medicated pig feed, i.e. mass medication, influences the prevalence of antibiotic resistance in pig farmers. In the present study only prevalence and degree of resistance were determined. Comparison of plasmids and transfer experiments between pig and human isolates may elucidate the mechanisms involved.

\section{ACKNOWLEDGEMENTS}

We would like to thank C. Driessen, M. Norder and J. Philips for technical assistance and P. Terporten for his help with statistical problems.

Also we would like to thank the Animal Health Laboratory South Netherland (Prof. Dr. Ir. M.J.M. Tielen), the meat inspectors of the Dutch national inspection service for livestock and meat (RVV) and the management of the slaughterhouses Coveco and Encebe for their co-operation. We also thank Prof. Dr. A. Knottnerus and Prof. Dr. D. Mclaren for 
critical reading of the manuscript. This work was supported by a grant, project number 28.0275, of the Prevention Fund of the Netherlands.

\section{REFERENCES}

1. Ahart JG, Burton GC, Blenden DC. The influence of antimicrobial agents on the percentage of tetracycline resistant bacteria in faeces of humans and animals. I Appl Bacteriol 1978; 44: 183-190.

2. Bonten M, Stobberingh E, Philips J, Houben A. High prevalence of antibiotic resistant Escherichia coli in faecal samples of students in the south-east of The Netherlands. J Antimicrob Chemother 1990; 26: 585-592.

3. Bonten M, Stobberingh E, Philips J, Houben A. Antibiotic resistance of Escherichia coli in fecal samples of healthy people in two different areas in an industrialized country. Infection 1992; 20:258-262.

4. Datta N. Drug resistance and R factors in the bowel bacteria of London patients before and after admission to bospital. Brit Med J 1969, 2: 407-411.

5. Degener JE, Hooft van IMS, Stiphout van WAHJ, Luchmun R. Veranderde gevoeligheid van Escherichia coli voor antibiotica in de bevolking. Ned Tijdschr Geneeskd 1990; 47: 2296-2299.

6. DuPont HL. Use of quinolones in the treatment of gastrointestinal infections. Eur J Clin Microbiol Infect Dis 1991; 10: 325-329.

7. Howe K, Linton AH, Osborne AD. An investigation of calf carcass contamination by Escherichia coli from the gut contents at slaughter. J Appl Bacteriol 1976; 41: 37-45.

8. Kling P, Ostensson R, Granstrom S, Burman L. A 7-year survey of drug resistance in aerobic and anaerobic fecal bacteria of surgical inpatients: clinical relevance and relation to local antibiotic consumption. Scand J Infect Dis 1989; 21: 589-596.

9. Lester SC, Pilur del M, Wang F, Perez Schael I, Jiang H, O'Brien TF. The carriage of Escherichia coli resistant to antimicrobial agents by bealthy children in Boston, in Caracas, Venezuela, and in Qin Pu, Chine. N Engl J Med 1990; 323: 285-289.

10. Levy SB, Fitzgerald GB, Macone B. Spread of antibiotic-resistant plasmids from chicken to chicken and from chicken to man. Nature $1976 ; 260: 40-42$.

11. Levy SB, Fitzgerald GB, Macone AB. Changes in intestinal flora of farm personnel after introduction of a tetracycline-supplemented feed on a farm. N Engl J Med 1976; 295: 583-588.

12. Levy SB. Emergence of antibiotic resistant bacteria in the intestinal flora of farm inhabitants. J Infect Dis 1978; 137: 688-690.

13. Levy SB, Marshall B, Schluederberg S, Rowse D, Davies J. High frequency of antimicrobial resistance in buman fecal flora. Antimicrob Agents Chemother 1988; 32: 1801-1806.

14. Linton KB, Lee PA, Richmond MH, Gillespie WA, Rowland AJ, Baker VN. Antibiotic resistance and transmissible R-factors in the intestinal coliform flora of healthy adults and children in an urban and rural community. J Hyg Camb 1972; 70: 99-104.

15. Linton AH, Handley B, Osborne AD, Shaw BG, Roberts TA, Hudson WR. Contamination of pig carcas- 
ses at two abattoirs by Escherichia coli with special reference to O-serotypes and antibiotic resistance. J Appl Bacteriol 1976; 41: 89-110.

16. Linton AH, Howe $\mathrm{K}$, Bennet PM, Richmond MH. The colonisation of the human gut by antibiotic resistant Escherichia coli from chickens. J Appl Bacteriol 1977; 43: 465-469.

17. Midtvedt T. The influence of quinolones on the faecal flora. Scand J Infect Dis 1990; Suppl. 68: 14-18.

18. Neu HC. The emergence of bacterial resistance and its influence on emperic therapy. Rev Infect Dis 1983; 5: Suppl. S9-520.

19. Nota Beleidsgroep "Veterinaire Apotheek". Veterinair antibioticum beleid. Koninklijke Nederlandse Maatschappij voor Diergeneeskunde, 1992.

20. Nijsten R, London N, Bogaard van den A, Stobberingh E. Antibiotic resistance of Enterobacteriaceae isolated from the faecal flora of fattening pigs. The Veterinary Quarterly 1993; 15: 152-157.

21. Ojeniyi AA. Direct transmission of Escherichia coli from poultry to humans. Epidemiol Infect 1989; 103: 513-522.

22. Ozanne G, Bedard P, Ducic S, Panisset JC. Antibiotic multiresistance among coliforms isolated from the gut of swine and abbattoir workers: evidence of transfer from animal to man. Can J Publ Health 1987; 73: 340344.

23. Preller L, Vogelzang P. Gezondheid varkenshouder aan risico's blootgesteld. Stichting Gezondheidsdienst voor Dieren in Zuid-Nederland, Boxtel/Heythuysen, The Netherlands 1993. Rapportar. 93.001.

24. Saida K, Ike Y, Mitsuhashi S. Drug resistance and R plasmids of Escherichia coli strains isolated from pigs, slaughterers and breeders of pigs in Japan. Antimicrob Agents Chemother 1981; 19: 1032-1036.

25. Seydel JK, Wempe E. Bacterial growth kinetics of $E$. coli in the presence of various trimethoprim derivates alone and in combination with sulfonamides. Chemotherapy 1980; 26: 361-371.

26. Shooter RA, Rousseau SA, Cooke EM, Breaden AL. Animal sources of common serotypes of Esherichia coli in the food of hospital patients. Lancet 1970; 226-228

27. Society of American Bacteriologists. Manual of Microbiological Methods, McGrawHill, New York 1957.

28. Wray C. Some aspects of the occurence of resistant bacteria in the normal animal flora. J Antimicrob Cbemother 1986; Suppl. C 18: 141-147. 
CHAPTER II

\section{ANTIBIOTIC RESISTANCE OF FAECAL ENTEROBACTERIACEAE ISOLATED FROM HEALTHY VOLUNTEERS, A 15-WEEK FOLLOW-UP STUDY.}

N. London, R. Nijsten, A. van den Bogaard, E. Stobberingh Journal of Antimicrobial Chemotherapy 1993; 32: 83-91 
40 


\section{SUMMARY}

From 25 March to 1 July 1991 faecal samples from healthy volunteers of two cities and their rural surroundings, Weert $(n=91)$ and Roermond $(n=96)$ were collected weekly and analysed for the presence of Enterobacteriaceae, resistant to ampicillin, ciprofloxacin, nalidixic acid, neomycin, nitrofurantoin, oxytetracycline, sulphamethoxazole or trimethoprim. In total, 682 and 690 samples from Weert and Roermond, respectively were analysed for the prevalence and the degree of resistance to each antimicrobial agent. The mean prevalence of resistance of the samples from Weert varied from $28 \% \pm 12 \%$ (mean \pm S.D.) for ampicillin to $0.1 \% \pm 1 \%$ (range $0 \%-2 \%$ ) for ciprofloxacin. For Roermond the prevalence of resistance varied from $41 \% \pm 7 \%$ for sulphamethoxazole to $0 \%$ for ciprofloxacin.

The high degree of resistance (i.e. $>50 \%$ of the faecal flora of one particular individual) varied from $8 \% \pm 4 \%$ for sulphamethoxazole to $2 \% \pm 2 \%$ for trimethoprim for Weert. For Roermond the figures varied from $14 \% \pm 4 \%$ for sulphamethoxazole to $0.3 \% \pm 1 \%$ (range $0 \%-2 \%$ ) for nalidixic acid. High degrees of resistance were not found for ciprofloxacin and nitrofurantoin in either city.

In Weert ampicillin-resistant Enterobacteriaceae were isolated from 69/91 individuals.

\section{INTRODUCTION}

Emergence of antibiotic-resistant microorganisms continues to be an important problem for the treatment of bacterial infections $[3,14,15,20]$. There is general agreement that antibiotic use in general practice and in veterinary medicine is responsible in part for the increase in the numbers of resistant bacteria. However, it is still not clear how the use in humans (hospital and/or general practice) or that in animals has contributed to the environmental pool of resistant microorganisms $[1,8,17,25,27]$. In hospitalized patients relatively large amounts of antibiotics are used both for therapy and prophylaxis, resulting in a high prevalence of antibiotic-resistant pathogens $[21,23,24]$. In veterinary medicine antimicrobial agents are used in both these indications and as growth promoters at subtherapeutic concentrations $[2,10,16]$. In addition, multiple-resistant bacteria are 
increasingly being isolated, and it is evident that these microorganisms can be spread from animals to the human population as well as from person to person $[5,10,15,17,19,26]$. Furthermore, resistant bacteria, e.g. Salmonella spp. and Campylobacter jejuni, can colonize the human intestinal tract after ingestion of contaminated food $[6,13,16]$.

The intestinal tract of the human open population is considered to be an important reservoir of antibiotic-resistant bacteria [12], and several reports emphasize the importance of the availability of information of the prevalence of antibiotic-resistant isolates from faecal flora $[7,18,22]$. Relatively little is known about the numbers of resistant bacteria in the healthy human population not receiving antimicrobials for therapy or prophylaxis $[7,18,22]$. In addition, hardly any data are available on the reproducibility of sampling, the intra-(or within) individual variation regarding the presence of antibiotic resistance in faecal isolates and possible changes in resistance over time.

In this study, the prevalence and the degree of resistance for each antimicrobial agent were calculated for all faecal samples each week and for the entire 15-week period for each individual in the study.

\section{MATERIALS AND METHODS}

\section{Sample collection}

From 25 March to 1 July 1991 faecal samples were collected once weekly for a period of 15 weeks in two medium sized cities, Weert and Roermond, (41.10 and $43 \times 10^{4}$ inhabitants, respectively) $30 \mathrm{~km}$ apart in the south of the Netherlands. Volunteers were randomly selected at the registry office. Of the first 100 people in Weert and Roermond who consented to participate in the study, 91 and 96 subjects finally entered the study. Of these individuals $61 / 91(67 \%)$ and $63 / 96(66 \%)$, respectively, could be followed up for at least ten weeks. Only one individual reported having taken antibiotics (tetracycline) in the previous 15 weeks.

\section{Sample processing}

One gram of fresh faeces was suspended in $9 \mathrm{~mL}$ of $0.9 \%(w / v) ~ N a C l$, supplemented with $20 \%(w / v)$ glycerol and stored at $-20^{\circ} \mathrm{C}$ until assayed. After thawing 
this suspension, serial ten-fold dilutions were made up to a final dilution of $1: 10^{5}$ and $0.037 \mathrm{~mL}$ of these dilutions were inoculated on to Levine agar plates (Oxoid CM69) with and without antibiotics using a spiral plater (Lameris Laboratorium B.V., Breukelen, the Netherlands). On Levine agar plates Escherichia coli has a purple appearance with a black centre and a green metallic sheen. Sometimes the green metallic sheen disappears if antibiotics are added to the Levine agar. Other bacteria that grow on these agar plates are: Pseudomonas spp, Klebsiella spp, Enterobacter spp, Citrobacter spp and Proteus spp. The following antibiotic concentrations were used based on NCCLS guidelines and modified where appropriate so that the data were comparable with that of previous studies [7]: ampicillin $25 \mathrm{mg} / \mathrm{L}$, ciprofloxacin $4 \mathrm{mg} / \mathrm{L}$, nalidixic acid $32 \mathrm{mg} / \mathrm{L}$, neomycin 8 $\mathrm{mg} / \mathrm{L}$, nitrofurantoin $50 \mathrm{mg} / \mathrm{L}$, oxytetracycline $25 \mathrm{mg} / \mathrm{L}$, sulphamethoxazole $100 \mathrm{mg} / \mathrm{L}$ and trimethoprim $8 \mathrm{mg} / \mathrm{L}$. If trimethoprim was used $5 \%(\mathrm{v} / \mathrm{v})$ lysed horse-blood was added to the agar. After incubation at $37^{\circ} \mathrm{C}$ for $18-24$ hours the total number and the number of resistant Enterobacteriaceae were determined. The lowest number of Enterobacteriaceae detectable was $10^{3} \mathrm{cfu} / \mathrm{g}$ faeces, the highest concentration approximately $10^{9} \mathrm{cfu} / \mathrm{g}$ faeces. One colony with the colonial morphology of Escherichia coli was randomly picked out from each agar plate \pm antibiotics and tested for indole reaction and growth at $42^{\circ} \mathrm{C}$. Isolates yielding positive results for both tests were considered to be Escherichia coli and stored at $-70^{\circ} \mathrm{C}$ in small plastic tubes containing beads (Microbank, PRO-LAB Diagnostics, the Netherlands).

The prevalence of antibiotic-resistance was defined as the number of faecal samples with resistant Enterobacteriaceae divided by the total number of samples tested multiplied by $100 \%$. The degree of resistance of each sample was defined as the ratio (in $\%)$ between the number of colonies grown on the agar plates \pm antibiotics. If the ratio was $\geq 50 \%$ or $<50 \%$ the degree of resistance was defined as high or low. The prevalence and the degree of resistance were calculated over time for all the samples tested ( $n=682$ and $n=690$ ) for Weert and Roermond, respectively, and for each individual participant ( $n=91$ and $n=96$ for Weert and Roermond, respectively).

For each week, the prevalence and the degree of resistance to each antibiotic were calculated on the basis of all the samples with a positive growth on the agar plate without antibiotics. The mean values for the entire 15 week period were also calculated. In 
addition, for each individual the mean values for the entire 15 week period were calculated.

\section{Statistics}

The error in the method by making serial ten-fold dilutions and by using a spiral plater was $0.5^{10} \log$ (i.e. $\pm 5 \times 10^{x}$ ). If the number of colonies found on the agar plates without antibiotics from the faecal samples of one particular individual was not significantly different from the mean value, the corresponding number of colonies on the agar plates with antibiotics was included in the analysis of prevalence and degree of resistance.

The F-test, Students $t$-test and chi-square test were used to analyse statistical differences $(P<0.05$, two-tailed) between the results for the cities of Weert and Roermond. Students $t$-test was also used to predict the number of individuals with a high degree of resistance to any of the antibiotics used.

The intra-(or within) individual variation was determined by analysis of variance. Variation of the prevalence and the degree of resistance within one person was due to measurement error as well as biological variation.

\section{RESULTS}

Prevalence of antibiotic resistant Enterobacteriaceae in faecal samples

The total number of faecal samples analysed was 943 and 956 for Weert and Roermond, respectively. After incubation at $37^{\circ} \mathrm{C}$ for $18-24$ hours no growth was visible on the agar plates without antibiotics in 249 and 255 samples from Weert and Roermond, respectively. Only those samples with a colony count on the agar plates without antibiotics, 682 and 690 samples for Weert and Roermond, respectively, were analysed. All further calculations were based upon those samples.

The mean total number, i.e. ${ }^{10} \log (\mathrm{CFU})$, of Enterobacteriaceae in the samples tested was for Weert $6.02 \pm 1.25$ per gram faeces with a range between 3.43 and 8.43 . For Roermond $6.30 \pm 1.00$ was found, with a range between 3.43 and 8.43 .

Of the randomly picked colonies 93\% (3007/3226) were considered to be Escherichia coli. No resistant Enterobacteriaceae were isolated from 10/91 and 9/96 
individuals, for Weert and Roermond, respectively.

The mean prevalence of antibiotic-resistant Enterobacteriaceae varied in the samples from Weert $(n=682)$ from $28 \%$ for ampicillin and sulphamethoxazole to $0.1 \%$ for ciprofloxacin (Figure 1, only one colony of Klebsiella spp. was found on the agar plate containing ciprofloxacin). For the samples from Roermond $(n=690)$ the percentages varied from $41 \%$ for sulphamethoxazole to $0 \%$ for ciprofloxacin (Figure 1). The mean prevalence of resistance to oxytetracycline and sulphamethoxazole in Roermond was significantly higher than in Weert $(P<0.05$, two-tailed).

Figure 1. Frequency of low degree of resistance for Weert $(\square, n=682)$ and Roermond $(\square, n=690)$ and frequency of high degree of resistance for Weert $(\square, n=682)$ and Roermond $(\mathbb{\nabla}, \mathrm{n}=690)$.

Amp=ampicillin; cip=ciprofloxacin; nal=nalidixic acid; neo=neomycin; nit=nitrofurantoin; oxy =oxytetracycline; sul=sulphamethoxazole; tmp=trimethoprim.

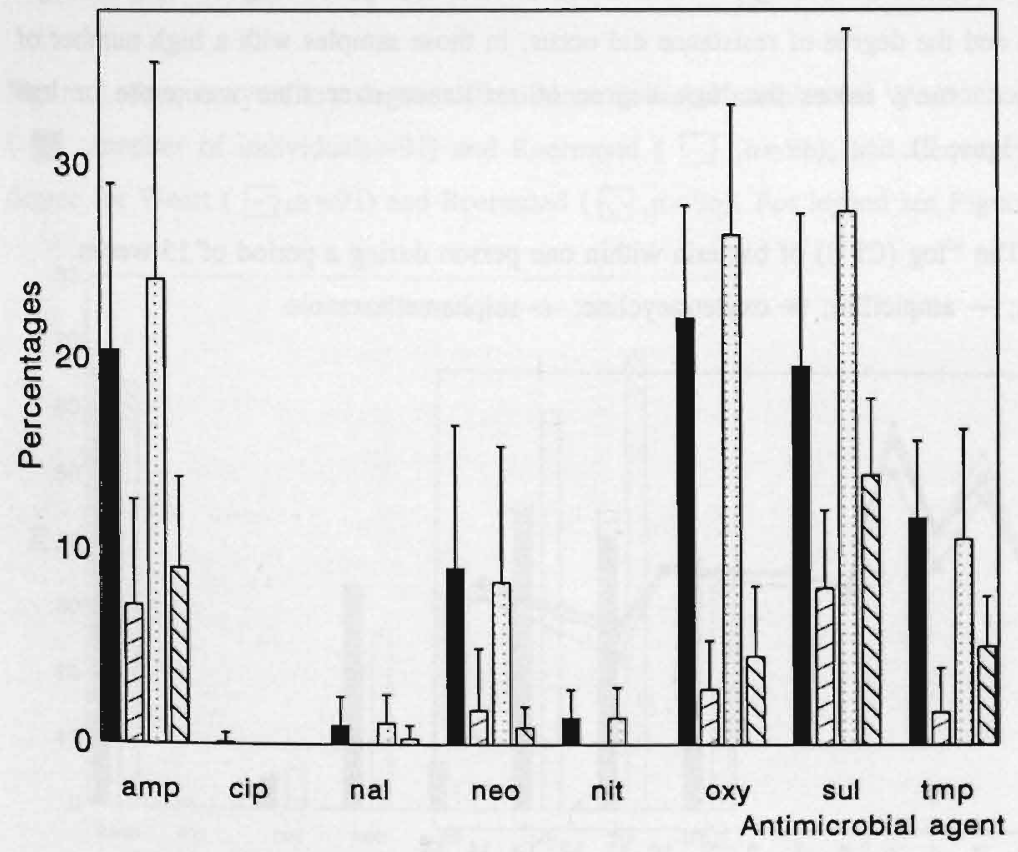


The mean percentages of the faecal samples with a relatively low degree of resistant Enterobacteriaceae varied in Weert from $22 \%$ for oxytetracycline to $0.1 \%$ for ciprofloxacin; in Roermond from $27 \%$ for sulphamethoxazole to $0 \%$ for ciprofloxacin (Figure 1). The mean percentages of a high degree of resistance varied in Weert from $8 \%$ for sulphamethoxazole to $0 \%$ for ciprofloxacin, nalidixic acid and nitrofurantoin, in Roermond from $14 \%$ for sulphamethoxazole to $0 \%$ for ciprofloxacin and nitrofurantoin (Figure 1).

Significant differences in the degree of resistance between Weert and Roermond were observed for trimethoprim (i.e. high degree) and for sulphamethoxazole (i.e. high as well as low degree) $(\mathrm{P}<0.05$, two-tailed).

During the 15-week period the individual variation in the number of Enterobacteriaceae present in the faecal samples was $\pm 1.25{ }^{10} \mathrm{log}$ and $\pm 1.36{ }^{10} \mathrm{log}$ for Weert and Roermond, respectively. Testing 15 samples from one subject consecutively, the total variation in the results observed is considered to be due to the measurement error variation (S.D.) and the biological variation (S.D. individual). Although variations in the prevalence and the degree of resistance did occur, in those samples with a high number of Enterobacteriaceae/g faeces the high degree of resistance over time was more or less constant (Figure 2).

Figure 2. The ${ }^{10} \log$ (CFU) of bacteria within one person during a period of 15 weeks.

$\rightarrow$ Blank; + ampicillin; * oxytetracycline; - - sulphamethoxazole.

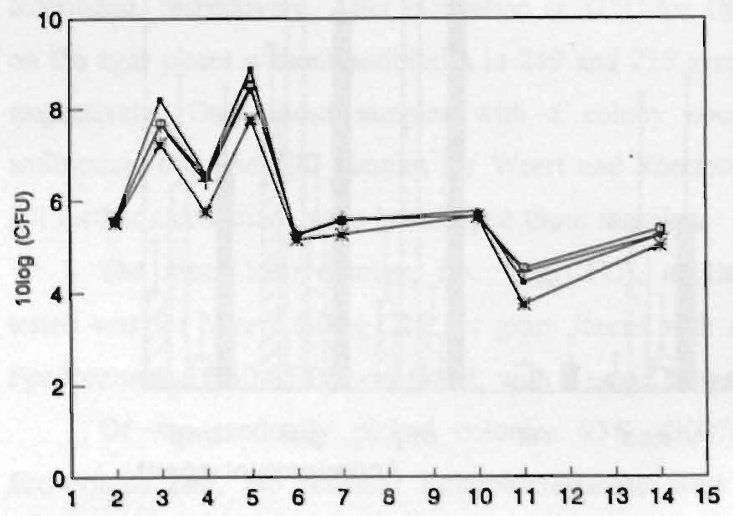


Ampicillin resistance was found in $69 / 91$ individuals from Weert, resistance to sulphamethoxazole was observed in $69 / 96$ individuals from Roermond (Figure 3). The prevalence of resistance for sulphamethoxazole in Roermond was significantly higher than in Weert $(\mathrm{P}<0.05$, two-tailed). The number of individuals with a relatively low proportion of resistant Enterobacteriaceae in the faecal samples, varied in Weert from 66 for ampicillin to one for ciprofloxacin (Figure 3). For Roermond the numbers varied from 69 for sulphamethoxazole to none for ciprofloxacin (Figure 3). A high degree of resistance to ampicillin was observed in three and seven individuals from Weert and Roermond, respectively. To ciprofloxacin, nalidixic acid and nitrofurantoin no high degrees of resistance were found for either population (Figure 3).

In Roermond the low degree of resistance to sulphamethoxazole was significantly different to that in Weert $(P<0.05$, two-tailed). The percentages of a high degree of resistance to either ampicillin, oxytetracycline, sulphamethoxazole or trimethoprim in the populations studied, can be predicted to be $29 \%$ and $35 \%$ for Weert and Roermond, respectively $(\mathrm{P}<0.05$, two-tailed).

Figure 3. Frequency of low degree of resistance in faecal samples for Weert ( $\square$,number of individuals $=91$ ) and Roermond ( $\square, n=96$ ); and frequency of high degree for Weert $(\square, n=91)$ and Roermond $(\nabla, n=96)$. For legend see Figure 1 .

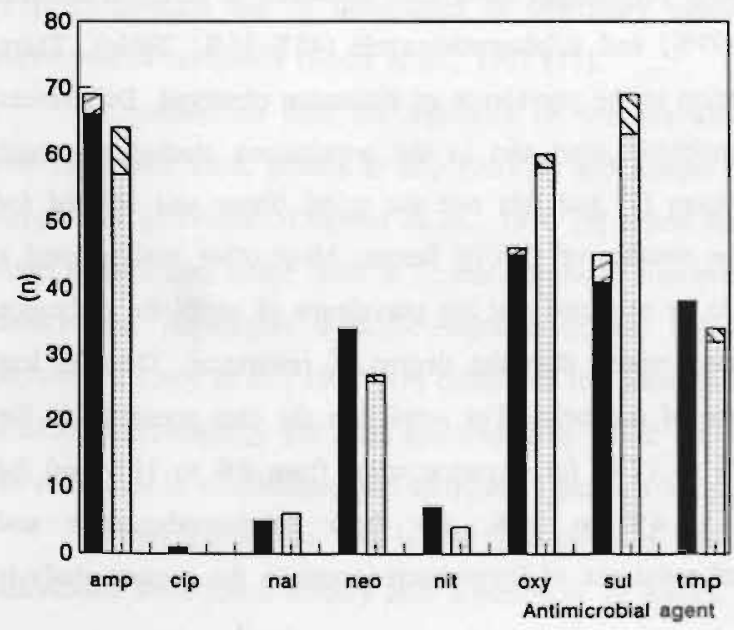




\section{DISCUSSION}

This study shows a relatively high prevalence of resistance of Enterobacteriaceae to ampicillin, oxytetracycline and sulphamethoxazole in healthy individuals from two relatively small cities in the south of the Netherlands. The prevalence of antibiotic resistance was more or less constant during the 15-week study period.

It was quite remarkable that $28 \%$ of the samples, both for Roermond and Weert, yielded no growth of Enterobacteriaceae on the agar plates without antibiotics. It is not very likely that this finding was due to the method used: as soon as the samples were delivered to the laboratory a 1:10 dilution was made in glycerol $(20 \%(w / v))$ and kept at $-20^{\circ} \mathrm{C}$ until analysis, which was performed with a spiral plater. The lowest detection limit using this apparatus was $10^{3} \mathrm{CFU} / \mathrm{g}$ faeces, thus no growth means that the sample contained less than $10^{3} \mathrm{CFU} / \mathrm{g}$ faeces. Moreover, no growth inhibitory factors could be demonstrated in the 50 randomly selected faecal samples yielding no growth. It is also unlikely that freezing the 1:10 dilution of specimens affected growth as for positive samples no appreciable difference between fresh and frozen samples was found. Although it is still not clear why $28 \%$ of the samples analysed contained less than $10^{3} \mathrm{CFU} / \mathrm{g}$ faeces it can be assumed that samples yielding no growth are a random part of the total number of samples collected. All data were calculated on the basis of those samples that yielded Enterobacteriaceae, thereby precluding any implications that samples yielding no growth could have on the results.

A wide range of prevalence percentages have been described in different studies, especially for ampicillin (25\%-99\%) and sulphamethoxazole (45\%-86\%; Table). There are several reasons for the variation in the prevalence of resistance observed. Differences in selective concentration of antibiotic used and in the populations studied are most important. In the studies of Bonten [7] and this one the spiral plater was utilized for quantitative determination of the number of CFU/g faeces. Most other studies used a semi-quantitative method. It is to be expected that the prevalence of antibiotic resistance is influenced by the method used more than the degree of resistance. There is less variation between the high degree of resistance. For ampicillin the data presented in the different studies varied from $5 \%$ to $17 \%$, for oxytetracycline from $6 \%$ to $19 \%$ and for sulphamethoxazole from $8 \% \pm 4 \%$ to $37 \%$. For both sulphamethoxazole and oxytetracycline the prevalence of resistance of Enterobacteriaceae in the present study is 
much lower than that found by Bonten et al.,1990 [7] and Degener et al., 1990 [9].

The tendency to a decrease in prevalence and in a high degree of resistance to sulphamethoxazole may be due to the decrease in the use of this agent since 1980 . Very little sulphamethoxazole was prescribed by the general practitioners in Weert and Roermond in 1991 (personal communication). Trimethoprim was prescribed twice as frequently in Weert compared to Roermond, and sulphamethoxazole-trimethoprim ten times more frequently. However, in Roermond norfloxacin was prescribed eight times as often compared to Weert. It is very likely that the general practitioners in Roermond prescribed norfloxacin instead of trimethoprim due to the high degree of resistance to sulphamethoxazole and trimethoprim. For tetracycline the explanation for the percentages found is less self-evident. The population tested in this study lives in an area with many stock-farms, while the populations tested by other authors were mainly city-dwellers. In veterinary medicine large amounts of tetracycline are used for therapy and prophylaxis as well as for growth promotion, therefore a higher prevalence may be expected in this study compared to others (Table). However, our values are of the same order of magnitude as those found by Levy et al., 1988 [18] and Degener et al., 1990 [9].

In this study no ciprofloxacin-resistant Escherichia coli were found. At present most Enterobacteriaceae are highly susceptible to the fluoroquinolones although the use of enrofloxacin in poultry has caused resistance in Campylobacter spp. (Endtz et al., 1991 [11]. Large-scale use of quinolones in veterinary medicine may further increase the prevalence of resistance (Endtz et al., 1991 [11].

At present no data are available on the prevalence of resistance in the same individual over time. Bonten et al., 1990 [7] and Amyes $e t$ al., 1992 [3] tested only one sample per individual. Degener et al., 1990 [9] tested the same population (but not the same individuals) twice with a 5 year interval. However, the study does not present census and population dynamic information on individuals of the original study population. Levy et al., 1988 [18] compared the prevalence of antibiotic resistance in the aerobic Gram-negative gut flora cultured from faecal samples from medical students with the resistance in hospitalized and ambulatory patients ten years earlier.

To our knowledge this is the first study in which faecal samples of the same individuals were tested weekly over a period of 15 weeks. The data clearly showed that a 
high degree of resistance in the individuals remained more or less constant over time (Figure 2). For the low degree of resistance more variation was observed (data not shown). Consequently testing only once is, as expected, less accurate. The most important cause of the variations observed in the prevalence and the degree of resistance was biological variation, rather than measurement error variation. In other studies, based upon one sample per individual, one does not take into account the biological variation. In those studies the variation in the data mentioned is also at least $\pm 1.25{ }^{10} \mathrm{log}$.

Testing over a period of time gives the possibility to predict the prevalence of resistance in the near future. This calculated future prevalence for ampicillin, oxytetracycline, sulphamethoxazole and trimethoprim in the population studied is $26 \%$ and $29 \%$ for Weert and Roermond, respectively. Whether these values correspond with the actual prevalence warrants surveillance of resistance of the faecal flora of healthy individuals. This surveillance of resistance will provide general practitioners with essential data for their choice of empirical therapy [22]. The Infectious Disease Society of America stressed the importance that hospital formularies are based on antibiotic susceptibility patterns of the own hospital isolates. General practitioners also have to base their empirical therapy on susceptibility data of outpatient isolates. Taking into account that the bowel flora are considered to be an important reservoir for antibiotic resistance genes [12], especially outside hospitals, knowledge about the antibiotic resistance of these isolates from healthy individuals will contribute to an educated guess of the empirical therapy. 
Table. Comparison of data from different studies.

Ampicillin :
(1)
(2)
(3)
(4)
(5)
(6)

$\begin{array}{llllll}1978-80 & 1987 & 1988 & 1990 & 1992 & 1992\end{array}$

$\begin{array}{llllllll}\text { (mg/L) } & 40 & 40 & 30 & 25 & 10 & 25 & 25 \\ \text { prevalence (\%) } & 25 & 27 & 35 & 76 & 99 & 28 \pm 12 & 33 \pm 12 \\ \text { high degree (\%) } & 5 & 11 & 17 & 8 & - & 7 \pm 5 & 9 \pm 5\end{array}$

Oxytetracycline :
(1)
(2) (3)
(4)
(5)
$(6)^{2}$

1978-80 $1987 \quad 1988 \quad 1990 \quad 1992 \quad 1992$

( $\mathrm{mg} / \mathrm{L})$

30

$\begin{array}{lllll}30 & 10 & 25 & - & 25\end{array}$

R

prevalence (\%)

42

$20 \quad 30$

$47 \quad-\quad 25 \pm 7$

25

high degree (\%)

12

$6 \quad 19$

$11-3 \pm 3$

$31 \pm 7$

Sulphamethoxazole :
(1)
(2)
(3)
(4)
(5)
(6)

1978-80 $1987 \quad 1988 \quad 1990 \quad 1992 \quad 1992$

( $\mathrm{mg} / \mathrm{L}$ )

prevalence (\%)

100

W R

high degree (\%)

45

$100-100-100$

100

' (1) Degener et al '78-'80;

(2) Degener et al '87;

$86 \quad-\quad 28 \pm 10 \quad 41 \pm 7$

'90; (5) Amyes et al '92; (6) present study.

${ }^{b} \mathrm{~W}=$ Weert and $\mathrm{R}=$ Roermond. 


\section{ACKNOWLEDGEMENTS}

This investigation is supported by the Prevention Foundation, grant number 28.0275. We would like to thank M.Norder, J.Philips, J.Kellens, N.Kiesser for their helpful assistance and P.Terporten for his statistical assistance.

\section{REFERENCES}

1. Adler-Mosca H, Altwegg M. Fluoroquinolone resistance in Campylobacter jejuni and Campylobacter coli isolated from buman faeces in Switzerland. J Infect, Letters to the editor, 1991; 23: 341-342.

2. Ahart JG, Burton GC, Blenden DC. The influence of antimicrobial agents on the percentage of tetracyclineresistant bacteria in faeces of humans and animals. J Appl Bacteriol 1978; 44: 183-190.

3. Amyes SGB, Gemmell CG. Antibiotic resistance in bacteria. J Med Microbiol 1992; 36: 4-29.

4. Amyes SGB, Tait S, Thomson CJ, Payne DJ, Nandivada LS, Jesudason MV ef al. The incidence of antibiotic resistance in aerobic faecal flora in South India. J Antimicrob Chemother 1992; 29: 415-425.

5. Anderson ES. The ecology of transferable drug resistance in the Enterobacteriaceae. Ann Rev Microbiol 1968; 22: 131-180.

6. Anderson JD. Factors that may prevent transfer of antibiotic resistance between gram-negative bacteria in the gut. J Med Microbiol 1975; 8: 83-88.

7. Bonten M, Stobberingh E, Philips J, Houben A. High prevalence of antibiotic resistant Escherichia coll in faecal samples of students in the south-east of the Netherlands. J Antimicrob Chernother 1990; 26: 585-592.

8. Burt SJ, Woods DR. Evolution of transferable antibiotic resistance in coliform bacteria from remote environments. Antimicrob Agents Chemother 1976; 10: 567-568.

9. Degener JE, Hooft van MS, Stiphout WAHJ, Luchmun R. Veranderende gevoeligheid van Escherichia coli voor antibiotica in de bevolking. Ned Tijdschr Geneeskd 1990; 134: 2296-2299.

10. DuPont HL, Steele JH. Use of antimicrobial agents in animal feeds: implications for human health. Rev Infect Dis 1987; 9: 447-460.

11. Endtz HPh, Ruijs GJ, Klingeren van B, Jansen WH, Reyden van de T, Mouton RP. Quinolone resistance in Campylobacter isolated from man and poultry following the introduction of fluoroquinoloaes in veterinary medicine. J Antimicrob Chemother 1991; 27: 199-208.

12. Hawkey PM. Resistant bacteria in the normal human flora. J Antimicrob Chemother 1986; 18, Suppl.C: 133-139.

13. Holmberg SD, Osterholm MT, Senger KA, Cohen ML. Drug-resistant Salmonella from animals fed antimicrobials. N Eng! J Med 1984; 311: 617-622.

14. Kunin CM, Johanses KS, Worning AM, Daschner FD. Report of a symposium on use and abuse of antibiotics worldwide. Rev Infeet Dis 1990; 12: 12-19.

15. Levy SB. Microbial resistance to antibiotics. An evolving and persistent problem. Lancet 1982; ii: 83-88.

16. Levy SB. Playing antibiotic pool: time to tally the score. N Engl J Med 1984; 311: 663-665. 
17. Levy SB. Antibiotic availability and use: cosequences to man and his environment. J Clin Epidemiol 1991; 44, Suppl. II : 83 S-87S.

18. Levy SB, Marshall B, Schluederberg S, Rowse D, Davis J. High frequency of antimicrobial resistance is human fecal flora. Antimicrob Agents Chemother 1988; 32: 1801-1806.

19. Linton AH. Flow of resistance genes in the environment and from animals to man. J Aatimicrob Chemother 1986; 18, Suppl. C : 189-197.

20. Murray BE. New aspects of antimicrobial resistance and the resulting therapeutic dilemmas. J Infect Dis 1991; 163: 1185-1194.

21. Murray B, Alvarado T, Kim K-H, Vorachit M, Jayanetra P, Levine MM et al. Inereasing resistance to trimethoprim-sulphamethoxazole among isolates of Escherichia coli in developing countries. J Infect Dis 1985; 152: 1107-1113.

22. O'Brien TF. Global surveillance of antibiotic resistance. N Engl J Med 1992; 326: 339-340.

23. Pont D, Fusté MC. Comparison of elinical and environmental strains of Escherichia coli isolated in Spain. J Infect 1991; 23: 271-278.

24. Richmond MH, Linton KB. The use of tetracycline in the community and its possible relation to the excretion of tetracycline-resistant bacteria. J Antimicrob Chemother 1980; 6: 33-41.

25. Singb M, Chaudhry MA, Yadava JNS, Sanyal SC. The spectrum of antibiotic resistance in buman and veterinary isolates of Escherichia coli collected from 1984-86 in Northern India. J Antimicrob Chemother 1992; 29: 159-168.

26. Walton, JR. Antibiotic resistance: an overview. Vet Rec 1988; 122: 249-251.

27. Wray C. Some aspects of the occurrence of resistant bacteria in the normal animal flora. I Antimicrob Chemother 1986; 18, Suppl.C: 141-147. 


\section{CHAPTER IV}

CARRIAGE OF ANTIBIOTIC-RESISTANT ESCHERICHIA COLI BY HEALTHY VOLUNTEERS DURING A 15-WEEK PERIOD.

N. London, R. Nijsten, A. van den Bogaard, E. Stobberingh Infection 1994; 22: 187-192 



\section{SUMMARY}

Escherichia coli strains $(n=678$ and $n=670)$ isolated from faecal samples from 90 and 93 healthy volunteers of two cities, Weert and Roermond respectively, were analysed for their susceptibility to 12 antimicrobial agents, during a 15-week period. Significant differences between both cities in the distribution of the MIC values were observed for apramycin, chloramphenicol, kanamycin, neomycin, nitrofurantoin, sulphamethoxazole and trimethoprim. For Weert $(n=678)$ the antibiotic resistance percentages varied from $0.4 \%$ for nalidixic acid to $26.7 \%$ for sulphamethoxazole. For Roermond $(n=670)$ the figures varied from $0.6 \%$ for nitrofurantoin to $37.5 \%$ for sulphamethoxazole. Resistance to amoxycillin/clavulanate was not found in either city.

The most frequent pattern was resistance to sulphamethoxazole only, followed by resistance to oxytetracycline, streptomycin and sulphamethoxazole.

In each individual there was only a small variation in resistance pattems of the isolates, i.e. the majority had one $(n=51)$ or two $(n=63)$ patterns with a maximum of five during the 15-week period. A fully susceptible pattern was found in the strains from 38 individuals.

\section{INTRODUCTION}

Bacterial resistance to antimicrobial agents is a problem of worldwide concem $[18,23,27]$. Also to recently introduced antibiotics, such as the newer fluoroquinolones $[14,35]$ and the third generation cephalosporins $[11,16,28]$ bacterial resistance does occur. In contrast to the extensive data available on antibiotic susceptibilities of hospital isolates $[6,7,9,24,25,30]$ less information is available on the incidence of antibiotic-resistant strains in general practice $[2,10,34]$ or in healthy volunteers $[1,21]$. Knowledge on the antibiotic resistance of strains colonising healthy people is important for several reasons. First, antibiotic-resistant strains are considered to be the largest reservoir of resistance genes [13]. Second, the mechanism of resistance in these isolates may be different from that in hospital strains and subsequently the therapy for them may be different as well [8]. Finally the correlation between antibiotic resistance of colonising strains and the resistance of infecting microorganisms as clearly demonstrated by Lester et al. [19] stressed the 
importance of ongoing antibiotic surveillance of colonising strains in healthy individuals to predict resistance in future infecting isolates and to support the antibiotic choices of empiric therapy.

Therefore a 15-week surveillance period was started during which faecal samples from about 100 healthy volunteers in each of two cities in the same region were collected weekly. One of the aims was to determine the antibiotic resistance patterns of the faecal Escherichia coli from all samples and to analyse the variation in antibiotic resistance of the isolates from each individual over the 15-week period. Also the mechanism of resistance to one of the antibiotics, trimethoprim, was tested.

\section{MATERIALS AND METHODS}

\section{Sample population}

Faecal samples of healthy volunteers of two cities and their rural surroundings, Weert $(n=91)$ and Roermond $(n=96)$, were collected weekly from 25 March to 1 July 1991 as described previously [22].

\section{Sample processing}

Faecal dilutions (1:10 to $1: 10^{5}$ ) were applied onto Levine agar plates (Oxoid CM69, Ltd., Basingstoke, England) without antibiotics using a spiral plater (Lameris Laboratorium B.V., Breukelen, the Netherlands). Colonies with the colonial morphology of Escherichia coli were randomly picked out from each agar plate without antibiotics, one colony per faecal sample, and tested for indole reaction and growth at $42^{\circ} \mathrm{C}$. Only isolates yielding positive results for both tests were considered to be Escherichia coli. The identification of 50 randomly chosen Escherichia coli strains, identified as mentioned above, were confirmed using the API $20 \mathrm{E}$ system to be Escherichia coli.

\section{Susceptibility tests}

The antibiotic susceptibility was determined using a microbroth dilution method in Iso-Sensitest Broth (Oxoid CM473). An inoculum of $5 \times 10^{5} \mathrm{CFU} / \mathrm{ml}$ was used. The plates were incubated for $18-24$ hours at $37^{\circ} \mathrm{C}$, the MIC being defined as the lowest antibiotic concentration completely to inhibit growth. Escherichia coli ATCC 25922 and Escherichia 
coli ATCC 35218 were used as reference strains. The antimicrobial agents used are shown in Table 1. The breakpoints for resistance were those recommended by the guidelines of the Dutch Working Party on Antimicrobial Susceptibility Testing [17]. For apramycin the breakpoint of resistance was $>16 \mathrm{mg} / \mathrm{L}$ [15].

\section{Characterisation of trimethoprim resistant strains}

Plasmid DNA was isolated as described by Sambrook $e t$ al. [29] Two probes encoding trimethoprim resistance were used : one was a $0.49 \mathrm{~kb} \mathrm{Kpnl/BamHI}$ fragment of pLKO627 encoding the dhfrI gene and the other was a $0.49 \mathrm{~kb} H \mathrm{Hal}$ fragment of pLKO2$2 \mathrm{~A}$ encoding the $d h f r V$ gene $[32,33]$. The DNA probes were purified by extraction with diatoms earth from agarose gels and labeled with digoxigenin according to the manufacturer's instructions (Boehringer Mannheim Biochemica, Mannheim, Germany). The strains were screened by making colony blots on nylon membranes (Nytran) according to the manufacturer's instructions (Nytran, Schleicher \& Schuell, Den Bosch, the Netherlands). As positive controls the strains containing the plasmids pLK0627 and pLKO22A were used, as negative control Escherichia coli $\mathrm{K}-12$. The probes for type I and V hybridised only with their own positive control strains; no other cross-hybridizations were detected. Prehybridization and hybridization were performed under stringent conditions ( $50 \%(\mathrm{v} / \mathrm{v})$ formamide and $5 \mathrm{xSSC}$ [ $1 \mathrm{xSSC}$ is $0.15 \mathrm{M} \mathrm{NaCl}$ plus $0.015 \mathrm{M}$ sodium citrate] at $42^{\circ} \mathrm{C}$, and washes in $2 \times S S C$ plus $0.1 \%(w / v)$ SDS and $0.1 \times S S C$ plus $0.1 \%(w / v)$ SDS at $68^{\circ} \mathrm{C}$. The detection of digoxigenin-labelled nucleic acids was performed by chemoluminescence on radiographic films (Kodak X Omat AR).

\section{Statistics}

The F-test, chi-square test, Mann-Whitney test and hierarchical cluster analysis by average linkage (UPGMA) and Squared Euclidian distances (i.e. Distance $(X, Y)=\Sigma\left(X_{i_{-}}\right.$ $\left.Y_{j}{ }^{2}\right)$ were used to analyse whether there were significant differences $(P<0.05$, twotailed) between the cities Weert and Roermond. 


\section{RESULTS}

\section{Antibiotic resistance}

In faecal samples from one individual from Weert and three individuals from Roermond, Escherichia coli was not detected. Finally, a total of 678 and 670 Escherichia coli strains for Weert and Roermond respectively were analysed for their susceptibility to 12 antimicrobial agents. Significant differences in the distribution of the MIC values were observed for apramycin, chloramphenicol, kanamycin, neomycin, nitrofurantoin, sulphamethoxazole and trimethoprim $(P<0.05)$ (Table 1).

For further analysis all values were first classified by hierarchical cluster analysis. Consequently, slight differences between the frequencies found in Table 1 and Table 2 might occur. The frequency of resistance to the antimicrobial agents tested is shown in Table 2. The highest frequency of resistance was found for sulphamethoxazole, $26.7 \%$ and $37.5 \%$, followed by streptomycin (20.5\% and $26.9 \%)$ and oxytetracycline $(17.3 \%$ and $24.6 \%$ ). Resistance to amoxycillin/clavulanate (2:1) was not observed in the samples of either city. High MIC values, i.e. MIC $\geq 512 \mathrm{mg} / \mathrm{L}$, for apramycin were observed for three isolates of Roermond, which were isolated from one individual. All three were also resistant to gentamicin (MIC $\geq 8 \mathrm{mg} / \mathrm{L}$ ). High level resistance to nalidixic acid (MIC $\geq$ $128 \mathrm{mg} / \mathrm{L}$ ) was observed for three and ten isolates from Weert and Roermond respectively, isolated from three and six individuals. None of these strains were resistant to ciprofloxacin (MIC $\leq 1 \mathrm{mg} / \mathrm{L}$ ). 
Chapter IV

Table 1. Distribution of MIC values for isolates from Weert $(n=678)$ and Roermond $(n=670)$.

Agent City Number of strains inhibited by concentration $(\mu \mathrm{g} / \mathrm{ml})$

\begin{tabular}{|c|c|c|c|c|c|c|c|c|c|c|c|c|c|c|c|}
\hline & & 0.0 & .130 .2 & 0.5 & 12 & & 4 & 8 & 16 & 32 & 64 & 128 & 256 & 512 & 1024 \\
\hline & $w^{b}$ & & & 0 & 12 & 22 & 365 & 210 & 23 & 1 & 1 & 3 & 0 & 52 & \\
\hline & $\mathbf{R}^{\mathbf{b}}$ & & & 1 & 45 & & 404 & 158 & 13 & 1 & 0 & 0 & 3 & 81 & \\
\hline & w & & & 0 & 03 & 31 & 345 & 244 & 46 & 11 & 1 & 0 & 0 & $0^{\circ}$ & \\
\hline & $\mathbf{R}$ & & & 0 & 13 & 36 & 382 & 201 & 41 & 6 & 0 & 0 & 0 & 3 & \\
\hline \multirow[t]{2}{*}{$\mathrm{AM} / \mathrm{CL}$} & W & & & 0 & 11 & 14 & 296 & 283 & 84 & 0 & 0 & 0 & 0 & 0 & \\
\hline & $\mathbf{R}$ & & & 0 & 38 & 8 & 294 & 269 & 96 & 0 & 0 & 0 & 0 & 0 & \\
\hline & w & & & . & 09 & & 101 & 485 & 49 & 1 & 3 & $30^{\circ}$ & & & \\
\hline & $\mathbf{R}$ & & & r & 16 & 6 & 170 & 404 & 27 & 2 & 1 & 59 & & & \\
\hline & w & & & & & 212 & 385 & 42 & 15 & 1 & 8 & 3 & $12^{\circ}$ & & \\
\hline & $\mathbf{R}$ & & & & & 253 & 338 & 44 & 10 & 2 & 6 & 1 & 16 & & \\
\hline & W & & & & 71 & 109 & 501 & 58 & 0 & 0 & 0 & 3 & & & \\
\hline & $\mathbf{R}$ & & & & 31 & 137 & 477 & 42 & 1 & 0 & 2 & 8 & & & \\
\hline & W & & & 3 & 3272 & 282 & 36 & 13 & 2 & 8 & 5 & $5^{\circ}$ & & & \\
\hline & $\mathbf{R}$ & & & 3 & 3742 & 216 & 49 & 8 & 4 & 1 & 12 & 6 & & & \\
\hline & w & & & & 45 & 5 & 27 & 390 & 221 & 25 & 4 & $2^{\circ}$ & & & \\
\hline & $\mathbf{R}$ & & & & 61 & 1 & 50 & 438 & 151 & 19 & 4 & 1 & & & \\
\hline & W & & & & 8 & 8 & 142 & 392 & 19 & 1 & 1 & 3 & 112 & & \\
\hline & $\mathbf{R}$ & & & & & 10 & 176 & 310 & 9 & 2 & 2 & 10 & 151 & & \\
\hline & W & & & & 03 & 36 & 365 & 122 & 17 & 21 & 35 & 82 & & & \\
\hline & $\mathbf{R}$ & & & & 12 & 29 & 342 & 94 & 21 & 48 & 41 & 94 & & & \\
\hline & W & & & & & & 0 & 248 & 162 & 41 & 28 & 19 & 25 & 37 & $118^{\circ}$ \\
\hline & $\mathbf{R}$ & & & & & & 1 & 209 & 110 & 49 & 28 & 17 & 6 & 18 & 232 \\
\hline & W & 2 & $\begin{array}{ll}58 & 247\end{array}$ & 285 & 34 & 1 & 1 & 0 & 21 & 0 & 1 & 1 & 0 & 27 & $0^{\circ}$ \\
\hline & $\mathbf{R}$ & 18 & $112 \quad 238$ & 200 & 32 & 6 & 4 & 0 & 6 & 0 & 0 & 0 & 1 & 51 & 2 \\
\hline
\end{tabular}

- $\mathrm{AM}=$ amoxycillin; $\mathrm{AP}=$ apramycin; $\mathrm{CH}=$ chloramphenicol; $\mathrm{CL}=$ clavulanate; $\mathrm{KA}=$ kanamycin; $\mathrm{NA}=$ nalidixic acid; $\mathrm{NE}=$ neomycin; $\mathrm{NI}=$ nitrofurantoin; $\mathrm{OX}=$ oxytetracycline; $\mathrm{ST}=$ streptomycin; $\mathrm{SU}=$ sulphamethoxazole; $\mathrm{TR}=$ trimethoprim.

${ }^{b} \mathrm{~W}=$ Weert and $\mathrm{R}=$ Roermond $\quad \cdot \mathrm{P}<0.05$ 
Table 2. Antibiotic resistance of isolated Escherichia coli from Weert $(n=678)$ and Roermond $(n=670)$ to 12 antimicrobial agents.

\begin{tabular}{lllll}
\hline Antimicrobial agent & \multicolumn{3}{l}{\begin{tabular}{l}
\multicolumn{3}{l}{ Number (percentage) of resistant isolates for } \\
Roermond
\end{tabular}} \\
\hline AM & 57 & $(8.4)$ & 83 & $(12.4)^{\circ}$ \\
AP & 15 & $(2.2)$ & 8 & $(1.2)$ \\
AM/CL & 0 & & 0 & \\
CH & 59 & $(8.7)$ & 68 & $(10.1)$ \\
KA & 24 & $(3.5)$ & 26 & $(3.9)$ \\
NA & 3 & $(0.4)$ & 10 & $(1.5)$ \\
NE & 18 & $(2.7)$ & 19 & $(2.8)$ \\
NI & 5 & $(0.7)$ & 4 & $(0.6)$ \\
OX & 117 & $(17.3)$ & 165 & $(24.6)^{\circ}$ \\
ST & 139 & $(20.5)$ & 180 & $(26.9)^{\circ}$ \\
SU & 181 & $(26.7)$ & 251 & $(37.5)^{\circ}$ \\
TR & 51 & $(7.5)$ & 65 & $(9.7)^{\circ}$ \\
\hline
\end{tabular}

"For abbreviations, see Table 1

$\cdot \mathrm{P}<0.05$, two-tailed

\section{Antibiotic resistance patterns of Escherichia coli}

Multiple resistance, i.e. resistance to two or more antibiotics, was found in $202 / 670$ strains from Roermond and 150/678 from Weert $(P<0.05$, two-tailed).

The resistance pattern most frequently observed for Weert and Roermond was resistance to sulphamethoxazole only, $n=80$ and $n=89$, respectively (Table 3 ). With a distinctly lower frequency resistance to oxytetracycline, streptomycin and sulphamethoxazole was observed in both groups ( $n=22$ and $n=25$ ), followed by streptomycin alone in Weert $(n=20)$ and oxytetracycline and streptomycin in Roermond $(n=25)$. Susceptibility to all agents tested was found for $395(58.3 \%)$ and 330 (49.3\%) isolates from Weert and Roermond, respectively (Table 3).

The majority (i.e. $568 / 678$ and $551 / 670$ ) of the faecal isolates of both cities had a resistance pattern belonging to one of the patterns shown in Table 3. In addition 23 patterns, i.e. only $42 / 678$ strains were unique for Weert and 35 patterns, only $66 / 670$ strains 
for Roermond, giving rise to 51 and 63 different patterns for Weert and Roermond, respectively. Testing faecal samples from each individual consecutively during a 15-week period, individual variation in resistance patterns could be analysed. One to seven different patterns in each individual were observed.

Table 3. The ten most frequent patterns of resistance for Escherichia coli isolates from Weert $(n=678)$ and Roermond $(n=670)$.

\begin{tabular}{|c|c|c|c|}
\hline \multicolumn{2}{|l|}{ Weert } & \multicolumn{2}{|l|}{ Roermond } \\
\hline & (n) & Pattem & (n) \\
\hline$--^{b}$ & 395 & - & 330 \\
\hline SU & 80 & SU & 89 \\
\hline OX-ST-SU & 22 & OX-ST-SU & 25 \\
\hline ST & 20 & OX-ST & 25 \\
\hline $0 \mathrm{X}$ & 14 & ST & 16 \\
\hline AM-CH-OX-ST-SU-TR & 13 & OX-SU & 15 \\
\hline CH-OX-ST & 9 & AM-OX-ST-SU-TR & 13 \\
\hline AM-OX-ST-SU & 8 & ox & 10 \\
\hline $\mathrm{AM}$ & 7 & ST-SU & 10 \\
\hline AM-OX-ST-SU-TR & 6 & AM-CH-OX-ST-SU-TR & 9 \\
\hline CH-OX-ST-SU-TR & 6 & CH-OX-SU-TR & 9 \\
\hline 568 & 678 & 55 & 670 \\
\hline
\end{tabular}

\footnotetext{
- For abbreviations, see Table 1

$b_{--}=$no resistance.
} 
The majority of the isolates had one $(n=51)$ or two $(n=63)$ different resistance patterns (Table 4).

Table 4. The number of resistance pattems present in each individual from Weert $(n=90)$ and Roermond $(n=93)$.

\begin{tabular}{lll}
\hline Number of patterns & \multicolumn{2}{l}{ Number of individuals } \\
& Weert & Roermond \\
\hline 1 & 27 & 24 \\
2 & 27 & 36 \\
3 & 17 & 20 \\
4 & 14 & 4 \\
5 & 4 & 6 \\
6 & 0 & 3 \\
7 & 1 & 0 \\
\hline
\end{tabular}

Because there were no significant differences in the number of pattems in the individuals of both cities, for further analysis all individuals were grouped together.

The number of patterns in relation to the number of strains tested per individual is given in Table 5. Because one strain from each sample was picked out, the number of strains corresponded to the number of samples tested. The number of samples (i.e. strains) analysed per individual ranged from one to 13 , whereas the number of different patterns observed in most individuals during the study period was not more than five. Only four individuals showed during 8,10 and 11 weeks, six and seven different patterns. A fully susceptible pattern during the 15-week period was found in $38 / 51$ individuals. Thus the isolates from these individuals had only one pattem (i.e. susceptible to all agents) during the whole period.

\section{Trimethoprim resistance}

Resistance to trimethoprim was observed in 116 isolates, from which 81 were resistant to high levels of trimethoprim (MIC $\geq 512 \mathrm{mg} / \mathrm{L}$ ). These strains were isolated from 29 individuals. After screening for the presence of the most frequently occuring dihydrofolate reductase genes, i.e. $d h f r I$ and $d h f r V$, all individuals except one were posi- 
tive for $d h f r l$, while $9 / 29$ individuals were positive for $d h f r V$.

Table 5. The number of patterns in relation to the number of strains tested per individual. Number of samples Number of individuals Number of pattems

\begin{tabular}{|c|c|c|c|c|c|c|c|c|}
\hline & & 1 & 2 & 3 & 4 & 5 & 6 & 7 \\
\hline 1 & 10 & 10 & & & & & & \\
\hline 2 & 11 & 4 & 7 & & & & & \\
\hline 3 & 14 & 7 & 5 & 2 & & & & \\
\hline 4 & 9 & 2 & 3 & 3 & 1 & & & . \\
\hline 5 & 14 & 3 & 5 & 3 & 3 & & & \\
\hline 6 & 11 & 5 & 3 & 2 & & 1 & & \\
\hline 7 & 12 & 4 & 4 & 1 & 2 & 1 & & \\
\hline 8 & 22 & 3 & 11 & 4 & 3 & 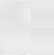 & 1 & \\
\hline 9 & 26 & 6 & 9 & 6 & 3 & 2 & & \\
\hline 10 & 17 & 2 & 7 & 4 & 2 & 1 & 1 & \\
\hline 11 & 16 & 2 & 5 & 3 & 1 & 3 & 1 & 1 \\
\hline 12 & 11 & 1 & 2 & 5 & 2 & 1 & . & \\
\hline \multirow[t]{2}{*}{13} & 10 & 2 & 2 & 4 & 1 & 1 & & \\
\hline & & 51 & 63 & 37 & 18 & 10 & 3 & 1 \\
\hline
\end{tabular}

\section{DISCUSSION}

The main feature of the study was the high frequency of resistance to sulphamethoxazole, streptomycin and oxytetracycline of the Escherichia coli strains $(n=678$ and $\mathrm{n}=670$ ) isolated from faecal samples of 90 and 93 healthy volunteers from Weert and Roermond, respectively. Moreover the differences in resistance to these compounds as well as to amoxycillin were significant $(\mathrm{P}<0.05)$. In addition, our data during the $15-$ week period strongly suggest that the pool of antibiotic-resistant strains is relatively constant over time and is maintained in the faecal flora of healthy individuals who have not taken any antibiotics recently.

The ten most frequent resistance pattems in this and in other studies are shown in 
Table 6. Although some differences did occur the majority of the resistance patterns observed in the studies mentioned were quite similar despite the different populations studied. The population analysed by Linton et al. [21] and in this study consisted of healthy people; Mфller et al. [25] studied in- and outpatients and Levy et al. [20] analysed healthy people, laboratory workers and hospital patients. In the present study, resistance to chloramphenicol was always (except for two strains) correlated with resistance to other antimicrobial agents. The most frequent pattem was resistance to chloramphenicol, oxytetracycline, streptomycin and sulphamethoxazole. Often resistance to amoxycillin and trimethoprim was present as well. Chloramphenicol and tetracycline do select for the chromosomal Mar-system which confers also resistance to structurally unrelated agents, including nalidixic acid, fluoroquinolones, rifampin, penicillins and cephalosporins. Isolates being resistant to oxytetracycline, chloramphenicol and nalidixic acid are more likely to select for this Mar-system and could therefore be a direct potential clinical problem in the hospital environment $[5,12]$.

Resistance to apramycin, an aminoglycoside used only in veterinary medicine, was observed in 23 Escherichia coll strains, three of which were resistant to high levels of apramycin (MIC $\geq 512 \mathrm{mg} / \mathrm{L}$ ). This high level apramycin-resistance confers also resistance to gentamicin, which is probably due to production of plasmid-mediated aminoglycoside acetyltransferase 3-IV (AAC(3)-IV). Notably, of the 187 individuals tested who did not have a history of recent hospital stay or antibiotic use, in one individual this type of resistance was present. It is to be expected that in the hospital environment a higher prevalence and spread of this plasmid will occur [3,4].

The presence of both $d h f r I$ and $d h f r V$ in one strain was also observed by Singh $e t$ al. [31]; of all colony isolates $21 \%$ hybridised under stringent conditions, and all of these were with type I $(17 \%)$ or type V $(4 \%)$; of the type $\mathrm{V}$ positive ones, two were also positive for type I. Resistance to trimethoprim was often correlated with resistance to amoxycillin, oxytetracycline, streptomycin, sulphamethoxazole and chloramphenicol.

In the present study, in the majority of the individuals only one or two different resistance patterns, with a maximum of five, could be observed, which were independent of the number of strains tested for that individual. In contrast, Levy et al. [20] found that $90 \%$ of all individuals showed a gain $(47.6 \%)$ and/or a loss $(65.7 \%)$ of one or more detectable resistances when analysing two samples obtained from individuals of the 
ambulatory group off antibiotics. No distinct explanation could be given for the differences in antibiotic resistance between the two populations studied. Because both cities have the same socio-economic level, and are only $30 \mathrm{~km}$ apart, it is not very likely that environmental circumstances could explain the differences observed. Only one person reported having taken antibiotics, i.e. tetracycline, during the study period so the influence of individual recent antibiotic use on the resistance percentage observed was negligible. Moreover differences in antibiotic prescriptions by the general practitioners during the year preceding the start of the surveillance could not explain the differences in resistance observed. Sulphamethoxazole is hardly used in either city. Amoxycillin has been prescribed slightly more in Weert compared to Roermond, whereas for the antibiotic resistance the reverse was found (8.4\% and $12.4 \%$ ), Quinolones (ciprofloxacin and norfloxacin) were eight times more frequently used in Roermond. In contrast, trimethoprim alone and in combination with sulphamethoxazole was used twice and eight times as much in Weert compared to Roermond. However the differences in antibiotic prescriptions were not reflected in the antibiotic resistance. Further studies to analyse factors influencing antibiotic resistance in healthy individuals remain to be performed.

Table 6. Comparison of the ten most frequent patterns of resistance for four different studies.

\begin{tabular}{lllll}
\hline Weert & Roermond & $(2)$ & $(3)$ & $(4)$ \\
\hline SU' & SU & OX & OX & OX-ST \\
OX-ST-SU & OX-ST-SU & AM & ST-SU & AM-OX-ST \\
ST & OX-ST & AM-OX & OX-ST-SU & AM-KA-OX-ST \\
OX & ST & OX-ST-SU & AM & AM-OX \\
AM-CH-OX-ST-SU-TR & OX-SU & ST-SU & AM-ST-SU & AM-ST \\
CH-OX-ST & AM-OX-ST-SU-TR & AM-ST-SU & ST & KA-OX-ST \\
AM-OX-ST-SU & OX & AM-OX-ST-SU & CH-ST-SU & AM-KA \\
AM & ST-SU & OX-ST & OX-ST & KA-ST \\
AM-OX-ST-SU-TR & AM-CH-OX-ST-SU-TR & ST & AM-CH-KA-OX-SU & AM-KA-ST \\
CH-OX-ST-SU-TR & CH-OX-SU-TR & CH-OX-ST-SU & OX-SU & KA-OX \\
\hline
\end{tabular}

" present study; (2) Linton et al. [21]; (3) Mфller et al. [25]; (4) Levy et al. [20]

bor abbreviations, see Table 1 


\section{ACKNOWLEDGEMENTS}

This investigation is supported by the Prevention Foundation, grant number 28.0275. We would like to thank M.Norder, J.Philips, C.Driessen for their helpful assistance; P.Terporten for his statistical assistance; J.Hunter for kindly providing apramycin and J.M $\phi$ ller for his computer programm [26].

\section{REFERENCES}

1. Bonten M, Stobberingh E, Philips J, Houben A. Antibiotic resistance of Escherichia coli in fecal samples of healthy people in two different areas in an industrialized country. Infection 1992; 20: 258-262.

2. Brumritt W, Reeves DS, Faiers MC, Datta N. Antibiotic-resistant Escherichia coli causing urinary-tract infection in general practice: relation to faecal flora. Lancet 1971; i: 315-317.

3. Chaslus-Dancla E, Glupczynski Y, Gerbaud G, Lagorce M, Lafont JP, Courvalin P. Detection of apramycin resistant Enterobacteriaceae in hospital isolates. FEMS Microbiol Lett 1989; 61: 261-266.

4. Chaslus-Dancla E, Pohl P, Meurisse M, Marin M, Lafont JP. High genetic homology between plasmids of human and animal origins conferring resistance to the aminoglycosides gentamicin and apramycin. Antimicrob Agents Chemother 1991; 35: 590-593.

5. Cohen SP, McMurry LM, Hooper DC, Wolfson JS, Levy SB. Cross-resistance to fluoroquinolones in multiple antibiotic-resistant (Mar) Escherichia coli selected by tetracycline or chloramphenicol: decreased dru\& accumulation associated with membrane changes in addition to OmpF reduction. Antimicrob Agents Chemother 1989; $33: 1318-1325$.

6. Cooksey R, Swenson J, Clark N, Gay E, Thornsberry C. Patterns and mechanisms of B-lactam resistance annong icolates of Escherichia coli from hospitals in the United States. Antimicrob Agents Chemother 1990; 34: 739-745.

7. Datta N, Dacey S, Hughes V, Knight S, Richards H, Williams G, Casewell M, Shannon K. Distribution of genes for trimethoprim and gentamicin resistance in bacteria and their plasmids in a general hospita. J Gen Microbiol 1980; 118: 495-508.

8. Degener JE, Michel MF, Valkenburg HA, Smit AC, Muller L, Thonus IP. Bacterial drug resistance in the community and in hospitals. Netb J Med 1985; 28: 182-191.

9. Fisher GM, Kelsey MC, Cooke EM. An investigation of the spread of gentamicin resistance in a district general hospital. J Med Microbiol 1986; 22: 69-77.

10. Gillespie WA, Lee PA, Linton KB. Antibiotic resistance of coliform bacilli in urinary infection acquired by women outside hospital. Lancet 1971; ii: 675-677.

11. Gutmann L, Kitzis D, Billot-Klein D, Goldstein F, Tran Van Nhieu G, Lu T, Carlet J, Collntz E, Williumson R. Plasmid-mediated B-Lactamase (TEM-7) involved in resistance to ceftazidime and aztreonam. Rev Infect Dis 1988; 10: $860-866$.

12. Hixchler H, Cohen SP, Levy SB. marA, a regulated locus which controls expression of chromosomal 
multiple antibiotic resistance in Escherichia coli. J Bacteriol 1991; 173: 5532-5538.

13. Hawkey PM. Resistant bacteria in the normal human flora. J Antimicrob Chemother 1986; 18, Suppl. C :133-139.

14. Hirai K, Aoyama H, Suzue S, Irikura T, Iyobe S, Mitsuhashi S. Isolation and characterization of norfloxacin-resistant mutants of Escherichia coll K-12. Antimicrob Agents Chemother 1986; 30: 248-253.

15. Hunter J, Shelley JC, Walton JR, Hart CA, Bennett M. Apramycin resistance plasmids in Escherichia coli: possible transfer to Salmonella typhimurium in calves. Epidemiol Infect 1992; 108: 271-278.

16. Jacoby GA, Archer GL. New mechanisms of bacterial resistance to antimicrobial agents. N Engl J Med 1991; 324: 601-612.

17. Klingeren van B, Mouton RP. Standaardisatie van gevoeligheidsbepalingen. Verslag van de werkgroep richtijnen gevoeligheidsbepalingen 1990. Rijksinstituut voor Volksgezondheid en Milieuhygiene, Bilthoven, the Netherlands.

18. Kunin CM, Johansen KS, Worning AM, Daschner FD. Report of a symposium on use and abuse of antibiotics worldwide. Rev Infect Dis 1990; 12: 12-19.

19. Lester SC, Pilar Pla del M, Wang F, Perez Schael I, Jiang H, O'Brien TF. The carriage of Escherichia coli resistant to antimicrobial agents by healthy children in Boston, in Caracas, Venezuela, and in Qin Pu, China. N Engl J Med 1990; 323: 285-289.

20. Levy SB, Marshall B, Schluederberg S, Rowse D, Davis J. High frequency of antimicrobial resistance in human fecal flora. Antimicrob Agents Chemother 1988; 32: 1801-1806.

21. Linton KB, Lee PA, Richmond MF, Gillespie WA. Antibiotic resistance and transmissible R-factors in the intestinal coliform flora of healthy adults and children in an urban and a rural community. J Hygiene 1972; 70: 99-104.

22. London N, Nijsten R, Bogaard van den A, Stobberingh E. Antibiotic resistance of faecal Enterobacteriaceae isolated from healthy volunteers, a 15-week follow-up study. J Antimicrob Chemother 1993; 32: 83-91.

23. Marr JJ, Moffet EL, Kunin CM. Guidelines for improving the use of antimicrobial agents in hospitals: a statement by the infectious diseases society of America. I Infect Dis 1988; 157: 869-876.

24. Mayer KH, Fing ME, Hopkins JD, O'Brien TF. Trimethoprim resistsnce in muttiple genera of Enterobacteriaceae at a U.S. hospital: spread of the type II dihydrofolate reductase gene by a single plasmid. J Infect Dis 1985; 151: 783-790.

25. Moller JK, Bak AL, BÜhow P, Christiansen C, Christiansen G, Stenderup A. Transferable and nontransferable drug resistance in enteric bacteria from hospital and from general practice. Scand I Infect Dis 1976; 8: 112-116.

26. Mфller JK. A microcomputer assisted analysis of drug resistance in bacteria. Comput Methods Programs Biomed 1986; 23: 217-223.

27. Murray BE. New aspects of antimicrobial resistance and the resulting therapeutic dilemmas. $J$ lnfect Dis 1991; 163: 1185-1194.

28. Neu HC. The emergence of bacterial resistance and its influence on empiric therapy. Rev Infect Dis 1983; 
5, Suppl.: S9-\$20.

29. Sambrook J, Fritsch EF, Maniatis T. Molecular cloning: a laboratory manual. 2 nd edition. Cold Spring Harbor Laboratory, Cold Spring Harbor, New York 1989.

30. Seetulsingh PS, Hall LMC, Livermore DM. Activity of clavulanate combinations against TEM-1 B-lactamase-producing Escherichia coli isolates obtained in 1982 and 1989. J Antimicrob Chemother 1991; 27: 749759.

31. Singh KV, Reves RR, Pickering LK, Murray BE. Identification by DNA sequence analysis of a new plasmid-encoded trimethoprim resistance gene in fecal Eschericlia coli isolates from children in day-care centers. Antimicrob Agents Chemother 1992; 36: 1720-1726.

32. Sundstrōm L, RÅström P, Swedberg G, Skőıı O. Site-specific recombination promotes linkage between trimethoprim- and sulfonamide resistance genes. Sequence characterization of dhfrV and sulI and a recombination active locus of Tn21. Mol Gen Genet 1988; 213: 191-201.

33. Sundström L, Skōld O. The dhfrl trimethoprim resistance gene of $T \square 7$ can be found at specific sites in other genetic surroundings. Antimicrob Agents Chemother 1990; 34: 642-650.

34. Towner KJ, Wise PJ. Transferable resistance plasmids as a contributory cause of increasing trimethoprim resistance in general practice. J Antimicrob Chemother 1983; 11: 33-39.

35. Yoshida $\mathbf{H}$, Bogaki M, Nakamura M, Nakamura S. Quinolone resistance-determining region in the DNA gyrase gyrA gene of Escherichia coli. Antimicrob Agents Chemother 1990; 34: 1271-1272. 


\section{CHAPTER V}

EFFECT OF ANTIBIOTIC THERAPY ON THE ANTLBIOTIC RESISTANCE OF FAECAL ESCHERICHLA COLI IN PATIENTS ATTENDING GENERAL PRACTITIONERS.

N. London, R. Nijsten, P. Mertens, A. van den Bogaard, E. Stobberingh Journal of Antimicrobial Chemotherapy 1994; 34: 239-246. 
72 


\section{SUMMARY}

To analyse the influence of antibiotic therapy on the faecal flora of patients from general practice with complaints of a respiratory tract infection (RTI), 189 paired faecal specimens were collected, before and after completing antibiotic therapy $(n=129)$ and symptomatic therapy $(n=60)$. Faecal specimens were examined for the prevalence and degree of resistance to amoxycillin, apramycin, ciprofloxacin, nalidixic acid, neomycin, nitrofurantoin, oxytetracycline, sulphamethoxazole and trimethoprim. In the antibiotictreatment group a significant increase in the prevalence of resistance to amoxycillin posttreatment from $50 \%$ to $64 \%$ ( $P<0.05$, Wilcoxon) was observed. In the symptomatic treatment group no significant differences in the prevalence of resistance were found. Using discriminant analysis, amoxycillin and doxycycline therapy contributed to an increased prevalence of resistance to amoxycillin and oxytetracycline, respectively. In the antibiotic-treated group Escherichia coli isolates post-treatment had a significantly increased resistance rate to amoxycillin $(15 \%-23 \%)$ and to neomycin $(2 \%-6 \%)(P<0.05$, Wilcoxon). Logistic regression analysis showed a cross resistance to neomycin and kanamycin, and for kanamycin cross-resistance to apramycin, neomycin and streptomycin occurred.

\section{INTRODUCTION}

Antimicrobial agents are one of our major resources for the prevention and therapy of infectious diseases. However, use of antibiotics selects for antibiotic-resistant strains, for example in the faecal flora $[3,14,19]$. Most studies dealing with the relation between antibiotic consumption and antibiotic resistance have been performed in hospitals and describe a positive correlation between usage and resistance $[2,8]$. In Finland the increased resistance of Escherichia coli to trimethoprim from $8 \%$ to $35 \%$ paralled the increased consumption of trimethoprim and co-trimoxazole between 1971 and 1984 [7]. Mouton et al., 1990 [15] found a positive correlation between antibiotic consumption of flucloxacillin, cephalosporines and gentamicin and prevalence of methicillin-resistant coagulase negative staphylococci. In contrast, Rosendal et al., 1977 [17] showed a rapid decrease in the percentage of methicillin-resistant Staphylococcus aureus from 1969 to 
1974, despite an increase in the usage of methicillin. Sometimes a decline in usage of one compound is not only related to a decreased resistance to that agent but also to a nonrelated antibiotic [13]. Only limited data are available on antibiotic resistance in general practice patients $[1,4,20,21]$. General practitioners prescribe antimicrobial agents mostly for the treatment of urinary tract infections (UTI) and respiratory tract infections (RTI). This study describes the effect of antibiotic treatment of RTI on the antibiotic resistance of faecal isolates of general practice patients.

\section{MATERIALS AND METHODS}

\section{Sample population}

During a six-week period, November to December 1992, patients in the south of the Netherlands, who attended their general practitioner with RTI were requested to participate in the study. Regardless of the therapy prescribed, they were asked to send in one faecal specimen before starting therapy and one just after completion treatment. In addition they were asked to fill in a questionnaire that included questions on the current therapy prescribed (antibiotic or symptomatic treatment), antibiotic use and/or hospitalization in the previous three months, keeping domestic animals, occupation (slaughter or stock-farmer or others). Patients were excluded if the first faecal sample was collected more than 24 hours after start of the therapy. In addition faecal samples had to be received and processed not more than 48 hours after collection and only those specimens which showed growth on the agar plates without antibiotics were included in the final analysis. Other exclusion criteria were antibiotic use and/or hospitalization in the previous three months.

\section{Specimen collection and processing}

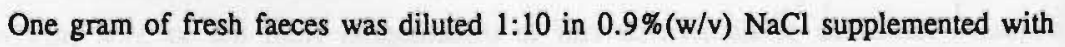
$20 \%(v / v)$ glycerol and stored at $-20^{\circ} \mathrm{C}$ until assayed. The methods used for the analysis were as previously described [11]. Briefly, after thawing the suspensions, serial ten-fold dilutions were made up and $0.037 \mathrm{~mL}$ were inoculated on to Levine agar plates (Oxoid CM 69, Ltd., Basingstoke, England) with and without antibiotics using a spiral plater (Lameris Laboratorium B. V., Breukelen, the Netherlands). On Levine agar plates 
Escherichia coli has a purple appearance with a black centre and a green metallic sheen. The antimicrobial agents and the concentrations used are shown in Table II. The total number and number of resistant Enterobacteriaceae were recorded after incubation at $37^{\circ} \mathrm{C}$ for $18-24$ hours.

The prevalence of antibiotic-resistance in the faecal specimens tested was defined as the number of specimens with resistant Enterobacteriaceae divided by the total number of specimens tested multiplied by $100 \%$. The degree of antibiotic resistance in each sample was defined as the percentage ratio between the number of colonies grown on the agarplates with antibiotics and without antibiotics. If the ratio was $\geq 50 \%$ the degree of resistance was defined as high, and a ratio between $0 \%$ and $50 \%$ was defined as low. From each sample one colony with the colonial morphology of Escherichia coli was randomly picked out from the agar plate without antibiotics and tested for indole reaction and growth at $42^{\circ} \mathrm{C}$. Only isolates yielding positive results for both tests were considered to be Escherichia coli. Identification was confirmed by random selection of 50

Escherichia coli using the API 20E system.

\section{Susceptibility tests}

The antibiotic susceptibility was determined for all Escherichia coli strains, isolated from the agar plates without antibiotics, using a microbroth dilution method in Iso-Sensitest Broth (Oxoid CM 473) and an inoculum of $5 \times 10^{5} \mathrm{CFU} / \mathrm{mL}$. The plates were incubated for $18-24$ hours at $37^{\circ} \mathrm{C}$, with the MIC defined as the lowest concentration to completely inhibit growth. Escherichia coli ATCC 25922 and ATCC 35218 were used as reference strains. The breakpoints for resistance of the antimicrobial agents (Table IV) were those recommended by the guidelines of the Dutch Working Party on Antimicrobial Susceptibility Testing [9]. For apramycin the breakpoint of resistance was $>16 \mathrm{mg} / \mathrm{L} \mathrm{[6]}$. Analysis of the antibiotic susceptibility of the Escherichia coli strains isolated before and after therapy was performed firstly using percentages of sensitive and resistant strains, according to these breakpoints, and secondly as a classification of the MIC values into two categories. This classification is based on the assumption that MIC values within one doubling-dilution step are considered to be the same. Category I includes strains with the same MIC value ( \pm one dilution) or a decreased MIC value of more than one dilution, 
and category II includes strains with an increased MIC value of more than one dilution.

\section{Statistics}

The chi-square test, Wilcoxon Matched-Pairs test and Mann-Whitney U-test were used to analyse whether there were significant differences in antibiotic-resistance pre-and post-treatment. Discriminant analysis was used to analyse the relationship of questionnaire answers to antibiotic resistance. These were considered to be dichotomised variables. When analysing resistance to one particular agent, pre- and posttreatment, the prevalences and degree of resistance to the other agents were also considered as variables. When analysing the changes in antibiotic resistance of the post-treatment-group, the prevalences and degree of resistance of all agents from the pre-treatment period were analysed together with the other variables. Logistic regression was used to analyse the contribution of questionnaire answers to the ratio between the categories I and II. The ratios of the other agents were also considered as variables.

$\mathrm{P}<0.05$ was considered significant.

\section{RESULTS}

\section{Sample population}

The total number of pre-treatment faecal specimens was 325. Excluded from further analysis were those patients who used any antibiotics, or were hospitalized in the previous three months ( $n=25$ and $n=2$, respectively), or from whom the first faecal sample was collected more than $24 \mathrm{~h}$ after start of the therapy $(n=10)$. This left 288 pretreatment samples, including 91 from symptomatic-treatment patients. Post-treatment 189 faecal specimens were collected, including 60 from symptomatic-treatment patients. Only paired samples, $(n=189)$ were included in the final analysis. The majority of the antibiotic-treatment patients received amoxycillin $(n=68)$ or doxycycline $(n=54)$. Only six patients received erythromycin and one co-trimoxazole. As symptomatic therapy mostly analgesic and mucolytic agents were used. The characteristics of the symptomatic- and the antibiotic-treatment patients were similar (Table I). 
Table I. Characteristics of the patient population.

\begin{tabular}{lll}
\hline & $\begin{array}{l}\text { symptomatic therapy } \\
(\mathrm{n}=60)\end{array}$ & $\begin{array}{l}\text { antibiotic therapy } \\
(\mathrm{n}=129)\end{array}$ \\
\hline Mean age/range (years) & $37.9 / 2-74$ & $35.3 / 1-82$ \\
Males (n) & 29 & 64 \\
Hospitalization of family member $(\mathrm{n})$ & 9 & 18 \\
Domestic pets ( $)$ & 32 & 68 \\
Slaughterer/stock-farmer $(\mathrm{n})$ & 7 & 3 \\
\hline
\end{tabular}

\section{Prevalence of antibiotic-resistant Enterobacteriaceae}

The mean $\log ^{10}(\mathrm{CFU})$ of Enterobacteriaceae per gram of faeces, in the specimens pre- and post-treatment was similar, regardless of the therapy prescribed. For the pre-treatment specimens of the antibiotic-treatment and the symptomatic-treatment groups the mean $\log ^{10}(\mathrm{CFU}$ ) was 7.60 (range $3.43-10.37$ ) and 7.49 (range $4.13-10.00$ ), respectively. For the post-treatment specimens the corresponding figures were 7.49 (range 3.43 10.12) and 7.40 (range $3.43-10.06$ ). As shown in Table II, no significant differences were observed in the prevalence of resistance to any of the antibiotics tested before and after symptomatic treatment. In the antibiotic-treated group the prevalence of resistance to amoxycillin increased significantly (from $50 \%$ to $64 \%, P<0.05$, Wilcoxon). The observed increases in resistance to oxytetracycline and sulphamethoxazole were not significant. Between the antibiotic-treatment and the symptomatic-treatment group, a difference in prevalence of resistance to neomycin was observed both pre- and posttreatment. The increased prevalence of antibiotic resistance post- versus pre-treatment was related to the antibiotic therapy prescribed (Table III). Amoxycillin therapy contributed significantly to the increased prevalence of resistance post-treatment not only to amoxycillin but also to oxytetracycline. Similarly, doxycycline therapy resulted in an increased prevalence of resistance post-treatment to oxytetracycline as well as to amoxycillin. Using discriminant analysis, antibiotic therapy as well as pre-treatment resistance were important factors contributing to the resistance post-treatment (data not shown). 
Table II. Prevalence of resistance of the symptomatic-treatment group $(n=60)$ and the antibiotic-treatment group $(n=129)$ pre- and post-treatment.

\begin{tabular}{lllll}
\hline Antibiotic & \multicolumn{2}{l}{ Symptomatic-treated group } & \multicolumn{2}{l}{ Antibiotic-treated group } \\
(mg/L) & \multicolumn{2}{l}{ prevalence } & \multicolumn{2}{l}{ prevalence } \\
& pre & post & pre & post \\
& $(\%)$ & $(\%)$ & $(\%)$ & $(\%)$ \\
\hline Amoxycillin (25) & $55^{1}$ & 48 & $50^{12}$ & $64^{2}$ \\
Apramycin (32) & 2 & 2 & 0 & 1 \\
Ciprofloxacin (4) & 0 & 0 & 0 & 0 \\
Nalidixic acid (32) & 2 & 2 & 1 & 2 \\
Neomycin (8) & $3^{3}$ & $5^{3}$ & $13^{3}$ & $19^{3}$ \\
Nitrofurantoin (50) & 3 & 0 & 2 & 2 \\
Oxytetracycline (25) & 37 & 43 & 38 & 49 \\
Sulphamethoxazole (100) & 40 & 46 & 44 & 52 \\
Trimethoprim (8) & 19 & 25 & 25 & 26 \\
\hline
\end{tabular}

${ }^{123} \mathrm{P}<0.05$

Table III. Relation between amoxycillin / doxycycline therapy and resistance.

\begin{tabular}{lllllll}
\hline Agent & $\begin{array}{l}\text { Kind of } \\
\text { therapy }\end{array}$ & $\begin{array}{l}\text { Pre- / } \\
\text { post- }\end{array}$ & Susceptible & $\begin{array}{l}\text { Low } \\
\text { degree }\end{array}$ & $\begin{array}{l}\text { High } \\
\text { degree }\end{array}$ & $\begin{array}{l}\text { Number of } \\
\text { patients }\end{array}$ \\
\hline Amoxycillin & amoxycillin & pre- & 34 & 20 & 14 & 68 \\
& & post- & 20 & 29 & 19 & 68 \\
& \multirow{2}{*}{ doxycycline } & pre- & 47 & 18 & 10 & 75 \\
& & post- & 44 & 23 & 8 & 75 \\
\multirow{2}{*}{$\begin{array}{l}\text { Oxytetra- } \\
\text { cycline }\end{array}$} & \multirow{2}{*}{ amoxycillin } & pre- & 31 & 21 & 9 & 61 \\
& & post- & 26 & 24 & 11 & 61 \\
& \multirow{2}{*}{ doxycycline } & pre- & 33 & 13 & 8 & 54 \\
& & post- & 22 & 19 & 13 & 54 \\
\hline
\end{tabular}


Susceptibility testing

From eight out of 60 and 13 out of 129 patients no Escherichia coli could be isolated either from the first or the second faecal sample, resulting in totals of 52 and 116 Escherichia coli strains, respectively, for susceptibility testing to 12 antimicrobial agents. As shown in Table IV, for the antibiotic-treatment patients a significant increase in resistance post-treatment was observed for amoxycillin (from $15 \%$ to $23 \%$ ) and for neomycin (from $2 \%$ to $6 \%$ ). For the symptomatic-treatment patients a significant increase in resistance post-treatment was only observed for sulphamethoxazole (19\% to $39 \%)$.

Table IV. Antibiotic resistance of Escherichia coli isolates from the symptomatictreatment group $(n=52)$ and the antibiotic-treatment group $(n=116)$ to 12 antimicrobial agents.

\begin{tabular}{|c|c|c|c|c|c|}
\hline \multirow[t]{4}{*}{ Antibiotic } & \multirow{4}{*}{$\begin{array}{l}\text { Breakpoint } \\
(\mathrm{mg} / \mathrm{L})\end{array}$} & \multicolumn{4}{|c|}{ Percentages of resistant isolates } \\
\hline & & \multirow{2}{*}{\multicolumn{2}{|c|}{$\begin{array}{l}\text { symptomatic } \\
(n=52)\end{array}$}} & \multirow{2}{*}{\multicolumn{2}{|c|}{$\begin{array}{l}\text { antibiotic } \\
(n=116)\end{array}$}} \\
\hline & & & & & \\
\hline & & pre- & post- & pre- & post- \\
\hline Amoxycillin & 16 & 6 & 15 & $15^{4}$ & $23^{4}$ \\
\hline Apramycin & 16 & 0 & 0 & 1 & 0 \\
\hline \multicolumn{6}{|l|}{ Amoxycillin/ } \\
\hline clavulanic acid & 16 & 0 & 0 & 0 & 0 \\
\hline Chloramphenicol & 8 & 2 & 6 & 3 & 9 \\
\hline Kanamycin & 16 & 2 & 2 & 4 & 7 \\
\hline Nalidixic acid & 8 & 0 & 0 & 3 & 2 \\
\hline Neomycin & 16 & 2 & 2 & 24 & $6^{n}$ \\
\hline Nitrofurantoin & 32 & 0 & 2 & 0 & 3 \\
\hline Oxytetracycline & 16 & 19 & 25 & 19 & 22 \\
\hline Streptomycin & 16 & 17 & 27 & 27 & 28 \\
\hline Sulphamethoxazole & 128 & $19^{\prime}$ & $39^{4}$ & 27 & 27 \\
\hline Trimethoprim & 2 & 4 & 8 & 10 & 10 \\
\hline
\end{tabular}

' $P<0.05$ 
After antibiotic treatment, the ratio between the number of strains in category I and II for neomycin and kanamycin was significantly higher than after symptomatic treatment. For sulphamethoxazole, the opposite was observed (Table V). Logistic regression analysis showed a positive correlation between the number of strains with an increase in neomycin resistance and kanamycin resistance (category II), and also between kanamycin and apramycin, neomycin and streptomycin resistance (data not shown).

Table V. Distribution of strains among the categories I and II (see text) for the symptomatic-treated group $(n=52)$ and the antibiotic-treated group $(n=116)$.

\begin{tabular}{lllll}
\hline & \multicolumn{2}{l}{$\begin{array}{l}\text { Symptomatic-treated } \\
\text { number of strains }\end{array}$} & \multicolumn{2}{l}{$\begin{array}{l}\text { Antibiotic-treated } \\
\text { number of strains }\end{array}$} \\
& \multicolumn{2}{c}{ in category: } & \multicolumn{2}{l}{ in category: } \\
Antibiotic & I & II & I & II \\
\hline Amoxycillin & 43 & 9 & 99 & 17 \\
Apramycin & 51 & 1 & 113 & 3 \\
Amoxycillin/ & & & & \\
clavulanic acid & 44 & 8 & 105 & 11 \\
Chloramphenicol & 48 & 4 & 108 & 8 \\
Kanamycin & 51 & $1^{*}$ & 107 & $9^{*}$ \\
Nalidixic acid & 50 & 2 & 109 & 7 \\
Neomycin & 49 & $3^{4}$ & 101 & $15^{4}$ \\
Nitrofurantoin & 48 & 4 & 106 & 10 \\
Oxytetracycline & 45 & 7 & 100 & 16 \\
Streptomycin & 44 & 8 & 98 & 18 \\
Sulphamethoxazole & 33 & $19^{*}$ & 90 & $26^{*}$ \\
Trimethoprim & 43 & 9 & 96 & 20 \\
\hline
\end{tabular}

$\cdot \mathrm{P}<0.05$

\section{DISCUSSION}

The main finding of the present study was the increased prevalence of antibiotic resistance in patients faecal flora receiving amoxycillin and/or doxycycline therapy for the treatment of RTI in general practice. In 1991 in the same region, the antibiotic resistance 
of isolates from faecal specimens from healthy volunteers was studied [11]. The prevalences of resistance to oxytetracycline, sulphamethoxazole and trimethoprim were similar to those observed in the present study. The prevalence of resistance to amoxycillin was higher in the faecal flora of patients in the present study compared with healthy volunteers (approximately $20 \%$ increase). Seasonal variations in antibiotic resistance may occur. The study with healthy volunteers was performed in spring, and the present one in early winter. However, in the study of Vorland et al., 1985 [21] the resistance percentages of antibiotic-resistant UTI isolates was constant throughout the year. Although in the present study the prevalence of antibiotic resistance in each group was similar (50\% and $55 \%$ ), the difference observed was significant. The antibiotic susceptibility of Escherichia coli isolates, pre- and post-treatment, was significantly different. For the antibiotic-treated group, amoxycillin resistance increased from $15 \%$ to $23 \%$. Remarkably, for the symptomatic-treatment group an increase in resistance to sulphamethoxazole from $19 \%$ to $39 \%$ was observed. However, in our previous study of healthy volunteers the frequency of resistance to sulphamethoxazole ranged from $26.7 \%$ to $37.5 \%$ [12]. Therefore, we suggest that the observed increase in resistance is artefactual, reflecting the low prevalence found pre-treatment. Rosner, 1985 [18] showed that Escherichia coli K-12 strains become significantly tolerant to chloramphenicol, tetracycline, ampicillin and nalidixic acid in the presence of chemorepellents such as acetylsalicylate (aspirin), and that this occurred regardless of the different modes of action of the antibiotics, and the lack of relation between the structures of the agents and the chemorepellents. Whether other analgesic or mucolytic agents can cause an increase in the prevalence of antibiotic resistance needs further study.

Another striking observation was the higher prevalence of resistance to neomycin in the antibiotic-treatment group pre-and post-treatment (Table II) and the increased resistance to this agent of the Escherichia coli isolates (Table IV). In the Netherlands neomycin is mainly used in veterinary medicine for the treatment of diarrhoea in young pigs, and the use in human medicine is limited to local treatment with skin ointments. Although the questionnaire did not include questions about use of such local treatment, it is not likely that the use in skin ointment could cause the increased resistance to neomycin of faecal flora. The influence of veterinary antibiotic use on the bacterial resistance in 
humans to antibiotics in general requires further study.

We conclude that in addition to antibiotic therapy pre-treatment, antibiotic resistance positively contributed to resistance post-treatment. Ongoing surveillance of antibiotic-resistance in the flora of healthy people should occur, because resistant bacteria in the community represent the largest reservoir of resistant genes [5], and because of the correlation between antibiotic-resistance of colonizing and infecting bacteria [10]. Knowledge of the prevalence of antibiotic-resistance provides general practitioners with essential data for their choice of empiric therapy [16].

\section{ACKNOWLEDGEMENTS}

This investigation was supported by the Prevention Foundation, grant number 28.0275. We thank C. Driessen, M. Norder and J. Philips for their technical assistance; P.Terporten for statistical assistance; J.Hunter for kindly providing apramycin; the Public Health Department in Roermond and the general practitioners from Roermond and Weert for their co-operation.

\section{REFERENCES}

1. Brumfitt W, Reeves DS, Faiers MC, Datta N. Antibiotic-resistant Escherichia coli causing urinary-tract infection in general practice: relation to faecal flora. Lancet 1971; $i, 315-317$.

2. Courcol RJ, Pinkas M, Martin GR. A seven year survey of antibiotic susceptibility and its relationship with usage. J Antimicrob Chemother 1989; $23: 441-451$.

3. Datta N, Faiers MC, Reeves DS, Brumfitt W, orskov F, orskov I. R factors in Escherichia coli in faeces after oral chemotherapy in general practice. Lancet 1971 ; i: 312-315.

4. Gillespie WA, Lee PA, Linton KB. Antibiotic resistance of coliform bacilli in urinary infection acquired by women outside hospital. Lancet 1971 ; ii: 675-677.

5. Hawkey PM. Resistant bacteria in the normal buman flora. J Antimicrob Chemother 1986; 18, Suppl.C: 133 139.

6. Hunter J, Shelley JC, Walton JR, Hart CA, Benett M. Apramycin resistance plasmids in Escherichia coli : possible transfer to Salmonella typhimurium in calves. Epidemiol Infect 1992; 108: 271-278.

7. Huovinen P, Pulkkinen L, Helin F-L, Mäkilï M, Toivanen P. Emergence of trimethoprim resistance in relation to drug consumption in a Finnish hospital from 1971 through 1984. Antimicrob Agents Chemother 1986; 29: $73-76$.

8. King JW, White MC, Todd JR, Conrad SA. Alterations in the microbial flora and in the incidence of 
bacteremia at a university hospital after adoption of amikacin as the sole formulary aminoglycoside. Clin Infect Dis 1992; 14: 908-915.

9. Klingeren van B, Mouton RP. Standaardisatie van gevoeligheids bepalingen. Verslag van de werkgroep richtlijnen gevoeligheidsbepalingen, 1990. Rijksinstituut voor Volksgezondheid en Milieuhygiene, Bithoven, the Netherlands.

10. Lester SC, Pilar Pla del M, Wang F, Perez Schael I, Jiang H, O'Brien TF. The carriage of Escherichia coli resistant to antimicrobial agents by bealthy children in Boston, in Caracas, Venezuela, and in Qin Pu, China. N Engl J Med 1990; 323: 285-289.

11. London N, Nijsten R, Bogaard van den A, Stobberingh E. Antibiotic resistance of faecal Enterobacteriaceae isolated from healthy volunteers, a 15-week follow-up study. J Antimicrob Chemother 1993; 32: 83-91.

12. London N, Nijsten R, Boganrd van den A, Stobberingh E. Carriage of antibiotic-resistant Escherichia coli by healthy volunteers during a 15-week period. Infection 1994; 22: 187-192.

13. Ma MY, Goldstein EJC, Friedman MH, Anderson MS, Mulligan ME. Resistance of gram-negative bacilli as related to hospital use of antimicrobial agents. Antimicrob Agents Chemother 1983; 24: 347-352.

14. Midtvedt T. The influence of quinolones on the faecal flora. Seand J Infect Dis 1990; 68, Suppl.: 14-18.

15. Mouton RP, Hermans J, Simoons-Smit AM, Hoogkamp-Korstanje JAA, Degener JE, Klingeren van B.

Correlations between consumption of antibiotics and methicillin resistance in coagulase negative staphylococci. J Antimicrob Chemother 1990; 26: 573-583.

16. O'Brien TF. Global surveillance of antibiotic resistance. N Engl J Med 1992; 326: 339-340.

17. Rosendal K, Jessen O, Bentzon MW, Bülow P. Antibiotic policy and spread of Staphylococcus aureus strains in Danish hospitals, 1969-1974. Acta Path Microbiol Scand 1977; 85, Sect. B: 143-152.

18. Rosner JL. Nonheritable resistance to chloramphenicol and other antibiotics induced by salicylates and other chemotactic repellents in Escherichia coli K-12. Proc Natl Acad Sci. USA 1985; 82: 8771-8774.

19. Sakata H, Fujita K, Yoshioks H. The effect of antimicrobial agents on fecal flora of children. Antimicrob Agents Chemother 1986; $29: 225-229$.

20. Towner $\mathrm{KJ}$, Wise $\mathbf{P J}$. Transferable resistance plasmids as a contributory cause of increasing trimethoprim resistance in general practice. J Antimicrob Chemother 1983; 11: 33-39.

21. Vorland LH, Carlson K, Aalen O. Antibiotic resistance and small $\mathbf{R}$ plasmids anong Escherichia coli isolates from outpatient urinary tract infections in Northern Norway. Antimicrob Agents Chemother 1985; 27 : 107-113. 


\section{CHAPTER VI}

\section{COMPARISON OF VIRULENCE FACTORS OF URINARY AND}

FAECAL ESCHERICHIA COLI ISOLATED FROM THE SAME PATIENT

N. London, C. Driessen, A. van den Bogaard, E. Stobberingh (submitted for publication) 


\section{SUMMARY}

The degree of correspondence between urinary and faecal Escherichia coli isolated from the same individual was assessed in twenty-seven non-pregnant women with urinary tract infection. Strains were biotyped, analysed for O:K serotypes, hemolysin production, P fimbriation, transfer of antibiotic resistance, plasmid content, outer membrane protein profile and presence of the aerobactin iron uptake system.

Cluster analysis revealed similar Escherichia coli isolates in the corresponding urine and faecal samples in 18 of 27 patients. Similar plasmid patterns and outer membrane protein profiles were obtained in 13 and 19 of the combinations tested, respectively. The genes for both the aerobactin-iron receptor and production were present in 9 urinary and 8 faecal strains. Resistance to amoxycillin, oxytetracycline, streptomycin and sulphamethoxazole in various combinations occurred most frequently in both groups of strains.

$\mathrm{O} 1$ was mainly associated with $\mathrm{K} 1$ antigen and $\mathrm{P}$ fimbriation, $\mathrm{O} 2: \mathrm{K}$ ? and $\mathrm{O} 6: \mathrm{K} 2$ with $\mathrm{P}$ fimbriation and hemolysin production.

The data in this study underscore the importance of the faecal flora as a reservoir and source of potentially uropathogenic bacteria in women.

\section{INTRODUCTION}

Of all Gram-negative bacteraemias Escherichia coli accounts for 30 to $45 \%$ of these episodes with an overall mortality of about $33 \%$ [25]. Despite the availability of new antimicrobial agents the mortality did not significantly reduce over the past twenty years [8]. Since, inadequate therapy will result in an increase in mortality. For optimal antibiotic therapy knowledge as to the antibiotic susceptibility of the microorganisms to be expected is essential.

The primary site of infection for Escherichia coli bacteraemia is the urinary tract followed by the gastrointestinal tract [25]. Urinary tract infection (UTT) is the most common form of extraintestinal Escherichia coli infection in women, and Escherichia coli is the pathogen most commonly isolated in UTI [13]. Since the faecal and periurethral flora are considered to be the reservoir for these bacteria, several studies have been 
performed to examine the correlation between urinary and periurethral Escherichia coli [2], urethral and faecal Escherichia coli [23] or urinary and faecal Escherichia coli $[3,5,18,21,22,29]$.

Although several studies stressed the importance of the faecal flora as the most important reservoir of potentially uropathogenic bacteria $[10,17]$, none of them analysed extensively virulence factors including antibiotic resistance of the uropathogen and the corresponding faecal isolate of the same patient. In the present study we provide ecidence as to the similarity between urinary tract and faecal isolates of the same patients using hierarchical cluster analysis.

\section{MATERIALS AND METHODS}

\section{Patients and strains}

During a six-week period adult, non-pregnant, female patients presenting to their general practitioner with either dysuria, stranguria, urinary frequency or urgency in the past 24 hours were included in the study. Patients were excluded if they had signs and symptoms of acute pyelonephritis or had known structural abnormalities of the urinary tract. Patients were also excluded if they had received immunosuppressive drugs or antibiotics, had been hospitalized or had a known urinary tract infection within the past three months. In addition to a clean voided urine specimen for standard quantitative and qualitative bacterial culture patients were asked to send in one faecal sample before starting antibiotic therapy. Only those patients were included if they had a bacterial colony count in the urine specimen $\geq 10^{5} \mathrm{CFU} / \mathrm{ml}$ of one single species and from whom a faecal sample was received and processed within 24 hours after receiving the urine specimen. For isolation and identification of the microorganisms standard bacteriological methods were used that included the API-20E biochemical system (API System, La Balme Les Grottes, Montalieu-Vercieu, France). From both urine and faecal sample one Escherichia coli-like colony was randomly picked out for comparative analysis. The study was approved by the Ethical Committee of the Maastricht University Hospital. All patients received oral and written information and all gave informed consent. 


\section{Serotyping of Escherichia coli}

Escherichia coli serotyping (for $\mathrm{O}$ and $\mathrm{K}$ antigens) was performed at the National Institute for Public Health and Environmental Protection (RIVM), Bilthoven, the Netherlands on those isolates from patients whose urine and faecal samples yielded Escherichia coli. The $O$ antigens were identified by bacterial agglutination using 170 antiO sera. Non-agglutinating strains were defined as O-nontypeable (ONT), spontaneous agglutination as SA. Strains without a detectable $\mathrm{K}$-antigen were defined as $\mathrm{K}$-, strains not agglutinating with any of the antisera related to a specific $O$ group were defined $K$ ?

\section{Hemolytic activity}

Hemolysin production was determined on nutrient agar plates (Oxoid CM3) containing $5 \%(\mathrm{v} / \mathrm{v})$ sheep blood. The presence of a hemolytic zone larger than the overlaying colony was considered positive.

\section{P Fimbriation}

The strains were subcultured twice on colonization factor antigen (CFA) agar plates [6] to stimulate $P$ fimbriae expression. $P$ fimbriation was assayed by indirect immunofluorescence with monoclonal antibodies raised against various serotypes of $P$ fimbriae, i.e. $F 7_{1}, F 7_{2}, F 8, F 9, F 11, F 12$ or pap (pyelonephritis-associated pilus). The same monoclonal antibodies were used as in the study of de Ree [27].

\section{Susceptibility testing}

The antibiotic susceptibility was determined using a microbroth dilution method in Iso-Sensitest broth (Oxoid CM 473) and an inoculum of $5 \times 10^{5} \mathrm{CFU} / \mathrm{ml}$. After incubation at $37^{\circ} \mathrm{C}$ for $18-24$ hours the MIC was defined as the lowest concentration that completely inhibited growth. Escherichia coli ATCC 25922 and ATCC 35218 were used as reference strains. The breakpoints for resistance were those recommended by the guidelines of the Dutch Working Party on Antimicrobial Susceptibility Testing [15]. For apramycin the used breakpoint was $>16 \mathrm{mg} / \mathrm{L}$ [12]. 


\section{Resistance transfer}

Broth culture mating was performed using Escherichia coli K-12 (nalidixic acidresistant) as recipient. In short, overnight cultures of recipient and donor were diluted $1: 10$ in fresh Brain Heart Infusion broth (Oxoid CM 225) and incubated at $37^{\circ} \mathrm{C}$ for $2 \mathrm{~h}$. Then they were mixed in the ratio $1: 1$ in fresh $\mathrm{BHI}$ and incubated at $37^{\circ} \mathrm{C}$ for another 2 h. Mixtures were inoculated on the surface of Iso-Sensitest agar (Oxoid CM 471) plates containing nalidixic acid ( $32 \mathrm{mg} / \mathrm{L}$ ) and one of the following antibiotics : amoxycillin (32 $\mathrm{mg} / \mathrm{L})$, chloramphenicol (32 mg/L), oxytetracycline (32 $\mathrm{mg} / \mathrm{L})$, streptomycin $(20 \mathrm{mg} / \mathrm{L})$ or sulphamethoxazole $(256 \mathrm{mg} / \mathrm{L})$. The plates were incubated overnight and then examined for growth. Control experiments were performed with donor or recipient and $0.9 \%(w / v) \mathrm{NaCl}$ as recipient or donor, respectively.

\section{Plasmid studies}

Plasmid profile analysis was done using the method of Kado and Liu [14]. Plasmid DNA was visualised by staining with ethidium bromide and visualised with ultraviolet light. As size markers $(4.4,5.8,7.6,39$ and $91 \mathrm{~kb})$ plasmids isolated from a Salmonella typhimurium strain (kindly provided by N.van Leeuwen, the National Institute of Public Health and Environmental Protection) were used.

Gels were photographed with a Polaroid camera with a red filter using a type 667 Kodak film.

\section{Characterization of amoxycillin-resistant Escherichia coli strains}

For all amoxycillin-resistant Escherichia coli strains sonicated extracts from th cultures in Isosensitest broth were used for analytical isoelectric focusing (IEF) using a $\mathrm{pH}$ range of 3-10 and 4-6.5 [26]. Escherichia coli strains producing either the TEM-1 or the TEM-2 B-lactamase were used as reference strains.

\section{Analysis of outer membrane protein profile}

Overnight cultures in Iso-Sensitest broth derived from single colonies were centrifuged ( $15 \mathrm{~min}, 6000 \mathrm{~g}, 4^{\circ} \mathrm{C}$ ), resuspended in $7 \mathrm{ml} 50 \mathrm{mM}$ Tris-2 mM EDTA buffer $\mathrm{pH} 8.5$ and lysed by ultrasonication five times during $20 \mathrm{~s}$ at $0^{\circ} \mathrm{C}$, with a $20 \mathrm{~s}$ cooling period between treatments. After centrifugation $\left(20 \mathrm{~min}, 2000 \mathrm{~g}, 4^{\circ} \mathrm{C}\right)$, the supernatants 
were cleared by centrifugation $\left(60 \mathrm{~min}, 26500 \mathrm{~g}, 4^{\circ} \mathrm{C}\right.$ ), the pellets resuspended in $5 \mathrm{ml} 2$ $\mathrm{mM}$ Tris buffer $\mathrm{pH} 7.8+0.5 \mathrm{ml} \mathrm{MgCl}$ and incubated for $60 \mathrm{~min}$ at $4^{\circ} \mathrm{C}$. After $15^{\prime}$ at roomtemperature $0.5 \mathrm{ml} 20 \%(\mathrm{v} / \mathrm{v})$ Triton X-100 was added and another $45 \mathrm{~min}$ incubated at the same temperature. Then the suspensions were centrifuged $(60 \mathrm{~min}, 140000 \mathrm{~g}$, $15^{\circ} \mathrm{C}$ ) and the resultant pellet resuspended in $1 \mathrm{ml} 2 \mathrm{mM}$ Tris buffer $\mathrm{pH} 7.8$ and stored at $-20^{\circ} \mathrm{C}$.

The protein content was estimated by the method of Bio-Rad with bovine serum as the standard (Bio-Rad Laboratories). For SDS-PAGE analysis, $10 \mu \mathrm{g}$ protein per sample was separated in $11 \%$ polyacrylamide gels (acrylamide/bisacrylamide ratio $30 \% / 2.67 \%$ ) according to the method of Laemmli [16]. Gels were stained with Coomassie brilliant blue R-250. As size standards the low molecular weight standards from Bio-Rad (Bio-Rad Laboratories) were used.

\section{Detection of genes codine for aerobactin production and aerobactin-iron receptor function}

The aerobactin biosynthesis probe was a $2 \mathrm{~kb}$ Ava $I$ fragment prepared from

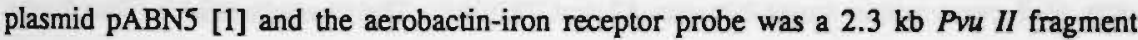
prepared from plasmid pABN1 [4], both kindly provided by K.G.Wooldridge. The DNA probes were purified by extraction with diatoms earth from agarose gels and labeled with digoxigenin according to the manufacturers instructions (Boehringer Mannheim Biochemica, Mannheim, Germany). The strains were screened by making colony blots on nylon membranes (Nytran) according to the manufacturers instructions (Nytran, Schleicher \& Schuell, Den Bosch, the Netherlands). As positive controls the strains containing the plasmids pABN5 and pABN1 were used, as negative control Escherichia coli K-12. Prehybridization and hybridization were performed under stringent conditions $(50 \%(\mathrm{v} / \mathrm{v})$ formamide and $5 \times \mathrm{SSC}$ [ $1 \mathrm{xSSC}$ is $0.15 \mathrm{M} \mathrm{NaCl}$ plus $0.015 \mathrm{M}$ sodium citrate] at $42^{\circ} \mathrm{C}$, and washes in $2 \times S S C$ plus $0.1 \%(w / v)$ SDS and $0.1 \times S S C$ plus $0.1 \%(w / v)$ SDS at $\left.68^{\circ} \mathrm{C}\right)$. The detection of digoxigenin-labeled nucleic acids was performed by chemoluminescence on radiographic films (Kodak X Omat AR). 


\section{Statistics}

Hierarchical cluster analysis by single linkage and Squared Euclidian distances (i.e. Distance $\left.(X, Y)=\Sigma\left(X_{i}-Y_{i}\right)^{2}\right)$ was used to determine the similarity between the urinary and faecal Escherichia coli.

\section{RESULTS}

During the six-week period 83 female patients presented to their general practitioner with complaints of UTI. Excluded from further analysis were patients who had used antibiotics $(n=8)$ or had being hospitalized in the previous three months $(n=6)$. From five patients the faecal sample was not received duly in time. Another 27 women were excluded because of a colony count of the urine of less than $10^{5} \mathrm{CFU} / \mathrm{ml}$. In nine cases another species than Escherichia coli was isolated. In one faecal sample no Escherichia coli could be isolated and therefore also excluded from further analysis. Finally a total of 27 patients with a bacterial count of $10^{5} \mathrm{CFU} / \mathrm{ml}$ Escherichia coli in urine specimens and from whom also a faecal sample was received were studied. The mean age of the patients was 46.8 years with a range between 17 and 78 years. The characteristics of the Escherichia coli isolates in the corresponding urine and faecal samples are shown in the Table.

\section{Biotyping of Escherichia coli}

The API 20E-profile most often found was 5144572, i.e for the urinary and faecal strains ten-and nine-times, respectively. The same profile was found in 17 of 27 pairs tested.

\section{$\mathrm{O}$ antigens and their association with $\mathrm{K}$ antigen}

In 19 of 27 urinary isolates $O$ antigen was detectable. 06 was the most common type ( 5 of 27), followed by $\mathrm{O} 2$ ( 4 of 27 ) and $\mathrm{O} 1$ ( 3 of 27). Of the faecal isolates 21 of 27 were O-groupable. The most common types were $\mathrm{O} 1$ and $\mathrm{O} 2$ (each 3 of 27), both types were mainly combined with $\mathrm{Kl}$ antigen. Spontaneously agglutinating (SA) strains were found in 5 urinary and 4 faecal strains, respectively. The same combination of $O$ and $K$ antigens was found in 14 of 27 pairs of urinary and faecal Escherichia coli. 


\section{Hemolysin production}

Seven urinary and 5 faecal strains were positive, which corresponded with 5 pairs of isolates. Hemolysin production was most often associated with $\mathrm{O} 6$ (6 of 12) and $\mathrm{O} 2$ (4 of 12) antigen, respectively.

\section{P fimbriation}

Four pairs of urinary and faecal strains were $P$ fimbriated. Serotype F9 was present in 4 strains (i.e. 2 pairs) and associated with $01: \mathrm{Kl}$ but not with hemolysin production. The other two serotypes, $F 12$ and $F 7_{2}$, found were associated either with $\mathrm{O} 2: \mathrm{K}$ ? or $\mathrm{O6: \textrm {K } 2}$ and hemolysin production.

\section{Antibiotic resistance}

Resistance to amoxycillin, oxytetracycline, streptomycin and sulphamethoxazole in various combinations occurred most frequently. In total 19 of the 54 strains were resistant to any (or combinations) of the antibiotics tested. In 12 of these 19 isolates the resistance was transferable to Escherichia coli $\mathrm{K}-12$ (underlined in Table). Resistance to amoxycillin was in the 8 amoxycillin-resistant isolates due to TEM-1 B-lactamase. Similar antibiotic resistance patterns were observed in 7 of 27 pairs of urinary and faecal strains, while susceptibility to all agents tested was found in 16 of 27 pairs.

\section{Plasmid profiles}

Similar plasmid profiles were observed in 13 of 27 pairs of isolates. Most profiles consisted of one or two large plasmids and several smaller ones. No plasmids could be isolated from 4 urinary and 4 faecal strains, respectively.

\section{Quter membrane protein profiles}

Analysis of the outer membrane proteins (OMPs) yielded 14 different profiles, which could be distinguished from each other by the various combinations of ten particular protein bands. Pattem 5 and 8 were observed 15- and 12-times, respectively. Similar OMPs were observed in 19 of 27 pairs of uninary and faecal strains. 


\section{Aerobactin production and aerobactin-iron receptor}

Thirteen urinary Escherichia coli strains possessed the genes for the aerobactiniron receptor; another 13 strains the genes for the aerobactin production. In 9 isolates both kind of genes were present. For the corresponding faecal strains the figures were 11, 11 and 8 , respectively. Positive results for both the receptor and the production of aerobactin were obtained for 5 pairs of isolates.

Cluster analysis using all characteristics tested revealed similar Escherichia coli isolates in the corresponding urine and faecal samples in 18 of 27 combinations tested. The dendrogram is shown in the Figure.

Figure. Dendrogram: The numbers placed vertically correspond with the paimumbers used in the Table. Horizontally the rescaled distance cluster combine is shown.

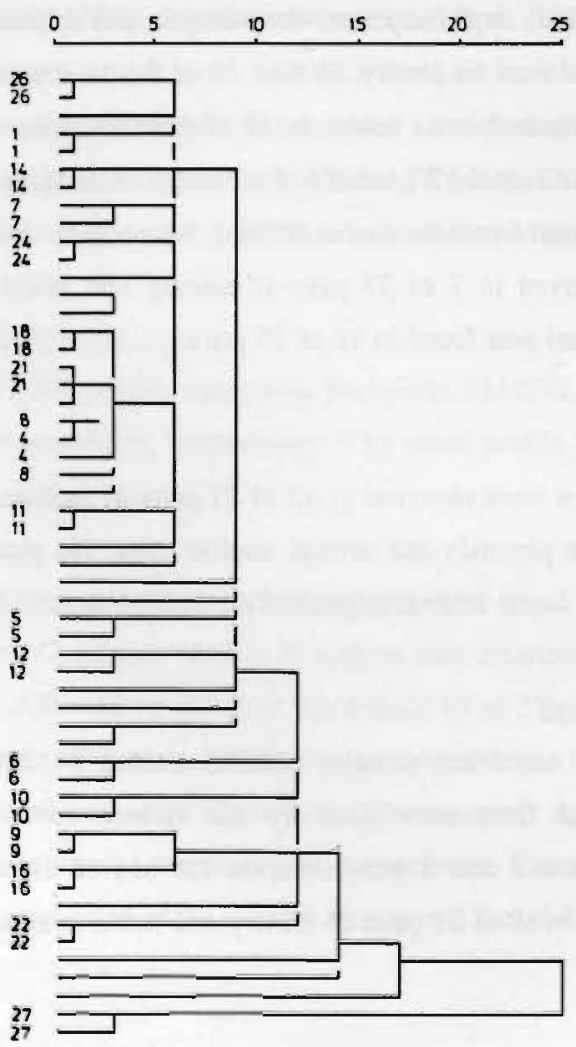


Chapter VI

Table. Prevalence of virulence factors in urinary and faecal Escherichia coli of 27 patients.

\begin{tabular}{|c|c|c|c|c|c|c|c|c|c|c|}
\hline \multirow{2}{*}{\multicolumn{2}{|c|}{ Source ${ }^{1}$}} & \multirow[t]{2}{*}{ API 20E } & \multirow[t]{2}{*}{ Serotype } & \multirow[t]{2}{*}{$H A^{2}$} & \multirow[t]{2}{*}{ Pf } & \multirow[t]{2}{*}{ R-type ${ }^{4}$} & \multirow{2}{*}{$\begin{array}{l}\text { Plasmids } \\
\text { (kb) }\end{array}$} & \multirow[t]{2}{*}{ OMP } & \multicolumn{2}{|c|}{ Aerobectin } \\
\hline & & & & & & & & & Synt & $R \times c^{6}$ \\
\hline \multirow[t]{2}{*}{$1^{\prime \prime}$} & $\mathrm{U}$ & 5044552 & 091:K- & $\cdot$ & $\cdot$ & & 24 & 1 & - & - \\
\hline & F & 5044552 & OIS:K? & - & $\cdot$ & & $\cdot$ & 1 & - & - \\
\hline \multirow[t]{2}{*}{2} & $\mathrm{U}$ & 5144552 & 06:K- & + & - & & - & 2 & + & + \\
\hline & $F$ & 5044152 & 0107:K? & - & - & & $21,19,3$ & 3 & - & + \\
\hline \multirow[t]{2}{*}{3} & $\mathrm{U}$ & 5044532 & 07:KI & - & - & & $20,2.8$ & 4 & + & - \\
\hline & $\mathbf{F}$ & 5144572 & O149:K? & - & - & OxStSu & $39,4.6$ & 1 & - & - \\
\hline \multirow[t]{2}{*}{$4^{\circ}$} & $\mathrm{U}$ & 5144572 & $\mathrm{O}: \mathrm{K}$ ? & - & - & & $71,9.1,4.3$ & 5 & + & + \\
\hline & $\mathbf{F}$ & 5144572 & $\mathrm{O} 50: \mathrm{K} ?$ & - & - & & $71,9.1,4.3$ & 5 & + & - \\
\hline \multirow[t]{2}{*}{$5^{\circ}$} & $\mathrm{U}$ & 5144542 & $\mathrm{O} 2: \mathrm{K}$ ? & + & - & & $56,3.9$ & 6 & + & + \\
\hline & $\mathbf{F}$ & 5144552 & $\mathrm{O} 2 \mathrm{~K}$ ? & + & - & & 21 & 6 & + & + \\
\hline \multirow[t]{2}{*}{$6^{\circ}$} & $\mathbf{U}$ & 5044552 & O1:K1 & $\cdot$ & F9 & & $20,17,8.7,5.2,4.4$ & 7 & + & + \\
\hline & $\mathbf{F}$ & 5044552 & O1:KI & $\cdot$ & F9 & & $20,17,8.7,5.2,4.4$ & 7 & + & - \\
\hline \multirow[t]{2}{*}{$7^{*}$} & $\mathbf{U}$ & 5144512 & O6:K & - & - & & $8.3,4.1$ & 8 & - & + \\
\hline & $\mathbf{F}$ & 5144512 & 0126 & - & - & & $8.3,4.1$ & 8 & + & + \\
\hline \multirow[t]{2}{*}{$8^{*}$} & $\mathbf{U}$ & 5144572 & $\mathrm{O} 2 \mathrm{~K} ?$ & - & - & & $71,21,8.7,4.1$ & 5 & - & + \\
\hline & $\mathbf{F}$ & 5144572 & $\mathrm{O} 2: \mathrm{K} 1$ & - & - & & $71,21,8.7,4.1$ & 5 & + & + \\
\hline \multirow[t]{2}{*}{$9^{*}$} & $\mathbf{U}$ & 5144532 & ONT & - & - & $\mathrm{AmSu}^{-}$ & $71,21,11,9.8,4.8$ & 9 & + & + \\
\hline & $\mathbf{F}$ & 5144532 & ONT & - & - & $\mathrm{AmSu}$ & $71,21,11,9.8,4.8$ & 9 & + & + \\
\hline \multirow[t]{2}{*}{$10^{*}$} & $\mathbf{U}$ & 5144572 & O102:K? & - & - & AmChOxSiSu & $112,39,9.3,5.5$ & 5 & + & - \\
\hline & $\mathbf{F}$ & 5144572 & O102:K? & - & - & $\mathrm{AmChOXStSu}$ & $112,39,19,9.3,5.5$ & 5 & + & + \\
\hline \multirow[t]{2}{*}{$11^{*}$} & U & 5144552 & SA & - & - & & 18 & 8 & - & - \\
\hline & $\mathbf{F}$ & 5144552 & SA & - & - & & 18 & 8 & - & - \\
\hline \multirow[t]{2}{*}{$12^{*}$} & $\mathrm{U}$ & 1044152 & SA & - & - & $\underline{\mathrm{StSu}}$ & $63,8.5,7.6,5,4.4$ & 8 & - & + \\
\hline & F & 1044152 & SA & - & - & $\underline{\text { StSu }}$ & $63,8.5,7.6,5,4.4$ & 8 & $\cdot$ & - \\
\hline \multirow[t]{2}{*}{13} & U & 5144572 & ONT & + & - & & 14 & 9 & - & - \\
\hline & $\mathbf{F}$ & 5044572 & SA & - & - & & 100,63 & 8 & - & - \\
\hline \multirow[t]{2}{*}{$14^{\circ}$} & $\mathrm{U}$ & 5144572 & $\mathrm{O} 2: \mathrm{K}$ ? & + & F12 & & $63,3.9$ & 5 & + & + \\
\hline & $\mathbf{F}$ & 5144572 & $\mathrm{O} 2: \mathrm{K} ?$ & + & $\mathrm{F} 12$ & & $63,3.9$ & 5 & + & + \\
\hline \multirow[t]{2}{*}{15} & $\mathrm{U}$ & 1044552 & O18AB:K? & - & - & & $100,19,3.6$ & 8 & - & - \\
\hline & $\mathbf{F}$ & 5144512 & O74:K- & - & - & & - & 5 & - & - \\
\hline
\end{tabular}




\begin{tabular}{|c|c|c|c|c|c|c|c|c|c|c|}
\hline \multirow[t]{2}{*}{$16^{*}$} & U & 7144572 & O14:K? & - & - & AmOxSu & $23,7.9,6.6,4.6,3.1$ & 9 & + & + \\
\hline & $\mathbf{F}$ & 5144572 & O14:K? & - & - & $\mathrm{AmOxSu}$ & $23,7.9,6.6,4.6,3.1$ & 9 & + & + \\
\hline \multirow[t]{2}{*}{17} & $\mathbf{U}$ & 5144572 & ONT & - & - & $\underline{\text { SiSu }}$ & 40,18 & 9 & + & - \\
\hline & $\mathbf{F}$ & 5144552 & 08-like & - & - & & $18,8.9,4.7$ & 5 & - & - \\
\hline \multirow[t]{2}{*}{$18^{*}$} & $\mathbf{U}$ & 5044572 & 011:K- & - & - & & - & 5 & - & - \\
\hline & $\mathbf{F}$ & 5044572 & 011:K- & - & - & & 16 & 5 & - & - \\
\hline \multirow[t]{2}{*}{19} & $\mathbf{U}$ & 5044552 & SA & - & - & St & $100,8.3$ & 8 & + & + \\
\hline & $\mathbf{F}$ & 5044552 & SA & - & - & OxSiSu & $100,8.3$ & 8 & - & + \\
\hline \multirow[t]{2}{*}{20} & $\mathbf{U}$ & 5144572 & O6:K- & + & - & & - & 10 & - & - \\
\hline & $\mathbf{F}$ & 5144552 & O22:K13 & + & - & & $12,6.2$ & 1 & - & $\cdot$ \\
\hline \multirow[t]{2}{*}{$21^{*}$} & $\mathbf{U}$ & 5144572 & SA & - & - & & $17,6.8$ & 5 & - & - \\
\hline & $\mathbf{F}$ & 5144572 & O135:K? & - & - & 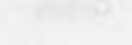 & $17,6.8$ & 5 & - & - \\
\hline \multirow[t]{2}{*}{$22^{\circ}$} & $\mathbf{U}$ & 5144552 & $06: \mathrm{K} 2$ & + & $\mathrm{Fl}_{2}$ & $\underline{\mathrm{Am}}$ & $17,2.5$ & 8 & - & + \\
\hline & $\mathbf{F}$ & 5144552 & $06: \mathrm{K} 2$ & + & $\mathrm{FT}_{2}$ & Am & $17,2.5$ & 8 & - & + \\
\hline \multirow[t]{2}{*}{23} & $\mathbf{U}$ & 5144152 & SA & - & - & $\underline{\text { OxSISu }}$ & $91,50,7.8,4.9,4.6$ & 11 & + & - \\
\hline & $\mathbf{F}$ & 5144572 & O25:K- & - & - & & 112 & 5 & - & - \\
\hline \multirow[t]{2}{*}{$24^{\circ}$} & $\mathbf{u}$ & 5144552 & OI:K1 & - & - & & $112,6.2$ & 1 & + & + \\
\hline & $\mathbf{F}$ & 5144552 & OI:K1 & - & - & & 112 & 1 & + & + \\
\hline \multirow[t]{2}{*}{25} & $\mathbf{U}$ & 5144572 & 0150:K- & - & - & & 71 & 12 & - & - \\
\hline & $\mathbf{F}$ & 1044552 & ONT & - & - & & $4.9,4$ & 13 & - & - \\
\hline \multirow[t]{2}{*}{$26^{*}$} & $\mathbf{U}$ & 5144572 & 06:K- & + & - & Ox & - & 1 & - & - \\
\hline & $\mathbf{F}$ & 5144572 & O6:K- & + & - & $\mathrm{Ox}$ & - & 1 & - & - \\
\hline \multirow[t]{2}{*}{$27^{\circ}$} & $\mathbf{U}$ & 4044102 & $\mathrm{O} 1 \mathrm{~K} 1$ & - & F9 & ChOxStSu & $50,4.9,4.4$ & 14 & - & - \\
\hline & $\mathbf{F}$ & 4044102 & O1:K1 & - & F9 & ChOxStSu & - & 14 & + & - \\
\hline
\end{tabular}

${ }^{1} \mathrm{U}=$ urinary and $\mathrm{F}=$ faecal isolate; ${ }^{2} \mathrm{HA}=$ hemolysin activity; ${ }^{3} \mathrm{Pf}=$ Serotype of $\mathrm{P}$ fimbriae; ${ }^{4} \mathrm{R}$-type $=$ Antibiotic resistance pattern : Am=amoxycillin, $\mathrm{Ch}=$ chloramphenicol, $\mathrm{Ox}=$ oxytetracycline, $\mathrm{St}=$ streptomycin and $\mathrm{Su}=$ sulphamethoxazole, ${ }^{*}$ underlining $=$ transferable; ${ }^{5}$ OMP $=$ outer membrane protein profile; ${ }^{\circ}$ Synt =aerobactin production and Rec $=$ aerobactin-iron receptor

- urinary and faecal sample similar obtained by hierarchical cluster analysis 


\section{DISCUSSION}

This study showed the similarity between urinary and faecal Escherichia coli isolated from the same patient as to the prevalence of virulence factors as well as the antibiotic resistance tested. Using cluster analysis the majority of the isolates (i.e. 18/27 pairs) was similar for all characteristics tested. In most other studies dealing with the similarity of urinary and faecal isolates, strains were derived from different patient populations $[9,21]$ or in the case the urinary and the faecal isolates were derived from the same patient a limited number of virulence factors were compared, i.e. O-serotyping only [29]. In the study of Lidin-Janson et al. [18] more virulence factors were analysed but only from asymptomatic schoolgirls. In the present study the uropathogens were isolated from symptomatic UTI in adult female patients and the virulence factors studied included the presence of the aerobactin system as well as plasmid profiles.

In general the prevalence figures of the virulence factors for the urine and faecal isolates were quite similar. However some differences did occur. For the uropathogens the 06-serogroup producing hemolysin was the most prevalent one.Of the $\mathrm{K}$ antigens the combination O1K1, P-fimbriae positive and hemolysin negative was found most frequently. Similar data were found by Evans $e t$ al. [6] and Hughes et al. [11]. A relation between antibiotic resistance and serogroup 08 and 077 was described by Lidin-Janson $e t$ al.[19]. In contrast, serogroup $\mathrm{O} 1, \mathrm{O} 2$ and $\mathrm{O} 6$ as well as $\mathrm{K} 1$ antigen were not related to antibiotic resistance. Also in the present study only three pairs of antibiotic-resistant urinary and faecal isolates belonged to the $01 \mathrm{~K} 1$ or O6-serogroup. However, it is known from other studies that plasmids, i.e. $F_{1}$ me plasmids, can code for both antibiotic resistance and for the production of the hydroxamate siderophore aerobactin, so it is possible that antibiotic resistance can be present as a result of a plasmid also coding for another virulence factor [28]. Of the remaining nine combinations the urinary and faecal strains were distinctly different. This might be explained by the fact that in this study only one single, randomly selected colony has been used for analysis. Although this single colony would have represented the dominant biotype in $86 \%$ of the specimens, it is to be expected that testing more colonies would result in a higher percentage of similarity [20].

In the present study the highest prevalence of resistance was found to sulphamethoxazole (urinary and faecal $26 \%$ ), streptomycin (urinary $22 \%$, faecal $19 \%$ ), oxytetracy- 
cline (urinary $19 \%$, faecal $22 \%$ ) and amoxycillin (urinary and faecal 15\%). No strains were found resistant to trimethoprim, nitrofurantoin or nalidixic acid. These percentages are similar to those we found in a previous study of the antibiotic resistance of faecal Escherichia coli isolated from healthy volunteers living in the same region [24].

According to a recnt study of Eykyn et al. [7] episodes of bacteraemia are either hospital acquired $(60 \%)$ or community acquired $(40 \%)$. Although Enterobacteriaceae were usually hospital acquired, Escherichia coli was considered community acquired in more than $40 \%$, with as primary site of infections the urinary or the gastrointestinal tract [25].

Thus optimal antibiotic therapy requires data as to the antibiotic resistance of the microorganism to be expected, especially Escherichia coli from urine or faecal specimen. The high similarity between urine and faecal isolates as shown in the present study gives us the possibility to obtain these data by monitoring antibiotic resistance of faecal isolates. Therefore ongoing surveillance of antibiotic resistance of faecal isolates is needed $[10,17]$.

\section{ACKNOWLEDGEMENTS}

This investigation is supported by the Prevention Foundation, grant number 28.0275. We would like to thank R. Hendrix, M. Norder and J. Philips for technical assistance; P. Terporten for statistical assistance; J. Hunter for kindly providing apramycin; the Public Health Department in Roermond and the general practitioners from Roermond and Weert for their co-operation.

\section{REFERENCES}

1. Bindereif A, Neilands J8. Cloning of the aerobactin-mediated iron assimilation system of plasmid ColV. J Bacteriol 1983; 153: 1111-1113.

2. Brooks ML, O'Grady F, McSherry MA, Cattell WR. Uropathogenic properties of Escherichia coli in recurrent urinary-tract infection. J Med Microbiol 1980; 13: 57-68.

3. Brooks HUL, Benseman BA, Peck J. Correlation between uropathogenic properties of Escherichia coli from urinary tract infections and the antibody-coated bacteria test and comparison with faecal strains. J Hyg 1981; 87: 53-61.

4. Carbonetti NH, Williams PH. A cluster of five genes specifying the aerobactin iron uptake system of plasmid ColV-K30. Infect Immun 1984; 46: 7-12.

5. Caugant DA, Levin BR, Lidin-Janson G, Whittum TS, Svanborg C, Selander RK. Genetic diversity and 
relationships among strains of Escherichia coli in the intestine and those causing urinary tract infections. Pros: Allergy 1983; 33: 203-227.

6. Evans DG, Evans jr DJ, Tjoa W. Hemagglutination of human A erythrocytes by enterotoxigenic Escheriekia coli isolated from adults with diarrhea : correlation with colonization factor. Infect Immun 1977; 18: $330-337$.

7. Eykyn SJ, Grandson WR, Philips I. The causative organisms of septicaemia and their epidemiology. I Antimicrob Chemother 1990; 25: Suppl.C 41-58.

8. Geerdes HF, Ziegler D, Lode H, Hund M, Loehr A, Fangmann W, Wagner J. Septicemia in 980 patieats at a university hospital in Berlin: Prospective studies during 4 selected years between 1979 and 1989. Clin Infect Dis 1992; 15: 991-1002.

9. Gillespie WA, Lee PA, Linton KB. Antibiotic resistance of coliform bacilli in urinary infection acquired by women outside hospital. Lancet 1971; ii: 675-677.

10. Hawkey PM. Resistant bacteria in the normal human flora. J Antimicrob Chemother 1986; 27: 133-139.

11. Hughes C, Hacker J, Roberts A, Goebel W. Hemolysin production as a virulence marker in symptomatic and asymptomatic urinary tract infections caused by Escherichia coli. Infect Immun 1983; 39: 546-551.

12. Hunter J, Shelley JC, Walton JR, Hart CA, Bennett M. Apramycin resistance plasmids in Escherichia coli : possible transfer to Salmonella typhimurium in calves. Epidemiol Infect 1992; 108: 271-278.

13. Johnson JR. Virulence factors in Escherichia coli urinary tract infection. Clin Microbiol Rev 1991; 4: 80128.

14. Kado CI, Liu ST. Rapid procedure for detection and isolation of large and small plasmids. J Bacteriol 1981; 145: 1365-1373.

15. Klingeren van B, Mouton RP. Standaardisatie van gevoeligheidsbepalingen. Report National Institute of Public Health and Environmental Protection, Bilthoven, the Netherlands, 1990.

16. Laemmli UK. Cleavage of structural proteins during the assembly of the head of bacteriophage T4. Nature $1970 ; 227: 680-685$.

17. Lester SC, del Pilar Pla M, Wang F, Perez Schael I, Jiang H, O'Brien TF. The carriage of Escherichia coli resistant to antimicrobial agents by healthy children in Boston, in Caracas, Venezuela, and in Qin Pu, China. N Engl J Med 1990; 323: 285-289.

18. Lidin-Janson G, Lindberg U. Asymptomatic bacteriuria in schoolgirls. VI. The correlation between urinary and faecal Escherichia coli. Relation to the duration of the bacteriuria and the sarapling technique. Acta Padiat Scand $1977 ; 66: 349-354$.

19. Lidin-Janson G, Falsen E, Jodal U, Käjser B, Lincoln K. Characteristics of antibiotic-resistant Escherichia coli in the recnum of bealthy school-children. J Med Microbiol 1977; 10: 299-308.

20. Lidin-Janson G, Kaijser B, Lincoln K, Olling S, Wedel H. The homogeneity of the faecal coliform flora of normal school-girls, characterized by serological and biochemical properties. Med Microbiol Immunol 1978; 164: $247-253$.

21. Lidin-Janson G, Hanson LA, Kaujser B, Lincoln K, Lindberg U, Olling S, Wedel H. Comparison of Escherichia coli from bacteriuric patients with those from feces of healthy schoolchildren. I Infect Dis 1977 ; 
136: $346-353$.

22. Lincoln $\mathbf{K}$, Lidin-Janson G, Winberg J. Resistant urinary infections resulting from changes in resistance pattern of faecal flora induced by sulphonamide and hospital environment. Br Med J 1970; 3: 305-309.

23. Lincoln $\mathbf{K}$, Lidin-Janson G, Winberg J. Faecal and periurethral flora after oral administration of aulphonamide, nitrofurantoin and nalidixic acid. Acta Pediat Scand 1972; 61: 643-647.

24. London N, Nüsten R, Bogaard van den A, Stobberingh E. Carriage of antibiotic-resistant Escherichia coli by healthy volunteers during a 15-week period. Infection 1994; 22: 187-192.

25. Maslow JN, Mulligan ME, Adams KS, Justis JC, Arbeit RD.: Bacterial adhesins and host factors: role in the development and outcome of Escherichia coli bacteremia. Clin Infect Dis 1993; 17: 89-97.

26. Matthew M, Harris AM, Marshall M, Rass GW. The use of analytical isoelectric focusing for detection and identification of B-lactamases. J Gen Microbiol 1975; 88: 169-178.

27. Ree de JM, Schwillens P, Bosch van de JF. Molecular cloning of Fll fimbriae from an uropathogenic Escherichia coli and characterization of fimbriae with polyclonal and monoclonal antibodies. FEMS Microbiol Lett 1985; $29:$ 91-97.

28. Riley PA, Threlfall EJ, Cheasty T, Wooldridge KG, Williams P. H., Phillips, I. Occurence of $F_{1} m e$ plasmids in multiply antimicrobial-resistant Escherichia coli isolated from urinary tract infection. Epidemiol Infect 1993; 110: 459-468.

29. Roberts AP, Linton JD, Waterman AM, Gower PE, Koutsaimanis KG. Urinary and faecal Escherichia coli O-serogroups in symptomatic urinary-tract infection and asymptomatic bacteriuria. J Med Microbiol 1975; 8: $311-318$. 


\section{CHAPTER VII}

\section{A PIPERACILLIN-TAZOBACTAM RESISTANT ESCHERICHLA}

\section{COLI STRAIN ISOLATED FROM A FAECAL SAMPLE OF A}

HEALTHY VOLUNTEER.

N. London, C. J. Thomson, S. G. B. Amyes, E. Stobberingh (submitted for publication) 



\section{SUMMARY}

As part of a surveillance program of the prevalence of antibiotic resistance, the faecal bacteria of healthy people $(n=1348)$ were examined and the antibiotic resistance of the Escherichia coli strains determined. One strain out of 142 amoxycillin-resistant isolates, Escherichia coli strain 1662, was also resistant to piperacillin-tazobactam but susceptible to amoxycillin-clavulanic acid. The piperacillin-tazobactam resistance determinant was transferable to standard Escherichia coli strains by conjugation. However, the strain produced a $\beta$-lactamase with several characteristics very similar to those of the TEM-1 $\beta$-lactamase, i.e. pI of 5.4, an $M_{r}$ value of 22000 and a comparable substrate profile. The enzyme was as efficiently inhibited by clavulanic acid and tazobactam as the TEM-1 and TEM- $2 \beta$-lactamases but more than the amoxycillin-clavulanic acidresistant TRC-1 enzyme. The transferable resistance to piperacillin-tazobactam appears to be mediated by a novel resistance mechanism that has previously not been described.

\section{INTRODUCTION}

Bacterial resistance to $\beta$-lactam antibiotics is due mainly to the production of $\beta$-lactamases and, by far the most common of the plasmid-mediated enzymes is the TEM$1 \beta$-lactamase [6]. In order to overcome the action of these ubiquitous enzymes, $\beta$-lactamase inhibitors, such as clavulanic acid or tazobactam, have been developed and used in combination with amoxycillin and ticarcillin or piperacillin, respectively [8]. The latter combination shows particular promise in vitro and in vivo, especially with all genera of the Enterobacteriaceae except Enterobacter spp. [4]. Recently some reports mentioned the isolation of Escherichia coli strains with increased resistance to the combinations amoxycillin-clavulanic acid and/or piperacillin-tazobactam $[1,11,12]$ and, up until now, all these strains were clinical isolates. In this study some characteristics of an amoxycillinclavulanic acid susceptible, piperacillin-tazobactam-resistant faecal Escherichia coli strain, isolated from a healthy person who had not undergone any antibiotic therapy in the previous three months, are described. The data are compared to the strain producing the TRC-1 $\beta$-lactamase, an amoxycillin-clavulanic acid-resistant variant of the TEM-1 enzyme identified in a clinical isolate [10]. 


\section{MATERIALS AND METHODS}

As part of a surveillance program investigating the prevalence of antibiotic resistance in healthy people, Escherichia coli from 1348 faecal specimens were examined and their antibiotic resistance profiles determined. Amoxycillin resistance was observed in 142 of the strains isolated. Four of these strains were also piperacillin-tazobactam resistant; however only one of these showed a stable resistance towards that combination (strain 1662).

Susceptibilities to amoxycillin (AM), amoxycillin/clavulanic acid $(\mathrm{XL})$, piperacillin (PP) and piperacillin/tazobactam (PTc) were determined by the E-test (AB Biodisk, Solna, Sweden) both with an inoculum of $0.5 \mathrm{McF}$ arland and $0.5 \mathrm{McFarland} \mathrm{1:100} \mathrm{diluted} \mathrm{(i.e.}$ $\left.5 \times 10^{5} \mathrm{CFU} / \mathrm{ml}\right)$. Escherichia coli ATCC 25922 and Escherichia coli ATCC 35218, were used as reference strains.

The MICs of aminoglycosides, cephalosporines, oxytetracycline, streptomycin, sulphamethoxazole, tazobactam and trimethoprim were determined by the microdilution method with an inoculum of $5 \times 10^{5} \mathrm{CFU} / \mathrm{ml}$. The breakpoints for resistance were those recommended by the guidelines of the Dutch Working Party on Antimicrobial Susceptibility Testing [3].

Transferability of antibiotic resistance from Escherichia coli 1662 to Escherichia coli K-12 (nalidixic acid resistant) was tested in broth mating experiments. Transconjugants were selected on IsoSensitest agar plates containing nalidixic acid $(32 \mathrm{mg} / \mathrm{L})$ plus one of the following antibiotics: amoxycillin $(32 \mathrm{mg} / \mathrm{L})$, oxytetracycline $(32 \mathrm{mg} / \mathrm{L})$, streptomycin $(20 \mathrm{mg} / \mathrm{L})$, sulphamethoxazole $(256 \mathrm{mg} / \mathrm{L})$ or trimethoprim $(4 \mathrm{mg} / \mathrm{L})$ after $2 \mathrm{~h}$ mixed incubation of donors with the recipient strain Escherichia coli $\mathrm{K}-12$, nap . Control experiments were performed with donor or recipient and $0.9 \%(w / v) ~ N a C l$ as recipient or donor, respectively. Co-transfer of piperacillin-tazobactam resistance with amoxycillin resistance determinant was analysed by replica plating. 
Plasmid DNA from donors and amoxycillin or piperacillin / tazobactam transconjugants was extracted by the method of Kado \& Liu [2], separated by agarose gel electrophoresis and visualised by straining with ethidium bromide and viewing with UV light.

The molecular masses $\left(M_{8}\right)$ of the outer membrane proteins of the strains were determined by SDS-polyacrylamide gel electrophoresis (SDS-PAGE).

Sonicated extracts from 4 hours cultures (with or without prior induction by $1 / 2$ MIC cefoxitin) in IsoSensitest broth were prepared from strain 1662 and from Escherichia coli strains producing the TEM-1, TEM- 2 and TRC- $1, \beta$-lactamases. The enzymes were characterised by analytical isoelectric focusing (IEF) over the $\mathrm{pH}$ ranges $3-10$ and $4-6.5$ [5]. $\beta$-lactamase activity, substrate profile and the inhibition by clavulanic acid or tazobactam $\left(\mathrm{ID}_{50}\right.$ ) were determined spectrophotometrically. The degree of purity of the enzymes were analysed both by SDS-polyacrylamide gel electrophoresis (SDS-PAGE) and IEF. Both kind of gels were stained with Coomassie Brilliant Blue (CBB).

\section{RESULTS}

\section{Antibiotic susceptibility of Escherichia coli strains}

The MICs of amoxycillin (>256 mg/L), piperacillin (>256 mg/L), amoxycillinclavulanic acid $(8 \mathrm{mg} / \mathrm{L})$, piperacillin-tazobactam $(32 \mathrm{mg} / \mathrm{L})$ and tazobactam alone $(>128$ $\mathrm{mg} / \mathrm{L}$ ) were determined for Escherichia coli strain 1662. The MIC of piperacillintazobactam was determined several times by using the E-test and ranged from $32 \mathrm{mg} / \mathrm{L}$ to $128 \mathrm{mg} / \mathrm{L}$ with an inoculum of $0.5 \mathrm{McF}$ arland and $0.5 \mathrm{McF}$ arland 1:100 diluted. The MIC distribution of all 142 amoxycillin-resistant strains is shown in Figure 1. When the TRC-1 producing strain was examined under the same conditions, MICs of amoxycillin (>256 mg/L), piperacillin (>16 mg/L), amoxycillin-clavulanic acid (24 mg/L) and piperacillin-tazobactam ( $4 \mathrm{mg} / \mathrm{L}$ ) were found. Both strains remained fully susceptible to second and third-generation cephalosporins. 
Figure 1. The MIC distribution of all 142 amoxycillin-resistant strains for piperacillintazobactam by using the E-test.

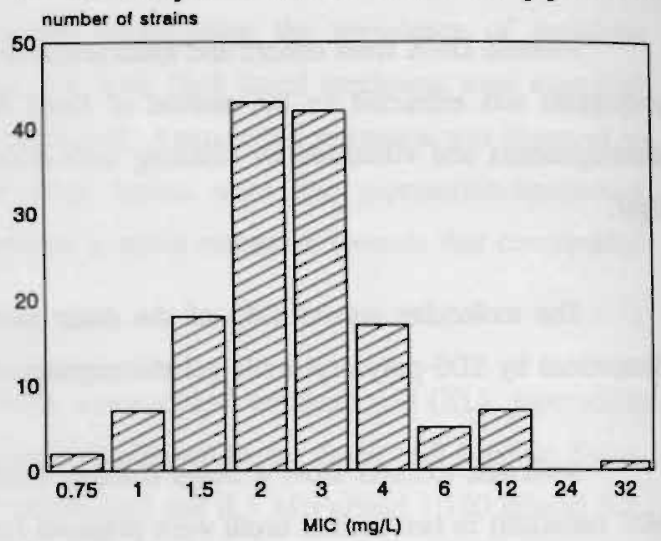

Escherichia coli strain 1662 was also resistant to oxytetracycline (MIC >256 $\mathrm{mg} / \mathrm{L}$ ), streptomycin (MIC $>128 \mathrm{mg} / \mathrm{L}$ ), sulphamethoxazole $(\mathrm{MIC}>1024 \mathrm{mg} / \mathrm{L}$ ) and trimethoprim (MIC $>512 \mathrm{mg} / \mathrm{L}$ ), but was susceptible to apramycin, neomycin, kanamycin and gentamicin. Resistance to amoxycillin, streptomycin, sulphamethoxazole and trimethoprim was transferable to Escherichia coli $\mathrm{K}-12$. The transfer frequencies (Table 1) show that the amoxycillin resistant determinant was not closely linked with oxytetracycline, streptomycin, sulphamethoxazole and trimethoprim resistance genes and was thus located on a different plasmid. However, in most cases, transfer of amoxycillin resistance was accompanied by co-transfer of piperacillin-tazobactam resistance. For these transconjugants the MIC of amoxycillin was $>256 \mathrm{mg} / \mathrm{L}$, piperacillin-tazobactam 32 $\mathrm{mg} / \mathrm{L}$ and tazobactam alone was $>128 \mathrm{mg} / \mathrm{L}$.

Table 1. Transfer frequencies for Escherichia coli strain 1662.

\begin{tabular}{lll}
\hline Antimicrobial & $\begin{array}{c}\text { Selecting concentration } \\
(\mathrm{mg} / \mathrm{L})\end{array}$ & $\begin{array}{l}\text { Transfer frequency } \\
\text { pent donor cell }\end{array}$ \\
\hline Amoxycillin & 32 & $5.4 \times 10^{-3}$ \\
Oxytetracycline & 32 & 0 \\
Streptomycin & 20 & $4.6 \times 10^{-5}$ \\
Sulphamethoxazole & 256 & $1.9 \times 10^{-4}$ \\
Trimethoprim & 4 & $5.2 \times 10^{-6}$ \\
\hline
\end{tabular}


The plasmid profiles of Escherichia coli 1662 and its transconjugants together with the strains producing the TEM-1, TEM-2 and TRC-1 $\beta$-lactamases, respectively, are shown in Figure 2.

Figure 2. Plasmids in the strains producing TEM-1 (a), TEM-2 (b), TRC-1 (c), Escherichia coli strain 1662 (d), Escherichia coli K-12 amoxycillin transconjugant (e) and Escherichia coli K-12 piperacillin-tazobactam transconjugant (f). As molecular weight standards plasmids of $91,39,7.8,5.6$ and $4.4 \mathrm{~kb}$ from Salmonella typhimurium ST13 (g) were used. Strains were grown in Luria broth and analysed in $0.7 \%$ agarose gels.

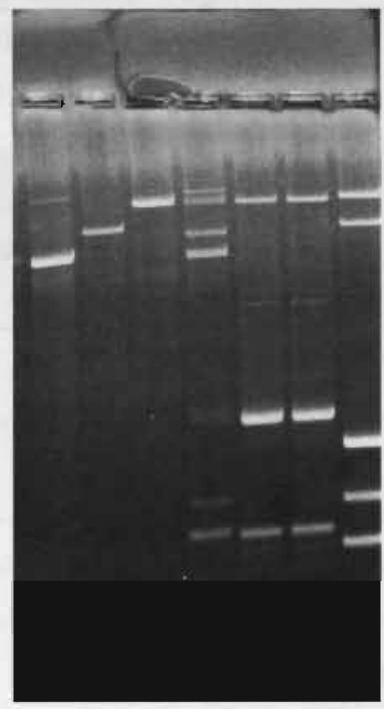

A $B$ B $C$ D $E$ E

\section{Characteristics of $\beta$-lactamase}

The $\beta$-lactamases produced by Escherichia coli strain 1662 and its transconjugants were not inducible, had a similar specific activity towards nitrocephin (Table 2) and focused at pI 5.4, similar to the TEM-1 $\beta$-lactamase. The substrate profiles of the enzymes from strain 1662, TEM-1 and TEM-2 are shown in table 3. No hydrolysis of cefazolin, cefipime, cefotaxime, cefoxitin, ceftazidime, ceftriaxone, cefuroxime, aztreonam and imipenem was detected by spectrophotometric assay. 
Table 2. Specific activities (nmol nitrocephin hydrolysed $/ \mathrm{min} / \mathrm{mg}$ protein) of B-lactamases 1662, TEM-1, TEM-2 and TRC-1.

\begin{tabular}{ll}
\hline B-lactamase & Specific activity \\
\hline 1662 & 3110 \\
TEM-1 & 2210 \\
TEM-2 & 9270 \\
TRC-1 & 1800 \\
\hline
\end{tabular}

Table 3. "Relative rates of hydrolysis (\%) of B-lactamases 1662 , TEM-1 and TEM-2.

\begin{tabular}{llll}
\hline B-Lactam substrate & 1662 & TEM-1 & TEM-2 \\
\hline Nitrocephin" & 100 & 100 & 100 \\
Penicillin & $>100$ & $>100$ & $>100$ \\
Amoxycillin & 37 & 26 & 27 \\
Piperacillin & 33 & 37 & 52 \\
Ticarcillin & 58 & 100 & 56 \\
Cephaloridine & 17 & 7 & 18 \\
\hline
\end{tabular}

- Rate for nitrocephin $=100 \%$

The concentrations of clavulanic acid and tazobactam required to inhibit enzyme activity by $50 \%\left(\mathrm{ID}_{50}\right)$ were quite similar for the 1662 enzyme and TEM-1, TEM-2. These concentrations were distinctly lower than those required for the inhibition of the TRC-1 enzyme (Table 4).

Table 4. Inhibitory dose $(\mu \mathrm{g} / \mathrm{L})$ of clavulanic acid and tazobactam required to inhibit enzyme activity by $50 \%\left(\mathrm{ID}_{50}\right)$ when nitrocephin was used as the substrate.

\begin{tabular}{lllll}
\hline Inhibitor & 1662 & TEM-1 & TEM-2 & TRC-1 \\
Clavulanic acid & $16-32$ & $16-32$ & 32 & $256-512$ \\
Tazobactam & $1-2$ & $1-2$ & 2 & $16-32$ \\
\hline
\end{tabular}


The molecular mass of the $\beta$-lactamase was estimated by Native-PAGE to be approximately 22,000 , similar to that of the TEM-1 enzyme. There were no visual differences in major outer membrane protein profile between Escherichia coli strains 1662 and its transconjugants and the Escherichia coli strains producing the TEM-1, TEM-2 or TRC-1 $\beta$-lactamases (Figure 3).

Figure 3. SDS-polyacrylamide gel electrophoresis patterns of cell envelopes of the strains producing TRC-1 (b), TEM-2 (c), TEM-1 (d), Escherichia coli K-12 piperacillintazobactam transconjugant (e), Escherichia coli $\mathrm{K}-12$ amoxicillin transconjugant (f) and Escherichia coli strain 1662 (g). In lane (a) molecular weight standards, i.e. 97.4, 66.2, 45 and $31 \mathrm{kD}$ are shown. $11 \%$ gel.

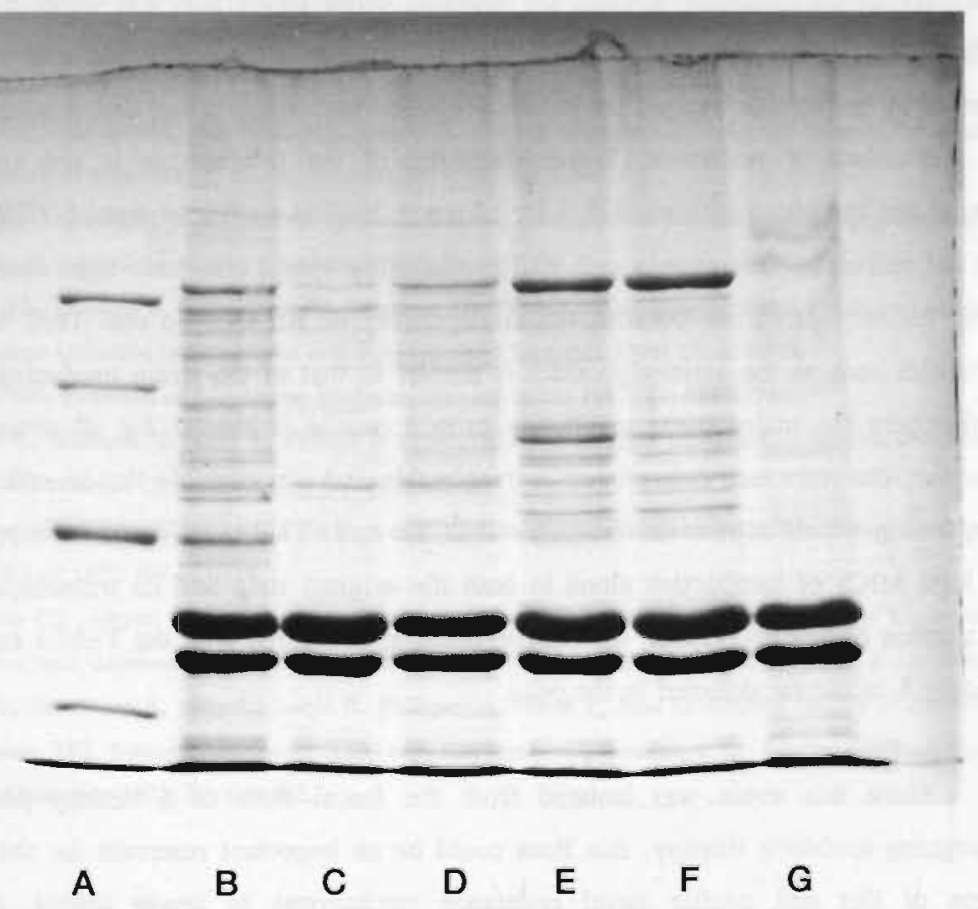




\section{DISCUSSION}

The piperacillin-tazobactam resistant Escherichia coli strain described in this study was isolated from a faecal sample of a healthy person who had not taken any antibiotics in the previous three months before sampling. The piperacillin-resistant determinant was usually co-transferable with the amoxycillin resistance gene. The $\beta$-lactamases produced by strain 1662 and its transconjugants were indistinguishable from the TEM-1 $\beta$-lactamase for all characteristics tested. Remarkably the $\beta$-lactamase from strain 1662 was as efficiently inhibited by clavulanic acid and tazobactam as the TEM-1 enzyme. However, the MIC of piperacillin-tazobactam for the original strain and its transconjugants is $\geq 32$ $\mathrm{mg} / \mathrm{L}$ and both had a high MIC of tazobactam on its own.

Besides alterations in the $\beta$-lactamase produced by the cell [10], resistance to the combinations of $\beta$-lactams with $\beta$-lactamase inhibitors has previously been explained either as a result of hyperproduction of the $\beta$-lactamase [9] or as a decrease in the permeablility of the inhibitor through the bacterial outer membrane, i.e. absence of porin $\mathrm{OmpF}$, [7]. Unless the alterations in the $\beta$-lactamase are very subtle and cannot be detected by convention assays, the results presented here suggest that this is unlikely to be the mechanism of resistance. Hyperproduction of the $\beta$-lactamase is not very likely because the specific $\beta$-lactamase activity of strain 1662 is similar to that of TEM-1 and it was not inducible. Decrease in cell wall permeability would also have been considered to be an unlikely candidate because the susceptibility of Escherichia coli 1662 to several antibiotics such as the aminoglycosides is similar to that of the strain producing TEM-1. Furthermore the major outer membrane protein profile is similar for all strains tested. However, the resistance determinant is transferable and it is possible that an efflux system is opcrating which exports tazobactam out of the cell. This view could be supported by the high MICs of tazobactam alone in both the original stain and its transconjugant and the absence of any decrease in tazobactam binding, compared with the TEM-1 enzyme, to the only B-lactamase detected in the cells.

Since this strain was isolated from the faecal flora of a healthy person, not undergoing antibiotic therapy, this flora could be an important reservoir for the dissemination of this and similar novel resistance mechanisms as newer agents, especially containing $\beta$-lactamase inhibitors, are introduced. 


\section{ACKNOWLEDGEMENTS}

This investigation was supported by the Prevention Foundation, grant number 28.0275. We thank C. Driessen and R. Hendrix for their technical assistance.

\section{REFERENCES}

1. Blazquez J, Baquero M, Canton R, Alos I and Baquero F. Characterization of a new TEM-type Blactamase resistant to clavulanate, sulbactam, and tazobactam in a clinical isolate of Escherichia coli. Antimicrob Agents Chemother 1993; 37: 2059-2063.

2. Kado CI, Liu ST. Rapid procedure for detection and isolation of large and small plasmids. J Bacteriol 1981; 145: $1365-1373$.

3. Klingeren van B, Mouton RP. Report National Institute of Public Health and Environmental Protection, Biltohoven, the Netherlands 1990.

4. Knapp CC, Sierra-Madero J, Washington JA. Activity of ticarcillin/clavulanate and piperacillin/tazobactam (YTR 830; CL-298,741) against clinical isolates and against mutants derepressed for class I beta-lactamase. Diagn Microbiol Infect Dis 1989; 12: 511-515.

5. Matthew M, Harris AM, Marshall, MJ, Ross GW. The use of analytical isoelectric focusing for detection and identification of B-lactamases. J Gen Microbiol 1975; 88: 169-178.

6. Nandivada LS, Amyes SGB. Plasmid-mediated B-lactam resistance in pathogenic Gram-negative bacteria isolated in South India. I Antimicrob Chemother 1990; 26: 279-290.

7. Reguera JA, Baquero F, Perez-Diaz JC, Martinez JL. Factors determining resistance to B-lactam combined with B-lactamase inhibitors in Escherichia coli. J Antimicrob Chemother 1991; 27: 569-575.

8. Rolinson GN. Evolution of B-lactamase inhibitors. Rev Infect Dis 1991; 13: S727-S732.

9. Shannon K, Williams H, King A, Phillips I. Hyperproduction of TEM-1 B-lactamase in clinical isolates of Escherichia coli serotype O15. FEMS Lett 1990; 67: 319-324.

10. Thomson CJ, Amyes SGB. TRC-1 Emergence of a clavulanic acid-resistant TEM B-lactamase in a clinical strain. FEMS Lett 1992; 91: 133-118.

11. Thomson CJ. Amyes SGB. Selection of variants of the TEM-1 B-lactumase, encoded by a plasmid of clinical origin, with increased resistance to B-lactamase inhibitors. J Antimicrob Chemother $1993 ; 31: 655-664$.

12. Vedel G, Belaaouaj A, Gilly L, Labia R, Phillipon A, Nevot P, Paul G. Clinical isolates of Escherichia coli producing TRI B-lactamases: novel TEM-enzymes conferring resistance to B-lactamase inhibitors. J Antimicrob Chemother 1992; 30: 449-462. 


\section{CHAPTER VIII}

\section{GENERAL DISCUSSION}




\section{GENERAL DISCUSSION}

This thesis describes the prevalence and degree of antibiotic resistance in healthy humans, i.e. pig farmers, abattoir workers and (sub)urban residents and, in particular, discusses the reproducibility of sampling and the intra-individual variation in resistance over time. Attention has been paid to the effect of antimicrobial chemotherapy on the prevalence of antibiotic resistance in the faecal flora of general practice patients. Evidence was provided as to the usefulness of monitoring antibiotic resistance of faecal Escherichia coli to predict antibiotic resistance of uropathogenic Escherichia coli in primary health care patients. The mechanisms of resistance of a faecal Escherichia coli strain resistant to the recently introduced combination of piperacillin and tazobactam, and isolated from a healthy individual not using any antibiotic therapy in the previous three months, were analysed.

Prevalence of antibiotic resistance in healthy humans

The highest prevalence of antibiotic resistance in the faecal samples of three populations of healthy volunteers studied was found for the pig farmers, the lowest for the (sub)urban residents. No significant differences in high degree of resistance to any of the antimicrobial agents tested were found, except for neomycin which was highest for the pig farmers.

The variations observed in the prevalence and the degree of resistance in faecal samples per individual over time could be explained by biological variation (i.e. \pm 1.25 $1 \% \log \mathrm{CFU}$ ) and measurement error variation (i.e. $0.5 \% \mathrm{Og} \mathrm{CFU}$ ). The high degree of antibiotic resistance per individual was rather constant over time, but more variation was observed for the low degree of resistance.

The small variation in antibiotic resistance holds true not only for the high degree of resistance but also for the antibiotic resistance pattern of the faecal Escherichia coli isolates. In Chapter IV the antibiotic susceptibility of 1348 faecal Escherichia coli isolated during the 15-week period, was determined. The majority of the isolates per individual had only one or two different antibiotic resistance patterns, with a maximum of five. The number of different patterns was independent of the number of strains per individual. 
The prevalences of antibiotic resistance in the faecal samples of both abattoir workers and (sub)urban residents were of the same order of magnitude. Higher prevalence percentages were found for the pig farmers. Although pig farmers and abattoir workers do have regular contact with pigs/carcasses and pig faeces, this factor is of minor importance as no significant differences are observed between these abattoir workers who have intensive contact and these in whom the contact is less intensive. Eight percent of the abattoir workers and $5 \%$ of the pig farmers mentioned personal antibiotic consumption recently, whereas none of the (sub)urban residents mentioned this. However, this antibiotic usage could not explain the differences found between the three populations. It is believed that exposure to low concentrations of antibiotics used in animal feed and for therapy of pigs is the most important factor for the higher percentages found in the pig farmers.

A wide range of prevalence percentages were found when the results of the 15week follow-up study were compared with earlier studies performed in the Netherlands. The high degree of resistance ( $\geq 50 \%$ of Escherichia coli resistant) showed less variation, as shown in the Table.

In comparing these data one has to take into account that the studies mentioned did not all use the same methodology. Although Degener et al. [6] used a higher selective concentration for ampicillin (40 mg/L) and tetracycline $(30 \mathrm{mg} / \mathrm{L})$ and a semi-quantitative method for determining the numbers of resistant Escherichia coli, the percentages found for the prevalence and high degree of resistance were quite similar to those found in the present study.

In the studies of Bonten er al [2,3] and our own studies the same methods and the same concentrations were used, and only the populations studied were different. The prevalences and degrees of resistance found, however, were quite different. These data suggest that several other factors such as differences in overall use of antibiotics in the populations studied and socio-economic variations are of influence. 
Table. Comparison of \% Prevalence (\% High Degree) of resistant Escherichia coli from different studies in the Netherlands.

\begin{tabular}{|c|c|c|c|c|c|c|c|c|c|}
\hline \multicolumn{10}{|l|}{ study/year } \\
\hline \multirow[t]{2}{*}{ (city) } & \multicolumn{3}{|c|}{ amoxycillin } & \multicolumn{3}{|c|}{ oxytetracycline } & \multicolumn{3}{|c|}{ sulphamethoxazole } \\
\hline & $\mathrm{mg} / \mathrm{L}$ & $\mathbf{P}$ & H.D & $\mathrm{mg} / \mathrm{L}$ & $\mathbf{P}$ & H.D & $\mathrm{mg} / \mathrm{L}$ & $\mathbf{P}$ & H.D \\
\hline \multicolumn{10}{|c|}{ Degener $6 / 1978-80$} \\
\hline (Zoetermeer) & 40 & 25 & 5 & 30 & 42 & 12 & 100 & 45 & 19 \\
\hline \multicolumn{10}{|c|}{ Degener $6 / 1987$} \\
\hline (Zoetermeer) & 40 & 27 & 11 & 30 & 20 & 6 & 100 & 46 & 21 \\
\hline \multicolumn{10}{|l|}{ Bonten $2 / 1990$} \\
\hline (Mrastricht) & 25 & 76 & 8 & 25 & 47 & 11 & 100 & 86 & 37 \\
\hline \multicolumn{10}{|l|}{ Bonten $3 / 1992$} \\
\hline (Maastricht) & 25 & 62 & 12 & 25 & 68 & 21 & 100 & 71 & 19 \\
\hline \multicolumn{10}{|l|}{ Bonten $3 / 1992$} \\
\hline (Zwolle) & 25 & 89 & 13 & 25 & 49 & 14 & 100 & 49 & 15 \\
\hline \multicolumn{10}{|l|}{ London/1993 } \\
\hline (Weert) & 25 & $28 \pm 12$ & $7 \pm 5$ & 25 & $25 \pm 7$ & $3 \pm 3$ & 100 & $28 \pm 10$ & $8 \pm 4$ \\
\hline \multicolumn{10}{|l|}{ London/1993 } \\
\hline (Roermond) & 25 & $33 \pm 12$ & $9 \pm 5$ & 25 & $31 \pm 7$ & $5 \pm 4$ & 100 & $41 \pm 7$ & $14 \pm 4$ \\
\hline
\end{tabular}

A high degree of resistance means that the majority ( $\geq 50 \%$ ) of the isolated faecal Escherichia coli are (multi-)resistant. About $10^{6}$ to $10^{8}$ Escherichia coli are generally found per gram of human faeces. Given about 100 grams of faeces produced daily per person, an individual with a high degree of resistance to an antimicrobial agent excretes at least $5 \times 10^{7}$ to $5 \times 10^{9}$ resistant bacteria per day. Therefore such people represent a large source of resistant bacteria and resistance genes [9].

Persons with a low degree of resistance are important as well. Shortly after an antimicrobial agent for which resistant Escherichia coli are present in the gastrointestinal tract has been taken, the resistant bacteria will be selected and excreted in high numbers. Moreover, both groups of humans have more chance of an infection caused by resistant microorganisms in the future [8].

The small variations in resistance patterns in each individual as found in our study are in contrast with those found by Levy er al. [9] who observed that $90 \%$ of all 
individuals showed a gain $(47.6 \%)$ and/or a loss $(65.7 \%)$ of one or more detectable resistances. However, his findings were based upon the two first faecal samples per individual while in our study one to 13 samples per individual were analysed during a 15 week period. Consequently testing more than two faecal samples per individual is, as expected, more accurate than testing only two samples.

\section{Effect of antibiotic therapy on antibiotic resistance}

The data in chapter $\mathrm{V}$ demonstrate that amoxycillin and/or doxycycline therapy results in an increase in prevalence of resistance post-treatment to oxytetracycline as well as amoxycillin in faecal Escherichia coli. These data are in line with those from other studies showing that antimicrobial agents can select for antibiotic-resistant strains, especially in the faecal flora $[5,7,11]$.

As the faecal flora is considered to be the reservoir and source not only of potentially pathogenic bacteria, but also of resistance genes, data concerning the antibiotic resistance of the faecal Escherichia coli will predict the antibiotic resistance of these potentially pathogenic microorganisms and will provide essential information for effective empirical therapy.

Chapter VII describes the isolation and characterization of a faecal isolate (Escherichia coli 1662) resistant to a recently introduced antimicrobial agent, i.e. piperacillin-tazobactam. The strain was isolated from a healthy person who had not received any antibiotics in the previous three months. Until then, piperacillin-tazobactamresistant strains were either in vitro isolated mutants or in a few cases clinical isolates. The mechanism of resistance of Escherichia coli strain 1662 seems to be different from other piperacillin-tazobactam-resistant strains as isolated so far. 


\section{GENERAL CONCLUSIONS AND RECOMMENDATIONS}

In the past 15 years in the Netherlands several studies have been performed regarding the prevalence and degree of antibiotic resistance of faecal Escherichia coli in healthy humans. The differences observed in the studies performed could be explained only in part by differences in methodology and it is very likely that differences in the populations studied have contributed to the observed variation. Differences in the population include differences in socio-economic circumstances as well as differences in direct (i.e. personal) antibiotic usage and indirect antibiotic usage (i.e. antibiotic usage in the population, degree of direct exposure to antibiotics, e.g. in animal feeds, to animals and animal waste or products).

In general, no steady increase in antibiotic resistance in the open Dutch population in the past decade has been observed. These data are in line with a survey of nearly one million hospital isolates in the New York area collected over a 10-year period which did not show any increase in resistance over time [1]. The authors stated that although local outbreaks with multi-resistant microorganisms do occur the overall situation is not too worrying.

It should be a public health goal that a low level of carriage of antibiotic-resistant strains is maintained in the near future $[8,10]$. To achieve this active surveillance of antibiotic resistance of extramural isolates has to be performed. These include establishment of national monitoring stations, which at regular intervals collect a sufficient number of strains from healthy persons to study antibiotic susceptibilities [4] and antibiotic resistance pattems as well as the mechanisms of antibiotic resistance.

Knowledge of the prevalence and degree of resistance present in the bacterial flora of the healthy human population will provide general practitioners with essential data for their choice of empirical therapy and could alert them to optimalize their prescribing practices.

\section{REFERENCES}

1. Atkinson BA, Lorian V. Antimicrobial agent susceptibility patterns of bacteria in hospitals from 1971 to 1982. J Clin Microbiol 1984; 20: 791-796. 
2. Bonten M, Stobberingh E, Philips J, Houben A. High prevalence of antibiotic resistant Escherichia coli in faecal samples of students in the southeast of the Netherlands. J Antimicrob Chemother 1990; 26: 585-592.

3. Bonten M, Stobberingh E, Philips J, Houben A. Antibiotic resistance of Escherichia coli in fecal samples of heal thy people in two different areas in an industrialized country. Infection 1992; 20: 258-262.

4. Casparie AF. Naar een optimaal antibioticumbeleid: een brede anpak nodig. Pharm Weekbl 1989; $124: 302$ 305.

5. Dutu N, Faiers MC, Reeves DS, Brumfitt W, brskov F, drskov I. R factors in Escherichia coliin faeces after oral chemotherapy in general practice. Lancet 1971; i: 312-315.

6. Degener JE, Hoon van IMS, Stiphout WAHJ, Luchman R. Veranderende gevoeligheid van Escherichia coli voor antibiotica in de bevolking. Ned Tijdschr Geneeskd 1990; 134: 2296-2299.

7. Harnet: N. High level resistance to trimethoprim, cotrimoxazole and other antimicrobial agents among clinical isolates of Shigella species in Ontario, Canada-an update. Epidemiol Infect 1992; 109: 463-472.

8. Lester SC, Pilur Pla del M, Wang F, Perez Schael I, Jiang H, O'Brien TF. The carriage of Escherichia coli resistant to antimicrobial agents by healthy children in Boston, in Caracas, Venezuela, and in Qin Pu, Chin. N Engl J Med 1990; 323: 285-289.

9. Levy SB, Marshall B, Schluederberg S, Rowse D, Davis J. High frequency of antimicrobial resistance in human fecal flora. Antimicrob Agents Chemother 1988; 32: 1801-1806.

10. Levy SB. Starting life resistance-free. N Engl J Med 1990; 323: 335-337.

11. Midtvedt T. The influence of quinolones on the faecal flora. Scand J Infect Dis 1990; Suppl 68: 14-18. 


\section{SUMMARY}

Emergence of antibiotic-resistant microorganisms continues to be an important problem for the treatment of bacterial infections. There is general agreement that antibiotic use in general medical practice and in veterinary medicine is responsible in part for the development and selection of antibiotic-resistant bacteria. However, it is still not clear whether antibiotic use in humans or animals has contributed most to the environmental pool of resistant microorganisms.

Up to now many studies have examined the prevalence of antibiotic resistance in hospitalized patients. In contrast, less information is available on the incidence of antibiotic resistance outside the hospital. In general, the faecal flora is considered the most important reservoir of antibiotic-resistant microorganisms. However, in the Netherlands no recent data are available about the prevalence of antibiotic-resistant bacteria in the faecal flora of non-hospitalized patients. Therefore, several studies analysing the prevalence of antibiotic-resistant faecal Escherichia coli of healthy volunteers and of patients from general practice with complaints of an urinary tract infection or a respiratory infection are presented in this thesis.

In chapter I, after a short introduction, a review of the literature concerning the prevalence of antibiotic-resistant microorganisms in different populations, i.e. pig farmers, abattoir workers and general practice patients is given. Furthermore the effect of antibiotic therapy on the selection of antibiotic-resistant bacteria from human and animal origin is described as well as possible routes (contact, foodchain) by which these animal bacteria can reach man and may cause resistance are discussed. Finally the prevalence of antibiotic resistance in humans outside the hospital, i.e. general practice patients and (sub)urban residents, is presented. As described in several studies the prevalence percentages observed are strongly influenced by the method used also data concerning the high degree of resistance, i.e. the proportion of faecal samples with a ratio $\geq 50 \%$, thus the majority of the faecal Escherichia coli showing resistance to that agent, are given.

In chapter II the prevalence of antibiotic resistance in three populations, i.e. pig farmers, abattoir workers and as a control group (sub)urban residents, all living in the same region in the South of the Netherlands, is described. The highest prevalence percentages were found for the pig farmers, indeed, for amoxycillin, neomycin, 
oxytetracycline, sulphamethoxazole and trimethoprim significantly higher percentages than for the abattoir workers and (sub)urban residents were found. It was quite remarkable that only the high degree of resistance to neomycin significantly differed for the three populations tested, which was again highest for the pig farmers. The differences in prevalence of resistance observed between pig farmers and abattoir workers could not be explained by their (intensive) contact with pigs only. Also personal antibiotic consumption, $5 \%$ for the pig farmers and $8 \%$ for the abattoir workers, could not explain the differences found between the three populations. It is to be expected that direct contact with antibiotic-supplemented pig feed, i.e. mass medication, is an important factor for the higher percentages found in the pig farmers.

Chapter III describes the individual variation regarding the presence of antibiotic resistance over time. The same group of individuals, already described in chapter II, were followed up during a 15-week period and their faecal samples analysed weekly. The high degree of resistance to an antimicrobial agent was more or less constant over time. Another striking observation were the significant differences in resistance found between individuals living in the regions Weert and Roermond, of which the last group showed a higher prevalence and degree of resistance to some of the agents tested compared to the first group. Although on one hand these results emphasize regional differences in prevalence of antibiotic resistance, it was on the other hand quite remarkable that these differences already occurred within such a short distance of $30 \mathrm{~km}$.

The small individual variation in antibiotic resistance was confirmed by the relatively small number of antibiotic resistance patterns per individual as found in the faecal Escherichia coli strains (chapter IV). The faecal Escherichia coli from 51 out of the 183 individuals studied showed only one antibiotic resistance pattern, from 63 individuals two pattems were found. The resistance patterns most frequently observed were resistance to sulphamethoxazole alone, followed by resistance to sulphamethoxazole in combination with oxytetracycline and/or streptomycin.

There is general agreement that antibiotic use is an important risk factor for selection of antibiotic-resistant bacteria not only to the agent used but also to other (un)related agents. Chapter $\mathrm{V}$ describes the effect of antibiotic therapy on the antibiotic resistance of faecal Escherichia coli from patients attending their general practitioners with complaints of a respiratory tract infection. Amoxycillin and doxycycline therapy 
resulted in an increased prevalence of faecal Escherichia coli resistant to both agents.

The faecal flora is not only considered to be the reservoir for antibiotic-resistant Escherichia coli but also for uropathogenic Escherichia coli. This last item is elucidated in chapter VI in which 27 paired isolates from faeces and urine were analysed. Based on data concerning several virulence factors including hemolytic activity, $\mathbf{P}$ fimbriation and aerobactin production an overall degree of correspondence between urine and faecal Escherichia coli could be shown in $66 \%$ of the patients.

In chapter VII the mechanism of resistance against a recently introduced combination of a B-lactam antibiotic, piperacillin and a B-lactamase inhibitor, tazobactam, is analysed. It was quite remarkable that the piperacillin/tazobactam-resistant Escherichia coli was isolated from a healthy person who had not undergone any antibiotic therapy recently. Up until now, all piperacillin/tazobactam-resistant strains were clinical isolates.

In the concluding chapter (chapter VIII) recommendations are made as mentioned in this summary. It is strongly recommended to establish monitoring stations to analyse at regular intervals antibiotic susceptibilities of faecal isolates from non-hospitalized patients in order to provide essential data for a correct choice of empiric therapy. 


\section{SAMENVATTING}

Het voorkomen van antibiotica-resistente microörganismen vormt nog steeds een belangrijk probleem bij de behandeling van bacteriele infecties. Algemeen wordt aangenomen dat het (dier)geneeskundig gebruik van antibiotica bijdraagt aan de ontwikkeling en selectie van antibiotica-resistente bacteriën. Het is echter nog steeds niet duidelijk of het gebruik in de geneeskunde of juist in de diergeneeskunde het meest heeft bijgedragen aan de omvang van het resistentie probleem.

Tot nu toe is veel onderzoek beschreven betreffende het voorkomen van antibiotica resistentie bij patiënten in ziekenhuizen. Daarentegen is nog relatief weinig bekend over het resistentie probleem buiten het ziekenhuis. Algemeen wordt de faeces beschouwd als het reservoir van antibiotica-resistente microörganismen. Echter recente gegevens betreffende het voorkomen van antibiotica-resistente bacteriēn in de faeces van personen buiten het ziekenhuis zijn in Nederland niet voorhanden. In dit proefschrift worden de resultaten van faecesonderzoek betreffende de antibiotica-resistente faecale Escherichia coli bij gezonde vrijwilligers en bij patiēnten welke de huisarts bezoeken met klachten van een urineweginfectie of een luchtweginfectie beschreven.

In het eerste hoofdstuk wordt, na een korte inleiding, een overzicht van de literatuur gegeven met betrekking tot het voorkomen van antibiotica-resistente microōrganismen in diverse groepen personen, zoals varkenshouders, slachthuispersoneel en huisartspatiēnten. Vervolgens wordt het effect van het antibioticagebruik op selectie van antibiotica-resistente bacteriën bij mens en dier beschreven en worden de mogelijkheden bediscussieerd (contact, voedselketen) hoe de bij dieren aanwezige resistentie kan leiden tot antibiotica resistentie bij de mens.

Tenslotte wordt het voorkomen van antibiotica resistentie bij personen buiten het ziekenhuis besproken, te weten bij patiēnten welke een huisarts bezoeken en bij stedelingen. Aangezien de prevalentiepercentages sterk afhankelijk zijn van de gehantcerde methode worden ook gegevens vermeld betreffende de hoge mate van resistentie, dat wil zeggen het percentage van de onderzochte personen waarvan het merendeel ( $\geq 50 \%$ ) van de faecale flora resistent is tegen het onderzochte antibioticum. 
In hoofdstuk 2 worden de prevalenties van antibiotica-resistentie in drie verschillende populaties, te weten varkenshouders, slachthuispersoneel en gezonde stedelingen, allen afkomstig uit de regio Weert en Roermond, beschreven. De hoogste prevalentiepercentages werden bij varkenshouders vastgesteld, welke voor amoxycilline, neomycine, oxytetracycline, sulphamethoxazole en trimethoprim significant hoger waren dan bij slachthuispersoneel en stedelingen. Opvallend was dat ten aanzien van de hoge mate van resistentie alleen die voor neomycine significant verschilde tussen de drie populaties. Deze was het hoogst voor de varkenshouders. Het verschil in antibiotica resistentie tussen de varkenshouders en het slachthuispersoneel kon niet alleen verklaard worden door het (intensieve) contact met varkens. Het eigen antibioticumgebruik, bij de varkenshouders $5 \%$ en het slachthuispersoneel $8 \%$, kon ook niet de verschillen tussen de drie populaties verklaren. Het wordt aangenomen dat het contact met antibioticum-gesupplementeerd varkensvoer een belangrijke rol speelt bij de hogere prevalentiepercentages bij de varkenshouders.

Hoofdstuk 3 beschrijft de individuele variatie in antibiotica resistentie in de tijd. Van de in hoofdstuk 2 beschreven groep gezonde personen werden gedurende 15 weken faecale monsters geanalyseerd. De hoge mate van resistentie tegen een bepaald antibioticum vertoonde weinig variatie tijdens de periode van onderzoek. Opvallend waren de significante verschillen waargenomen tussen de regio's Weert en Roermond, waarbij Roermond een hogere prevalentie en mate van resistentie vertoonde dan Weert. Hoewel enerzijds deze resultaten regionale verschillen in antibiotica resistentie benadrukken is het opvallend dat ook binnen een afstand van $\pm 30 \mathrm{~km}$ reeds verschillen waarneembaar zijn.

De geringe individuele variatie in antibiotica resistentie bleek ook uit het relatief beperkte aantal resistentie patronen van de faecale Escherichia coli per individu (hoofdstuk 4). Van de 183 onderzochte personen vertoonden de Escherichia coli isolaten van 51 van hen eénzelfde antibioticum resistentie patroon, bij 63 personen werden twee patronen vastgesteld. De meest voorkomende resistentie betrof resistentie tegen sulfamethoxazole alleen, gevolgd door resistentie tegen sulfamethoxazole in combinatie met oxytetracycline en streptomycine. 
Algemeen wordt aangenomen dat gebruik van antibiotica een belangrijke risicofactor is voor de selectie van bacteriên resistent tegen het gebruikte middel maar mogelijk ook tegen (niet-)verwante antibiotica. Hoofdstuk 5 beschrijft het effect van antibioticum therapie in de eerste lijn bij patiēnten met klachten van een luchtweginfectie op het voorkomen van antibiotica-resistente faecale Escherichia coli. Amoxycilline en doxycycline therapie leidde tot een toename in percentage Escherichia coli resistent tegen beide antibiotica.

De faecale flora wordt niet alleen beschouwd als reservoir voor antibioticaresistente Escherichia coli maar ook als reservoir voor uropathogene Escherichia coli. Dit laatste aspect wordt in hoofdstuk 6 nader toegelicht aan de hand van 27 gepaarde isolaten van faeces en urine. Op basis van verschillende virulentiefactoren zoals hemolytische activiteit, P-fimbriae en aerobactine-produktie kon bij $66 \%$ van de patiēnten overeenkomst tussen faecale en uropathogene Escherichia coli worden vastgesteld.

In hoofdstuk 7 wordt het mechanisme van resistentie tegen een recent geintroduceerde combinatie van een B-lactam antibioticum, piperacilline en een B-lactamase remmer, tazobactam nader geanalyseerd. Opvallend was dat de piperacilline-tazobactam resistente Escherichia coli geïsoleerd was bij een persoon die vermeldde recent geen antibioticum gebruikt te hebben. De tot nu toe beschreven piperacilline/tazobactam resistente isolaten waren allen klinische isolaten.

Tenslotte worden in hoofdstuk 8 aanbevelingen gedaan voor een continue monitoring van antibiotica resistentie in de niet-ziekenhuis populatie.

Gepleit wordt regelmatig vast te stellen het resistentie niveau in de open populatie via resistentie peilstations om zodoende een bijdrage te kunnen leveren aan een juisto keuze van empirische therapie. 


\section{DANKWOORD}

In september 1989 begon ik met mijn stage bij de vakgroep Medische Microbiologie van de Rijksuniversiteit Limburg. In augustus 1990 werd het stagecontract omgezet in een tijdelijk contract voor de duur van én jaar. Het jaar was voor driekwart ten einde toen Ellen mij de vraag stelde of ik geen interesse had in een baan als AIO op een door het Preventiefonds gesubsidieerd onderzoek voor een periode van ongeveer drie jaar. Alhoewel het antwoord eigenlijk al meteen "ja" was, werden alle mogelijke positieve en negatieve kanten van het AIO zijn eerst goed overdacht.

$\mathrm{Nu}$ dat het onderzoek bijna afgerond is besef ik dat ik toen wel degelijk de juiste beslissing heb genomen maar ook dat ik dit onderzoek nooit tot een goed einde had kunnen brengen zonder de hulp en het medeleven van een aantal mensen die ik hier met name wil noemen.

Ellen Stobberingh, de goede band die wij samen hebben gekregen is voomamelijk te danken geweest aan het feit dat zowel jij als ik geen blad voor de mond namen en vonden dat alles bespreekbaar moest zijn. We hebben over allerlei onderwerpen gepraat en gediscussieerd, of ze nu met het onderzoek te maken hadden of niet. Ondanks het "drammen" dat je wel eens kon doen ben ik je erg dankbaar voor de vele uren en de motivatie die je toonde om dit onderzoek tot een goed einde te brengen. Je stond altijd open voor nieuwe suggesties, ook al wilde ik soms "de puntjes te zeer op de i zetten".

Ton van den Bogaard, bedankt voor de tijd die je aan mij en het onderzoek besteedt hebt. Al kon je af en toe nuchter en bot uit de hoek komen, ik heb altijd geweten dat je het beste met me voor had.

Professor Knottnerus, mijn promoter, ben ik zeer erkentelijk voor zijn hulp met name tijdens de eindfase van dit onderzoek. Ik heb dit zeer gewaardeerd.

José Philips, lieve José, jij hebt een speciaal plekje in mijn hart gekregen. Ik weet zeker dat ik zonder jou aanwezigheid bij lange na niet zo'n fijne tijd zou hebben gehad op het lab. Je kon altijd goed naar me luisteren en een eerlijke mening geven als ik weer eens mijn hart moest Juchten. We hebben samen heel wat afgelachen en ik hoop dat we nog een aantal jaren kunnen blijven samenwerken.

Ruth Nijsten, mijn collega AIO, ik denk dat er niet veel AIO's zijn die het geluk hebben gehad samen met een ander op eén onderzoek te mogen promoveren. De tijd die 
we samen hebben doorgebracht was vooral een gezellige tijd, denk maar aan de congressen die we samen hebben bezocht maar we waren ook altijd bereid om elkaar te motiveren en op te vangen tijdens moeilijkere tijden.

Christel Driessen, dankzij jouw hulp zijn er heel wat experimenten met succes uitgevoerd. Ik kon veel aan jou overlaten omdat ik wist dat de werkzaamheden correct en gemotiveerd werden uitgevoerd. We hebben ons een aantal malen moeten vastbijten in een proef maar we bleven lachen en kwamen uiteindelijk tot goede resultaten.

Marjon Norder, ook jij hebt een enorme hoeveelheid werk verzet met het verwerken van de vele faecesmonsters.

Peter Terporten, jouw hulp bij de statistiek is onmisbaar geweest. We hebben menig uurtje, vaak heftig discussiërend, doorgebracht achter jouw beeldscherm.

Ron Hendrix, jouw kennis met name op het gebied van de moleculair-biologische technieken kon altijd aangesproken worden als we weer eens niet verder kwamen. Al leek het voor een buitenstaander soms op ruziemaken, het was toch echt samenwerken wat wij deden.

Daisy, Jan, Monique en Wanda, ieder van jullie heeft op z'n eigen wijze er voor gezorgd dat ik altijd met veel plezier heb kunnen werken in een collegiale sfeer. We hebben samen heel wat gelachen en flauwekul uitgehaald maar er werd ook goed werk afgeleverd.

De medewerkers van de vakgroep Medische Microbiologie, met wie het fijn werken was.

Alle vrijwilligers uit Weert en Roermond die bereid waren om én maar soms ook 15 faecesmonsters te verzamelen en op te sturen naar ons. Zonder hun "bijdrage" was het niet mogelijk geweest dit onderzoek uit te voeren. Er zijn namelijk niet veel mensen te vinden die bereid zijn om hun poep in een potje te stoppen (met behulp van een lepeltje uiteraard) in plaats van deze direct door te spoelen in het toilet.

De GGD, Paul Mertens, Ton Houben, de PAREL-groep, Professor Tielen van de Gezondheidsdienst voor Dieren te Boxtel, directie van de slachthuizen Coveco en Encebe, directie en keurmeesters van de RVV-lokatie Weert en Dr.J.H.M Nieuwenhuijs voor jullie inzet en bijdrage aan het verzamelen van de faecesmonsters.

Dr. B. I. Davies, voor het corrigeren van de Engelse teksten. 
Mijn ouders, lieve pap en mam, jullie hebben het mogelijk gemaakt dat ik kon gaan studeren en datgene kon gaan doen wat ik graag wilde. Van jullie kant was er altijd de motivatie en de steun bij alles wat ik deed. Jullie interesse in mij werd de afgelopen jaren beloond met heel wat (onsmakelijke) verhalen, vooral tijdens het eten, maar jullie waren altijd bereid te blijven luisteren.

Shirley, mijn zus, jouw eenvoudige en simpele kijk op het leven deed me steeds opnieuw beseffen dat er meer is dan werk en verplichtingen alleen en dat ik ook moest blijven genieten van het leven.

Familie, vrienden, buren en kennissen, jullie belangstelling voor dit onderzoek heb ik als zeer plezierig ervaren.

En natuurlijk last, but not least, Johan, mijn kameraadje. Jij was één van diegenen die vond dat ik deze kans om mezelf waar te maken moest aangrijpen. Afgezien van de figuren en tekeningen die je voor me maakte, was jij vooral degene die me mentaal opving en met je nuchtere kijk op de dingen er voor zorgde dat ik met beide benen op de grond bleef staan. De vele uren die ik aan dit onderzoek besteedde in plaats van aan jou, werden mij nooit kwalijk genomen. En je ziet het, het einde is in zicht. 


\section{CURRICULUM VITAE}

De schrijfster van dit proefschrift is op 19 februari 1968 in Maastricht geboren. In 1986 behaalde zij het Atheneum B diploma aan het Stedelijk Lyceum te Maastricht. In hetzelfde jaar begon zij aan de HLO-biochemie opleiding an de Hogeschool Heerlen te Sittard. In 1990 behaalde zij haar examen en kreeg ze een baan bij de vakgroep Medische Microbiologie. Vanaf september 1991 werkte ze aan het onderzoek, dat in dit proefschrift beschreven is. 
